Portland State University

PDXScholar

Summer 7-20-2018

\title{
A Foucaultian Discourse Analysis of Person- Centered Practice Using a Genealogical Framework of Intellectual Disability
}

Nick Winges-Yanez

Portland State University

Follow this and additional works at: https://pdxscholar.library.pdx.edu/open_access_etds

Part of the Disability Studies Commons, Feminist, Gender, and Sexuality Studies Commons, and the Social Work Commons

Let us know how access to this document benefits you.

\section{Recommended Citation}

Winges-Yanez, Nick, "A Foucaultian Discourse Analysis of Person-Centered Practice Using a Genealogical Framework of Intellectual Disability" (2018). Dissertations and Theses. Paper 4505.

https://doi.org/10.15760/etd.6389

This Dissertation is brought to you for free and open access. It has been accepted for inclusion in Dissertations and Theses by an authorized administrator of PDXScholar. Please contact us if we can make this document more accessible: pdxscholar@pdx.edu. 
A Foucaultian Discourse Analysis of Person-Centered Practice Using a

Genealogical Framework of Intellectual Disability

\author{
by \\ Nick Winges-Yanez \\ A dissertation submitted in partial fulfillment of the \\ requirements for the degree of \\ Doctor of Philosophy \\ in \\ Social Work and Social Research
}

Dissertation Committee:

Ben Anderson-Nathe, Chair

Mary Oschwald

Erin Flynn

Alex Sager

Portland State University

2018 


\section{(C) 2018 Nick Winges-Yanez}




\begin{abstract}
A genealogical framework highlights the important role sexuality has played in constructing the current label of intellectual disability (ID). The genealogical framework is meant to replace the social, medical, and/or rights-based model(s) that have dominated social work and social services working in the disability field. With this framework, or perspective, I used a Foucaultian discourse analysis to read through seminal texts regarding person-centered practice. Person-centered practice is the foremost intervention used in social work, and other disciplines, to work with people labeled with intellectual disability. My research questioned what PCP reveals about ID through a genealogical framework and what implications do these discoveries hold for sexuality education and social services, including social workers?

I used predetermined concepts taken from the genealogical framework in the Foucaultian discourse analysis. These concepts (subject, government, biopower, and normalization) provide insight into how ID has been constructed and maintained through the practice of person-centered processes. Paradoxes emerge throughout the analysis, providing space for productive resistance by professionals working in sexuality education and social services to improve equity for people labeled with intellectual disability, specifically regarding their sexuality and healthy expression of it.
\end{abstract}


A Foucaultian Discourse Analysis ii

\section{Acknowledgements}

First and foremost, I thank my sister. Without her, I would never have stumbled into this work. She has patiently listened to me, helped me, and provided much needed laughter and silliness when I needed it most. My parents have also patiently grown with me through this work and I thank their determination, perseverance, and humor.

I would not have finished this work, let alone attempted a doctorate, without the amazing and eternal support of my wife. We met as I began my undergraduate career at the age of 27, pushing and supporting me throughout the entire journey. She worked as hard as I to understand the philosophy of Foucault, admittedly with less enthusiasm and adulation. I have never known a more intelligent, modest, supportive person - and she is an awesome cook who never let me get away with "forgetting to eat!"

I also thank my Chair for continuously pushing me while also allowing me to falter. Every step of this process was new and confusing and I always felt supported to explore without judgement. Thank you, Dr. Anderson-Nathe.

To my committee members, your feedback and engagement with this process was enlightening and thought-provoking. Thank you for all of your work and guidance.

Finally, to my beloved fur baby, Boycat. He sat with me during long days and nights in my office, quietly sleeping in the corner or, if reading, on my lap. He passed away just a few months before I finished. Frankie the Dog and Miss Annie worked hard to continue your supportive ways, if only so I didn't forget to feed them. 
Table of Contents

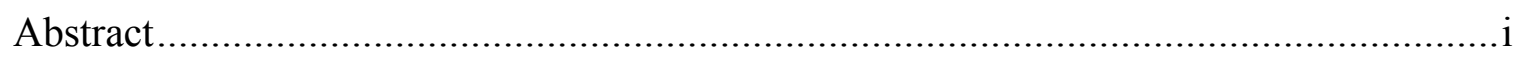

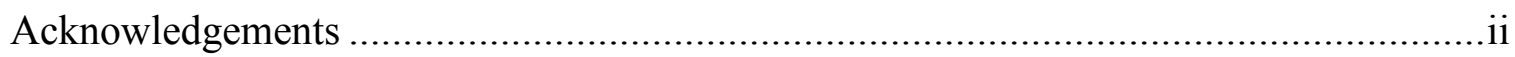

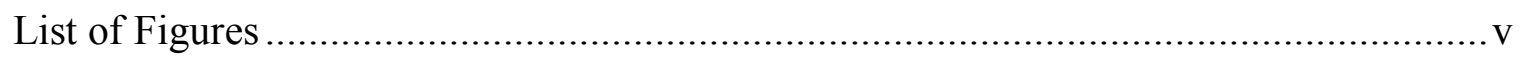

Chapter 1

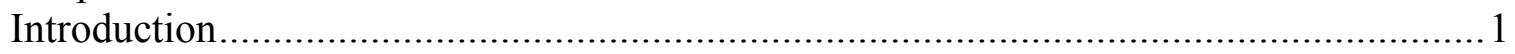

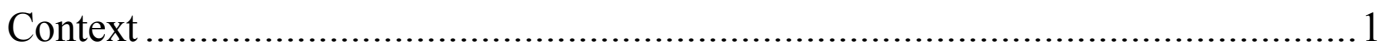

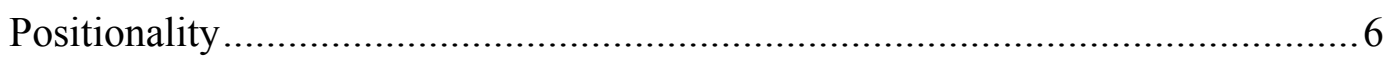

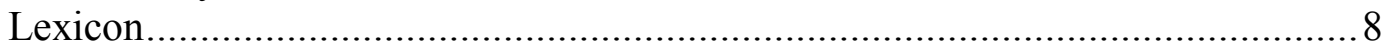

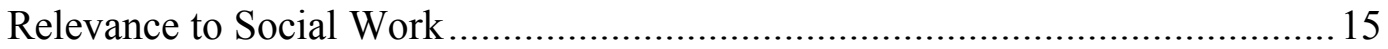

Chapter 2

Review of Current Research ............................................................................. 18

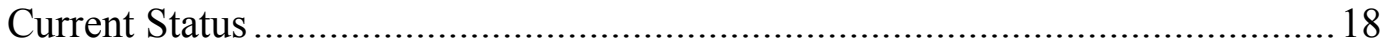

Contemporary Accounts of ID and Social Work.......................................... 22

Chapter 3

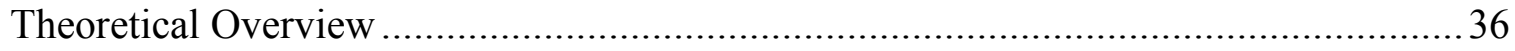

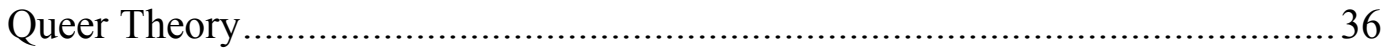

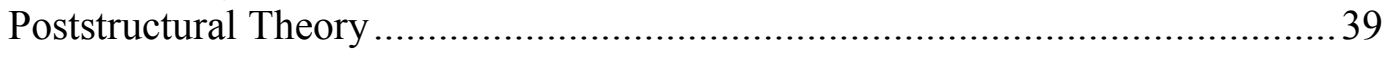

Chapter 4

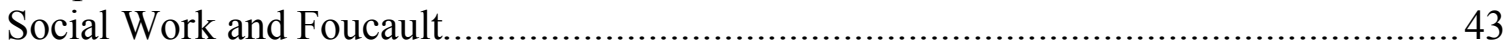

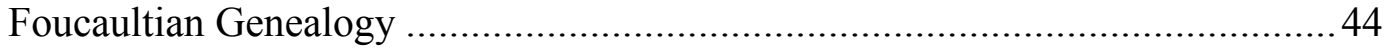

Current Accounts of Social Work and Genealogy .................................... 48

Chapter 5

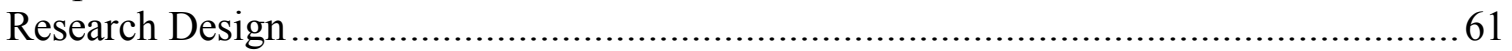

Framework of Genealogical Model of Intellectual Disability.........................63

Foucaultian Discourse Analysis ......................................................... 91

Chapter 6

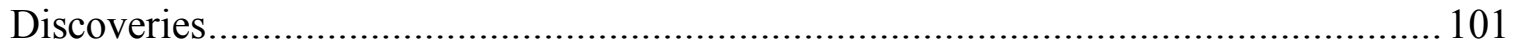

Relationship of Texts ....................................................................... 102

Discourse Analysis Using Genealogical Framework ................................... 112

Conclusion...................................................................................... 142

Chapter 7

Implications. 
A Foucaultian Discourse Analysis iv

Intimacy/Normalization .............................................................. 146

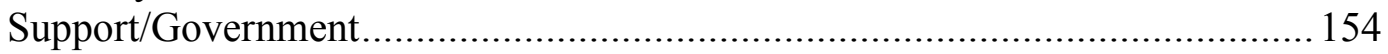

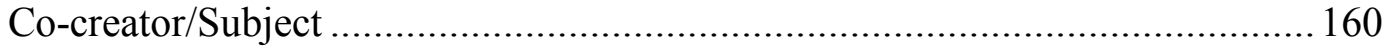

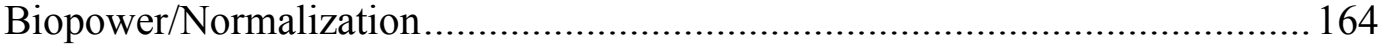

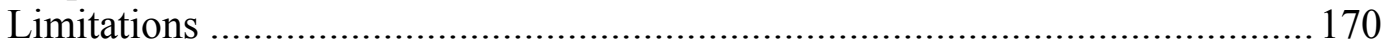

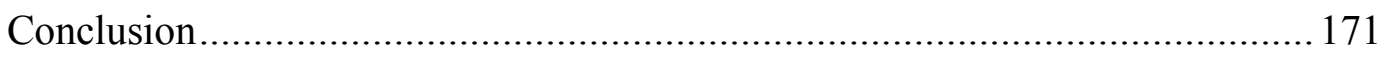

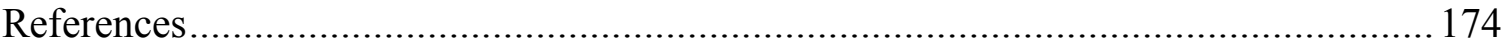

Appendix A. Notes from Voice Recorder ........................................................... 189

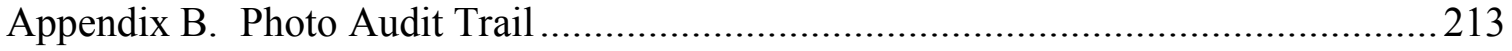




\section{List of Figures}

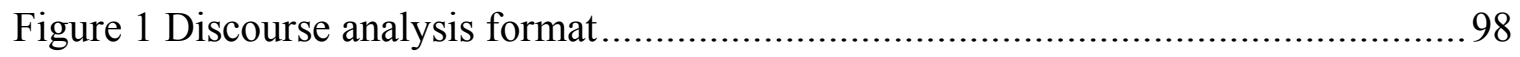

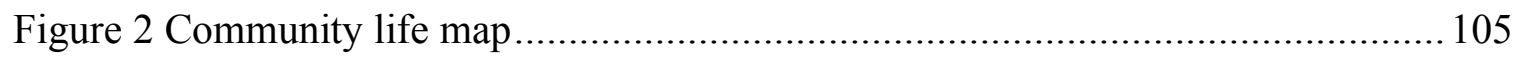

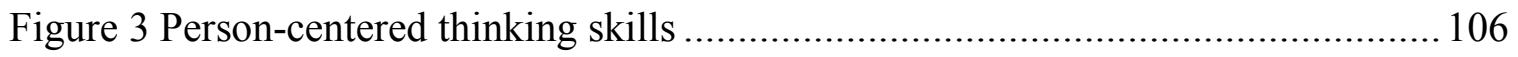

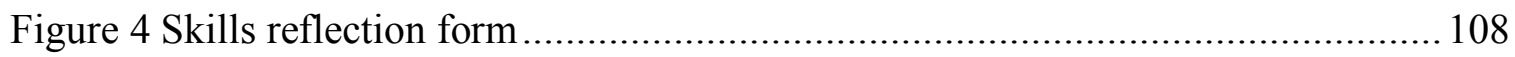

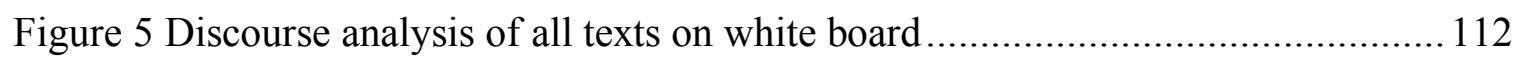

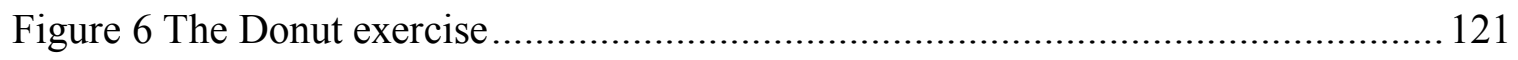

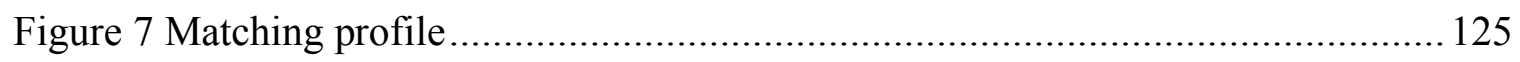

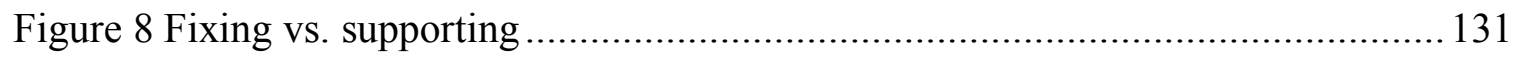




\section{Chapter 1: Introduction}

I created a genealogical framework to analyze intellectual disability throughout a well-known intervention known as person-centered planning. This framework highlighted the important role sexuality has played in constructing the current label of intellectual disability (ID). The genealogical framework is meant to replace the social, medical, and/or rights-based model(s) that have dominated social work and social services working in the disability field. With this framework, or perspective, I used a Foucaultian discourse analysis to read through seminal texts regarding person-centered practice. Person-centered practice is the foremost intervention used in social work, and other disciplines, to work with people labeled with intellectual disability. My research questions focused on what is revealed about ID in PCP through a genealogical framework and what implications do these discoveries hold for sexuality education and social services, including social workers?

\section{Context}

My sister was born in 1977. There were some complications during birth. The doctors told my parents that she may be "retarded" and would best be served living in an institution. My parents ignored this advice and took my sister home. The doctors said my sister would most likely never talk or walk. My mother took her to a speech therapist to work on language. True, she spoke later than typical and walked later than typical, but she succeeded in both.

Even though we were only two years apart, we often attended different schools because Special education wasn't usually available at the school I attended. I loved school 
and attended back-to-school nights whenever I could, both hers and mine. I was always confused by the curriculum in Special education. Though my sister received a lot of support around speech, there were very little academics available. So little in fact, that when she began high school, most of the school day was spent in vocational training and hygiene skills.

She graduated when she was 21 years old. Afterwards, there wasn't much available to someone not living in a group home or in an assisted living facility. Because she lives with my parents, few services are available to her. Her social circle is nonexistent, and transportation is difficult since mass transit is lacking outside of the city. Most services in her area are focused on providing assistance with daily living activities or health care. According to social service providers in her area, she doesn't need anything, so, therefore, she doesn't need services. I disagree.

With a label of intellectual disability proven via a doctor's note, she has applied to services to help her integrate into the community and live her life with agency. She has trouble with paid work since she has Crohn's disease and no reliable transportation. She could volunteer, but transportation is an issue again. A provider could help her with budgeting or cooking skills, but there are no grants to currently support such a provider. So, as a person with this label, she is viewed as unimportant to her community and unnecessary as a recipient of services.

This is not an isolated case; hers is not an unusual story. Though she could move, what about the thousands of other adults with the ID label who cannot or do not want to leave their home? They are left on the fringes of society, viewed as unable to contribute 
to society in any fiscal manner, unable to make decisions or understand them, and are essentially considered a burden. Goodey (2011) speaks to this phenomenon when describing how ID has essentially been viewed historically by society. ID becomes a label and a justification for marginalization when we, as a society, perceive people labeled with ID as burdens because they are deemed "less than," i.e. less intelligent, less deserving, less capable.

"Intellectual disability" is the reserve tank in which anyone who needs a justification for other, supposedly more arguable discriminations, can dip momentarily, an insurance policy guaranteeing that some of the normal population are more intelligent than others: that is, individually....and in groups (Goodey, 2011, p. 6).

Though this topic is personal for me, my interest in it also speaks "to the deepest problems of exclusion, oppression, and dehumanization" within our society and my own "proximity" to a person labeled with ID should not "be grounds for disqualification when speaking philosophically about this topic" (Carlson, p. 3, 2009). I have worked in various residential facilities for adults labeled with intellectual and developmental disabilities (I/DD). These experiences opened my eyes to another torrent of oppression I was not aware of before, namely, societal beliefs surrounding intimacy for labeled people.

The academic literature has noted the obstacles residents living in a group setting must navigate if they are interested in a physical relationship with someone (Bernert, 2011; Eastgate, 2008; Kelly, Crowley, \& Hamilton, 2009; Lofgren-Martenson, 2004; Richards, Miodrag, \& Watson, 2006; Swango-Wilson, 2008; Taylor-Gomez, 2012; Winges-Yanez, 
2014). Bedard, Zhang, and Zucker (2010) have stated the "sexuality and sexual behavior" of people labeled with an intellectual disability are among some of the least understood issues by service providers (p. 167). Regarding parents, the literature highlights a "cognitive dissonance" that occurs wherein parents believe their child is "a gift from God...but definitely asexual" until adolescence hits (Foley, 2012, p. 308). Again, throughout much of the literature, parents and caregivers support sexuality education for labeled people, but who should be responsible for providing that information is much more difficult to answer (Foley, 2012; Winges-Yanez, 2014). This dilemma is emphasized in the FLASH sexuality education curricula for public school Special education in that concepts such as sexual orientation and gender identity are explicitly left out while discussions of body autonomy are couched within non-sexual situations (Winges-Yanez, 2015). This lack of understanding from service providers and caregivers can lead to a lack of discussion or acceptance. Bedard and colleagues (2010) have discussed studies showing participants unable to express themselves even verbally due to lack of "education, information, language, identity and acceptance," leading to risky sexual behavior, sexual acting out, and victimization (p. 173). People labeled with an ID are often seen as incapable of making decisions regarding their sexuality, including orientation or gender identity (Bedard et al., 2010; Taylor Gomez, 2012).

Innately tied to intellectual disability is the concept of sexuality. During an analysis of a sexuality education program for Special education, I realized what was being discussed and what was being taught was not necessarily sexuality, but ID—-the program implicitly focused on limitation (Winges-Yanez, 2015). Students were not given information on 
gender identity or sexual orientation, because the curriculum assumed they may not understand. Most of the curriculum avoided specifically and explicitly discussing sexuality. In this avoidance, it becomes clear which people are deemed "allowed" to have a sexuality and which are not. By not discussing orientation or identity, a common concept within the discourse of ID emerges, which is inability to understand. Another concept that emerges out of the absences is eternal child; by not discussing core concepts of sexuality or explicitly avoiding the topic within sexual terms, such as discussing how to say no when a friend asks for a ride home versus in the context of body sovereignty, the view of ID over that of a sexual being takes precedence. Similarly, according to Oregon statute regarding sexual consent, one must be without "mental deficiency" (Or. Rev. Stat. 163.315, 2015) in order to consent to sexual activity. Mental deficiency is not defined, but it does pose an a priori challenge to those labeled with an intellectual disability. Does sexuality disallow for mental deficiency or does mental deficiency disallow for sexuality? Through this dissertation, I have illustrated the networks of power relations that have used sexuality as a way to oppress labeled people and set present day understandings of the concept of ID. This discussion of power relation networks necessarily included examination of social services as a major provider for many labeled people.

I examined best practices in social services as they play into these power relationships. For example, independent living options offered by social services are considered best practices within I/DD services, and one could argue independent living restores power to the individuals. In reality, however, many individuals who end up living in group homes do not have any choice in who their housemates are or where their house 
is located. Additionally, many people labeled with ID do not make a living wage to allow for actual housing independence, or independence itself is not ideal as many need some support throughout the day. The goals of many service providers, even if created with intent to restore agency, end up reinforcing the status quo of non-individualized options.

\section{Positionality}

I entered this project with experience working in group homes, vocational settings, and as an independent contractor. My sister is a labeled individual. I consider myself both an advocate and an ally to labeled people. My paradigm is critical and poststructuralist. My values affected my work; I tried to untangle the many voices over time that have contributed to the current understanding of the concept "intellectual disability" because it was clear to me — and it became clearer through this work — that labeled people have had little to no say in this understanding. I explored and analyzed the connections between the concepts of sexuality and intellectual disability.

I position myself as Queer, middle class, able-bodied, White, and a cis-gendered woman. Some of these identities allow me to speak from a position virtually unhindered by domination. I take ownership of the fact that I am able to speak about issues such as sexuality and (dis)ability without the same risks as labeled people. I became even more aware of the fear inherent in the intersections of these topics when I worked at a state-level nonprofit advocacy agency. I had a position statement from the national affiliate of my organization posted in my cubicle and was told to take it down. When I asked why, especially given the statement came from our parent organization, the answer was that we

are "separate organizations and we [the state agency I worked for] did not support this 
position statement" (the statement can be found at http://www.thearc.org/who-weare/position-statements/life-in-the-community/sexuality). This fear creates silence around this topic, taboo that many do not have the privilege to challenge. As both a social worker and a researcher, I also take ownership of the fact that historically these professions have been (and continue to be) contributors in the domination of labeled people.

I must also be clear that I am not disabled, and, as an outsider, I cannot truly comprehend the harm that has been done under the guise of good intentions. As I have previously stated, I have a personal stake in this topic through my sister. This personal connection has drawn both suspicion and understanding from peers regarding the validity and legitimacy of my work. I acknowledge that I did not approach this work from a place of objectivity. I have spoken with parents, professionals, students, and friends; all have approached the topic of ID with a foundation of what I perceived to be protectionism, wherein protectionism is defined as shielding a person from potential harm through overprotection or withholding of information, such as sexuality education. I can't say it isn't my first response to feel protection towards a labeled person, but I try to mitigate this gut response with respect and uncertainty. I must make clear that I am not immune to society's hegemony concerning ID, but I offer another perspective: genealogy.

For my dissertation, I used a Foucaultian genealogical perspective because it is not value free and does not claim to be (Koopman, 2013). However, this perspective does lead to an unraveling of current understandings; it attempts to shake the "unshakeable" foundation of an issue so that a clearer picture may emerge of whom has contributed to its current iteration and how. Genealogy begins with an articulated issue and then, using 
historical texts (to be clarified in chapter 5), identifies various institutions/professionals/authorities that contributed to current comprehension of the concept. The purpose of a genealogy is to clarify where dominant beliefs and understandings of a topic descend from with the intention of changing them; in essence, this perspective analyzes how the power/knowledge network historicizes and constitutes ID.

\section{Lexicon}

In order to facilitate a comprehensive understanding of my work, I need to define and explicate some important ideas and terms. Foucault used words in very specific ways. Because of this, I discuss Foucaultian terms (such as discourse) in the following section.

\section{Foucaultian terminology.}

Foucault specifically analyzed issues relating to power relations, subjectivity, and ethics. He used certain terms repeatedly throughout his work, becoming more precise with definitions as he went. Of these, I discuss discourse, biopower, government, subject, and normalization because they are integral to my work. Foucault often highlighted the importance of evolving societal definitions and contexts in identifying what was "normal" or "abnormal." He did this through a historical mapping (genealogy) that included the disciplines of economics, history, political science, philosophy, and medicine, to name a few. Foucault illuminated the interconnectivity of organizations and relations that at first glance appear disparate and unrelated. Throughout this work, I italicize these Foucaultian terms to assist the reader to recognize when the terms are being used specifically in this framework. 
Discourse. Discourse is a fluid notion, meaning anything from a discussion to an overarching ideology. Discourse analysis enables us "to question the intelligibility of truth/s we have come to take for granted" (Graham, 2011, p. 666). The text from which one can analyze discourse can also range from a TV commercial to written words in a book. Discourse in context of my work is an expression of an overarching ideology within Western society regarding intellectual disability. Discourses are "produced by processes such as the sanctioning, including, excluding, valuing, and devaluing of certain concepts, ideas, language, and words" (Strega, 2005, p. 219). Mills (as cited in Strega, 2005) states "discourse is a set of sanctioned statements which have some institutionalized force, which means that they have a profound influence on the way that individuals act and think" ( $p$. 219). Connections among what at first appear to be disparate entities are the exterior limitations of a discourse. For instance, some of the exterior limitations of a discourse of sexuality, according to Foucault, are: the Church, medical institutions (such as psychiatry), the State (including the police), and schools (Foucault, 1976/1990).

To illustrate the power of discourse, Foucault analyzed a court document that told the case of three men engaged in sexual relations as well as thievery. The expert (the psychiatrist in this case) opined these men were "repugnant" and "immoral" (Foucault, 1999/2003, pp. 5-6). Foucault concluded that this particular discourse deserved attention because it was spoken by "qualified people" in a "scientific institution" (judicial arena) and had the ability to kill, declare a "truth," and provoke laughter (p. 7). Looking at labeled people, there are similarities; people labeled with ID have been detained, sterilized, warehoused, and ridiculed through slang (e.g., "That's retarded!"). The concept of 
sexuality is commonly believed to be beyond the understanding of people labeled with ID, despite the empirical evidence that sexuality is a part of all people independent of (dis)ability (Milligan \& Neufeldt, 2001; Mollow \& McRuer, 2012; Richards, Watson, Monger, \& Rogers, 2011; Siebers, 2008; Swango-Wilson, 2010; Winges-Yanez, 2014). However, the techniques of biopower have named this population as non-conducive to a healthy society, needing protection from themselves and others (Gill, 2009).

Biopower. Biopower is a relation of power that through statistics, medical knowledge, and economics (among many others) creates an "average," or concept of "normal" that is not only statistical but normative and value laden while simultaneously creating a normative and value laden concept of "abnormal." This system then provides a limited number of choices from which the "normal" population must choose in order to thrive and produce, while also providing limited number of choices for those deemed "abnormal," and thus non-productive to a population. This includes regulation, normalizing society in regards to life, the surveillance and reporting of life, death, birth, and health. Technologies and mechanisms exist to deal with the management of life and how to make practices conducive to a healthy society. Biopower techniques aim to let people live, as a population that has been codified and classified, in a productive manner. Charitable organizations, clinics, hospitals, and other institutions were erected to "partition the random element of populations from the collective at large in order to maximize the conditions conducive to life" (Tremain, 2005, p. 5). Biopower specifically looks at how people have been codified and controlled through the division of abnormal and normal. Biopower includes the discussion of subjectivity and objectivity; specifically, how one is 
made into a subject (subjected to normalizing as well as subject of a discourse) versus an object (an object of discourse).

For example, the medical field systematically medicalized objects, naming and defining according to "norms" (normalization) that have been created through techniques of biopower. Terms such as "invert" and "homosexual" have created and maintained a discourse governing how a person can and should interact in society as a person who is labeled as engaging in "deviant" (read: outside of what is considered "normal") sexual behaviors. This discourse offers little room for discussion of sexual rights.

Biopower is concerned with the health of a society. Reproductive health is inherent in this definition. Once eugenicists began to question the worth of various people (based on race, ability, incarceration history, and so on) as well as the likelihood that their traits would be hereditary, certain people began to be sterilized without their knowledge or consent (Wehmeyer, 2013). This relation of power created a discourse in which society came to view certain traits as defects to be controlled. Sexuality, then, became an entity that took on various tenets of danger. "Danger" being something that could potentially harm or endanger the well-being of the non-disabled population.

Government. Despite this overwhelming evidence of power inequity inherent in the discussion of biopower, another concept leaves room for revolutionary work. Government, the art of governing or "the conduct of conduct," has often been misconstrued as a totalitarian effort that illustrates power as a commodity that can be held and withheld in a one-sided relationship. Foucault refutes this idea by describing power as an active relationship among participants. Foucault uses this term as it was used in the $16^{\text {th }}$ century: 
conduct. When I use the term government, then, I am discussing how a person, a group, or an institution is conducted. Foucault (2000b) stated: "The exercise of power is a "conduct of conducts" and a management of possibilities, ... [therefore] to govern, in this sense, is to structure the possible field of action of others" (p. 341). Power can be viewed as a discursive strategy that creates subjects or objects; the participation of the subject is inherent to the concept of power as those who view themselves through the dominant discourse and participate in the discourse through discursive actions (Mckee, 2009).

In his discussion of the emergence of the "dangerous individual," Foucault (2000a) describes the power to be had by the social sciences through a specific type of government (p. 184). Through this governing, the social scientists view the "social body ... a biological reality and a field for medical intervention" wherein "the doctor is the technician of the social body and medicine [is] public hygiene" (Foucault, 2000a, p. 184). The changes that had taken place were the adoption of such techniques as demographics, urban structures, nutrition, birth and death rates (also known as biopower) (Foucault, 2000a). Here, we see government take a new turn that embraces social science as a legitimate form of knowledge that exerts power over those deemed dangerous. Foucault, in this essay, illustrates danger as someone who threatens the overall well-being of the population.

Subject. Foucault had remarked that much of his work was not focused on power, but a history of how humans have been constituted as subjects (Foucault, 1997c, p. 327). In Foucaultian terms, subject refers to a dual meaning. Individuals understand themselves through the ideologies prescribed within a specific discourse. Also, a person is subject to 
government via various forms of power relations with other individuals, organizations, or institutions. Tremain (2005) summed this up with:

For Foucault, to be subject is, in one sense, to be subject to someone else by control and dependence and, in another sense, to be tied to one's own identity by a conscience or self-knowledge (p. 6).

An example of this subjectivity: a person who identifies as a lesbian may come to know herself and her identity through such discursive practices as sexuality education, media representation, and religious doctrines. She may attempt to repress her identity or believe that in order to "be" lesbian, she must have short hair, act masculine, and possibly not participate in her faith. She not only constructs a subject, an identity, she is subjected to various representations of how a "lesbian" looks and behaves. This specific example is based on a student I had who is of Japanese descent and stated she felt the only way to accept her lesbian identity (in the beginning) was to stop wearing skirts and to cut her hair short. She constructed herself as "abnormal" in relation to "normal."

Normalization. Normalization is integral to biopower and subjectivity. Normalization is the process by which varying institutions create techniques and discourses identifying what is "normal," (i.e., productive) and what is "abnormal." Chambon and Wang (1999) eloquently stated that normalization "implies processes by which society (specifically, the human sciences and the helping professions) acts upon individuals and groups to regulate, shape, or make them conform to a norm” (p. 276).

This is illustrated through the example of homosexuality. Until 1973 in the US, homosexuality was considered a mental illness as defined in the DSM (Diagnostic and 
Statistical Manual of Mental Disorders). Up until this time, the medical profession deemed homosexuality to be deviant and perverse behavior. Various therapies were available to "fix" the individual identifying as homosexual, legal discriminations existed, and many people were ostracized from society and their families. In concert with normalization are the concepts of biopower and subject. In this example, an individual is subjected to a specific discourse of what is "(re)productive and healthy" sexuality, leaving the person to create a subjectivity based on these overarching ideas, such as heterosexuality. Through statistical norms identifying a majority of the population as heterosexual, a value is also created through the reification of heterosexuality through medical, legal, and religious texts.

The power of this discourse, however, is illustrated by: religions continuing to grapple with the concept of homosexuality; legal institutions continuing to discriminate against this community or refuse to act on behalf of a person due to accepted legal prejudice; and reparative therapy still a legal therapeutic intervention for individuals who wish to change their orientation (or are forced to via parental request).

Dispositif. Foucault identified specific networks of power and knowledge in his works of genealogy. Foucault (1977) called these networks dispositifs, a French term that has no direct English translation, and argued dispositifs are constructed when:

...power produces knowledge (and not simply by encouraging it because it serves power or by applying it because it is useful); that power and knowledge directly imply one another; that there is no power relation without the correlative 
constitution of a field of knowledge, nor any knowledge that does not presuppose and constitute at the same time power relations (p. 27).

This network is a conglomeration of various institutions and relations that, together, create a lens through which to view or identify a problematization. When a problem is "regarded as a specific kind of problem for specific authorities at a specific point in time" (Garland, 2014, p. 378), this is a problematization. Intellectual disability is a problematization because it is employed as a regulatory mechanism by various authorities, historically and currently, and is used in the creation of the subject via strategies of biopower (such as normalization).

In summary, these terms and concepts are tied to each other in the discussion of genealogy. A fuller discussion of how these concepts interact and are used in my project occurs in chapter 5 when I discuss data gathering.

\section{Relevance to Social Work}

Social workers often work in areas that directly relate to people labeled with ID. Schools, residential facilities, case management, therapy, hospitals - social work as a profession is present in all of these institutions. For families figuring out the complicated network of social services, social workers are present to assist with the process. This has been true since the burgeoning age of institutions in the early part of the twentieth century and it is true now. Social workers' Code of Ethics, put forth by the National Association of Social Workers (NASW), helps guide professional behavior and decision-making. The most recent update to this document occurred in 2008, expressing core values of service, 
social justice, dignity and worth of the person, importance of human relationships, integrity, and competence (NASW, 2008).

Social work functions within multiple venues and interacts with multiple communities. Social work borrows from other fields, such as sociology and psychology, but is unique in how it presents its "regime of truth" (Philp, 1979, p. 90). This regime of truth creates a "subject in objective knowledge" (Philp, 1979, p. 91). What this means is through social work's doctrine of values, a universal view of the subject emerges, values ascribed to a person, regardless of ability, race, sexual orientation, and so on illustrated through beliefs of self-determination, agency, and social responsibility. These beliefs are then reproduced by the social worker to an individual, thus, creating a subject via Foucaultian logic; the individual also creates their identity based in part on interactions with social work(ers). As a discipline, social work encompasses its own regime of truth and values which are then used to subjugate others, or as Chambon (1999) stated: social workers do not really start from "where the client is at...[c]lients do not exist outside of the historical activity of social work; they are the result of that activity" (p. 53). Through this lens, labeled individuals (and family, advocates, allies) also become a part of this regime of truth that is unique to social work.

The discourse of ID has fluctuated throughout history, at once claiming different titles (idiot, feebleminded, moron) and different criteria (moral depravity, mental health challenges), but has long been looked on as a condition that needs protecting (Carlson, 2009; Gougeon, 2009; Mollow, et al., 2012). Because of the unstable nature of the ID label, social work has approached labeled people differently depending on the context. During 
the era of eugenics, Block (2000) specifically called out the profession of social work in policing the sexual lives of labeled people in the U.S. claiming "certain doctors and social workers continued to advocate for the practice" of sterilization on an individual level despite a national policy stating otherwise in the 1970s (p. 247). Trent (1994) also implicated social work professionals alongside other disciplines stating:

The care that they [professionals involved in institutions and state schools] gave people whom they labeled mentally retarded, then, was never separated from, nor incompatible with, the personal and professional legitimacy that the control over these same people brought them (p. 272).

Social work as an institution has provided services, interventions, and support for all people, but particular attention is paid to those deemed "vulnerable, oppressed, and living in poverty" (NASW Code of Ethics, 2008, preamble). As social workers, the "control" and "legitimacy" Trent (1994, p. 272) spoke of is inherent in the supports offered via the NASW Code of Ethics. Social work must acknowledge this connection as well as begin to acknowledge the oppression and harm constitutive in the label of intellectual disability given the unstable history of the concept and the current discourse surrounding it. Unless social work does this, supports, interventions, and services will be based on a history of accepted - read "natural" - inequity. A genealogical perspective offers an alternative view of ID, one that highlights the disruptions and subjugated knowledge of the label and critically analyzes the interdependence between the dominant discourse of ID and sexuality. 


\section{Chapter 2: Review of Current Research}

First, I discuss the current status of the concept of ID, followed by a brief presentation of the major models used to frame disability and disability services within social work practice. Finally, I present a brief introduction to person-centered planning.

\section{Current Status}

Intellectual disability. As of 2010, approximately 57 million people in the U.S. identify as having a disability (www.census.gov). This community includes visible and invisible disabilities, mental health challenges, physical differences, and intellectual disabilities, just to name a few. As mentioned, even the label of disability can be - and is - contested. Disability theorist Tobin Siebers (2008) stated:

Disability is not a physical or mental defect but a cultural and minority identity. To call disability an identity is to recognize that it is not a biological or natural property but an elastic social category both subject to social control and capable of effecting social change (p. 4).

Samuels (2014) pushed back on disability as identity when stating “...[identities] claim a scientific, often medical framework and function to consolidate the authority of medicine yet in practice often exceed or contradict any actual scientific basis" (p. 3). Mollow and McRuer (2012) added: "Disability identity... is never simply a natural fact; it is rather made and remade in historical circumstances and by historical agents" (p. 7). These historical agents and circumstances are understood and enacted through discourses, creating subjects and subjecting them to ideas of normalization. 
A possible framework of disability is the genealogical model, as proposed by Jenkins (2012). In this model, the view of disability moves beyond the binary of "normal/abnormal" to a framework accounting for malleability and highlights the "constructed nature of impairment" (Jenkins, 2012, p. 6) as seen through various historical mechanisms that have assisted in creating and labeling disability. These alternate interpretations are intrinsic to genealogy as they offer a more nuanced history. Even human sexuality, as Foucault (1976/1990) illustrated in his genealogy The History of Sexuality, Volume 1, has varied and surprising manifestations dependent on culture, history, and power relations.

Of the 57 million people identifying as having a disability label, approximately 1$3 \%$ are labeled with an intellectual disability (www.thearc.org). The Arc is one of the largest and most well-known organizations working in policy and advocacy issues for people labeled with intellectual and/or developmental disabilities. The main difference between these two terms is developmental encompasses differences such as autism spectrum, epilepsy, and cerebral palsy. Intellectual disability is under the umbrella of developmental disabilities if it occurs before the age of eighteen years old. The definition of intellectual disability is:

1. Intelligent quotient (or I.Q.) is between $70-75$ or below

2. Significant limitations in adaptive behaviors (the ability to adapt and carry on everyday life activities such as self-care, socializing, communicating, etc.)

3. The onset of the disability occurs before age 18 (www.thearc.org). 
I choose to use the term "labeled with intellectual disability (ID)" (or "labeled people" for shorthand) because I believe it is important to acknowledge that no matter what current times reveal to be appropriate, unbalanced power relations continue to create labels for a specific grouping of people without their input. Schalock, Luckasson, and Shogren (2007) illustrated the continuing power imbalance in their article discussing the change within academic and professional circles from using the terms "mental retardation" to “intellectual disability." In it, the authors put forth criteria showing how the label ID:

(a) reflects the changed construct of disability proposed by AAIDD and WHO; (b) aligns better with current professional practices that are focused on functional behaviors and contextual factors; (c) provides a logical basis for individualized supports provision due to its basis in a social-ecological framework; (d) is less offensive to persons with disabilities; and (e) is more consistent with international terminology (Schalock, et al., p. 120).

Interestingly, nowhere does it state that people labeled with ID chose this label. The validity of this term is a difficult one to untangle and continues to be a topic of debate. Throughout this work, I use terms that were used during various historical eras, such as "feebleminded" during the 1920s-1950s or "mentally retarded" from the 1950s to the early 2000s. Again, this is important in constructing a genealogical perspective of ID to identify who is contributing and how.

The definition of ID has also become increasingly complex over time. This complexity could be viewed as professionals attempting to expand the criteria defining ID, 
creating a more holistic illustration of ID versus a simple score on an IQ test. The American Association on Intellectual and Developmental Disabilities (AAIDD) stated:

Intellectual disability is a disability characterized by significant limitations in both intellectual functioning and in adaptive behavior, which covers many everyday social and practical skills. This disability originates before the age of 18 (http://aaidd.org/intellectual-disability/definition\#.VNvHzFV4os0).

Additional definitions and considerations regarding ID are also discussed on this webpage. Wehmeyer (2013) stated the condition is "best defined in terms of limitations in typical human functioning" (p. 9). This articulation speaks to how ID is constructed and reified; the foundation of ID, regarding its constitution in society, is limitation.

Carlson (2009) highlighted the tension amongst academics regarding the validity of naming ID, specifically, a social construction. She spoke to the false dichotomy between "real and socially constructed" when discussing ID (p. 86). The issues that emerged were: ...there are real people who...have been directly affected by that label...some who have intellectual limitations, some result of endogenous biological or genetic causes, others caused by external factors, and for some of which is there is no identifiable cause (p. 86).

In many states, labeled people must prove they have an ID in order to receive services. These services range from early childhood intervention, Special education, social services, and Social Security benefits. Tremain (2005) analyzed this requirement of proof as a way of constituting a definition of "impairment" that would not exist without the concept of disability. She stated: 
...governmental practices into which the subject is inducted and divided from others produce the illusion that they have a prediscursive, or natural, antecedent (impairment), which in turn provides the justification for the multiplication and expansion of regulatory effects of these practices (Tremain, 2005, p. 11).

This argument leads into the concept of labeling. Is ID a natural impairment, or does it follow a socially constructed view of what is "normal"?

The concept of ID is not static, nor has it ever been. What at one time was labeled as mental illness would now fall under the definition of ID in some instances, and vice versa (Carlson, 2005; Wehmeyer, 2013). In attempting to find a beginning to the concept of ID, it's possible to fall into the trap of believing these objects are not constituted by discourse and discursive practices (Hook, 2005). Under this false pretense, one could lose sight that it is our own creation, our own rules, as society and as experts, which have oppressed labeled people using techniques of biopower, including the belief sexuality must be policed because labeled people are innately incapable of understanding or controlling it.

\section{Contemporary Accounts of ID and Social Work}

Within the last three decades...the number of social workers committed to the disability field has escalated and, currently, social workers worldwide are engaged in service, policy and research aimed towards enhancing the quality of life and procurement of rights for persons with disabilities (Ballan, 2008, p. 195). 
Social workers are strategically positioned to develop, implement, and advocate for policies, programs, services, and research that support and benefit persons with a disability (International Federation of Social Workers, 2012).

Approximately $12 \%$ of U.S. schools of social work (out of about 192) offered core courses relating to disability and/or people with disabilities (Ballan, 2008, p.195). However, social workers often work in contact with labeled people due to the nature of their work, whether it be in case management, schools, hospitals, or nonprofit organizations. Despite this, social work education provides little in the way of resources or information regarding disability. There are two major frameworks of disability: medical and social. Social work aligns with a rights-based perspective that is embedded within the social model (Bigby \& Frawley, 2010). However, due to the complicated nature of ID and the reliance on interdisciplinary knowledge (because social work education does not prioritize disability information within their schools), all three models are often in play when analyzing interventions and services designed to support labeled people. It is important to become familiar with these different frameworks because

...the prevailing conceptualization of the problem of intellectual disability at any historic time will strongly influence the roles of social workers either as part of the system of services or in attempting to reframe and reform policy (Bigby, et al., 2010, p. 23).

I briefly summarize the models in the following sections. These descriptions highlight social work's current utilization of each. 
Medical model. The medical model of disability focuses on the person and their perceived impairment as a deficit that needs to be dealt with and as the cause of difficulty in adapting to various activities. The medical model is emphasized in, as its name suggests, the medical diagnosis of the disability. A person who has been diagnosed with Down syndrome would be approached from a deficit perspective with questions such as: What are the person's challenges? What limitations affect his daily living activities? Due to his diagnosis, what other behaviors or medical issues does this person also have?

Because social workers may act as primary care coordinators (in such disciplines as Case Management) for labeled people and their families, this model can be perceived as limiting. Social workers in this capacity work with interdisciplinary teams to provide wrap around care for families and labeled people. A medical model may be the most prominent as doctors, psychiatrists, nurses, and various therapists are inevitably part of this team. Specifically, a team functioning under this model will work to assist the labeled person to perform an activity, or activities, "in the manner considered normal for a human being" (Bigby, et al., 2010, p. 11). This model does not look at current strategies that are working for the person or how to structure supports using creative and/or natural resources, such as community members and recent technology such as the iPhone. Instead, this model focuses on ways to fix what is perceived as "broken," which, in this case, is intelligence and adaptive skills. The importance of IQ and adaptive skills are evidenced by usage of IQ scores and functional assessments to identify level and severity of ID. Oliver (1996) drew attention to this model as providing a "personal tragedy theory of disability" in which the 
person with the disability must come to terms with their disability and may need professional intervention to do so.

The discourse arising from this framework echoes Oliver's (1996) "personal tragedy theory" by providing a clear idea of what is "normal." The discourse provides a very limited choice of how to constitute a subject that has any agency while providing a multitude of ways to subject the person to a deficit-based lifestyle. Because the labeled person is deemed to be functioning at a deficit, this leads to the societal notion that labeled people are "childlike" and "dependent" (Neely-Barnes, Marcenko, \& Weber, 2008; Winges-Yanez, 2014). This model historically led to services and interventions such as the institution and training schools but, more recently, provides the foundation for day centers, segregated education, and labor camps, such as the one described in the recent book 'Boys' in the Bunkhouse (Barry, 2016).

Additionally, this model does not allow for the discussion of sexuality or reproductive justice because labeled people are perceived unable to understand or fathom the complexity of the discussions (Winges-Yanez, 2015). This lack of discussion also leads to current iterations of normalization and biopower. Labeled people are not considered sexual beings (Kelly, Crowley, \& Hamilton, 2009; Lofgren-Martenson, 2004; Milligan \& Neufeldt, 2001; Pitceathly \& Chapman, 1985; Richards, et al., 2006; Rogers, 2009; Weeks, 1998; Winges-Yanez, 2014) and social service workers "rarely extend practice support" (Kelly, et al., 2009, p. 304) to include sexuality. The inclusion of the topic of sexuality is important when discussing current accounts of social work and ID because it highlights the continued use of the medical model within the field. Biopower helps to illustrate how some 
people are considered productive and useful within a society and others are explicitly segregated and purposefully misinformed or given less information (Winges-Yanez, 2015). Tremain (2005) echoed this when she stated "a vast apparatus, erected to secure the wellbeing of the general population, has caused the contemporary disabled subject to emerge into discourse and social existence" (p. 5) through such institutions as special education, income support, and sheltered workshops, to name a few.

Another model that is often used as a foundation for services and interventions is the social model. Though this model professes a much more holistic view of disability, those labeled with intellectual disability have routinely been left out of the development of this model (Bigby, et al., 2010, p. 15).

Social model. The social model of disability evolved from the U.K. advocacy movement, mostly comprised of family and self-advocates, during the late 1970s (Bigby, et al., 2010, p. 14). This model claims impairment does not have a linear relationship to disability. Disability occurs when institutions, physical structures, societal attitudes and policies prevent the person with the impairment from living a full life, having “independence, choice, and control...over their own lives" (Bigby, et al., 2010, p. 13).

This model also makes room for support for people to occur if tasks cannot happen autonomously. In fact, a rights model is embedded within this framework owing to the work of activists and academics who have pushed the discourse of disability studies forward. The social model encourages universal access that does not specify only one type of person as needing special access; for instance, curb cuts are useful for people using wheelchairs as well as for bicyclists, children, people with different mobility, and those 
pushing strollers or carts. The social model encourages the acknowledgement of impairment existing prediscursively and disability occurring once the person with the impairment comes in contact with society.

Much of social work practice utilizes a social model of disability. Person-centered planning, in the form of individual educational plans, essential lifestyle plans, and individual support plans, place the labeled person at the center of the discussion and claims they are the expert in their own life. Natural support systems, as differentiated from paid supports, are brought into discussions of best ways to support labeled people while also highlighting goals and dreams identified by the labeled person.

Recent court decisions mandating more housing choices (Olmstead v. United States) helped create more community living options, allowing more labeled people the option to live in their community outside of an institution. Community settings sprung up all over the country with the mindset (theoretically) that labeled people should have the choice of where they live and have (some) control over their lives and be included in their community. This is the social model of disability in action.

Some issues with this model have arisen in the last decade that question its utility and effectiveness, some of which are directly related to the community living boom. An eloquent summary of this particular issue is provided by Clapton (2009): "the extent of change required for society to achieve inclusion of all people with intellectual impairment is so far reaching, that the concept of inclusion would no longer be meaningful" (as cited in Bigby, et al., 2010, p. 16). This quotation identifies the enormous amount of change 
required of society to actually include labeled people; a breakdown of current societal infrastructure would need to occur for true inclusion of labeled people.

It also becomes difficult to separate the medical from the social model when the social model requires the acknowledgement of an impairment existing prediscursively. What this acknowledgement does is unintentionally claim impairment exists outside of social discourse, reinforcing ideas of normalization. This reification puts forth another discourse that provides limited choice in subjectivity. Tremain (2005) furthered this argument: "there is indeed a causal relation between impairment and disability, and it is precisely this: the category of impairment emerged and, in many respects, persists in order to legitimize the governmental practices that generated it in the first place" (p. 11).

Specifically, when a functional assessment is done with a labeled person, the worker is measuring functional limitations in order to determine financial amounts commensurate with support services. Though the labeled person can now choose which supports are important and who will provide these supports (via court decision Staley v. Kitzhaber in Oregon), impairment must still be proven to exist and assessed before supports are provided. In this context, then, universal access does not truly exist, nullifying a basic tenet of the social model and blurring the belief in a line of demarcation between social and medical.

Rights-based model. Although a rights-based perspective is deeply embedded within a social model of disability, it is important to parse out some of the specifics because this particular approach to the social model is often used within social work (Bigby, et al., 2010). These approaches claim all people, regardless of ability, are worthy and deserve 
equitable outcomes regarding rights. This particular claim is different from the social model because it takes into account that societal and cultural viewpoints do not need to wholly change in order to facilitate inclusion. Bigby and Frawley (2010) articulated that: ...even if institutional or structural change falls short of enabling inclusion in the workforce, for instance, people with [ID] have the right to individualized support that compensates for their disadvantaged positions, enables participation and inclusion in aspects of their own life and the community, and a quality of life similar to that of other citizens (p. 17).

Inherent in this model is the belief of citizenry that was shared by Weeks (1998) wherein a citizen "must be about involvement in the wider society...carrying rights and entitlements but also responsibilities to fellow citizens and to the community which defines citizenship" (p. 36). Weeks (1998) also posited a sexual citizen that blurs the line between public and private, encourages acceptance and respect of diversity, and "broaden[s] the definition of belonging" (p. 37), all ideas that could easily translate to the citizenship of those labeled with ID. The sexual citizen is one who identifies their experiences, desires, and social location together, inseparable, while also calling for rights and respect, something that was unheard of in the not too distant past (Weeks, 1998). The term citizen was once only attributed to acts of public and community-based actions, but through social changes, sexuality as an identity, an experience, and a civil rights issue, led to the emergence of the sexual citizen.

During my own research into various approaches and models, I came across a critique of framing certain topics through a rights-based perspective. As I have advocated 
throughout this work, sexuality is intimately tied to the concept of ID. Many scholars have taken up this heatedly debated topic and proposed a rights-based perspective to the question of who can have a sexuality. The question becomes: is sex a right? At first glance, this would seem to open up the discussion, bringing in such notable organizations such as the World Health Organization and the United Nations Convention on the Rights of People with Disabilities, both of whom have released statements advocating sexuality as a human right. The issue with this is that instead of opening up the discussion, this perspective tends to shut it down. An example is if sexuality "were simply a matter of access...then a question like "Is sex a right?" would generate minimal controversy" (Kulick \& Rydström, 2015, loc. 586, e-book), but access to whom or what, exactly? This plays into the entire rights-based perspective in that interventions discussed (such as PCP) are not necessarily about demanding access to specific locations or institutions or who has a right to what; instead, this perspective can lead to the "trivialization and dismissal of their [labeled people] concerns" (Kulick, et al., 2015, loc. 616) because the issue becomes special treatment. The access many labeled people face due to historical oppressions are not adequately addressed using a rights-based model.

This may seem a far leap from the original discussion of various models used with social work to work with labeled people, but I don't believe so. If social workers rely on a rights-based perspective, concerns regarding housing, employment, sexuality, and transportation can be trivialized to a comparison to access by other groups without a more specific focus on ID. Through a genealogical framework, the limiting discourse of ID 
provided to society through the concepts of normalization, biopower, and government uncovers the regulating control of this label.

Additionally, it is important to note that a rights-based perspective is used to identify which rights a person has, rights most people are aware of. Yet, beginning from this vantage point—making labeled people and stakeholders aware of their rights—can supersede services and interventions. This approach speaks to the inherent lack of equity presumed by stakeholders. By proceeding via a rights-based perspective, service providers are implicitly acknowledging the societal discourse that ID is inherently limiting and unequal, leading to necessary regulation.

Once this regulation is uncovered, it becomes possible to view such current social work practice as PCP in a more effective way. Social workers will be able to identify historical practices that comprise PCP and spaces they may be able to advocate within policy, research, practice, and systems.

Brief overview of person-centered planning. Person-centered planning (PCP) is an approach to services that utilizes a rights-based perspective and social model of disability. Throughout this paper, I used the acronym PCP to refer to both person-centered planning and person-centered processes; I differentiated as much as possible by citing "plan" when specifically discussing person-centered processes. Initially developed in the US over thirty years ago, it dominates service planning for labeled people in both the US and UK (Mansell \& Beadle-Brown, 2003) for activities ranging from financial planning, health management, and daily living routines to long range goals and dreams. Connie Lyle O'Brien and John O'Brien were frustrated with "the failure of services to put values into 
practice and achieve inclusion, choice, and control in the everyday lives of people" labeled with ID (Bigby, et al., 2010, p. 141). The characteristics that set this approach apart from others are: its emphasis on beginning with the labeled person's view of the future, via goals and dreams; utilizing circles of friends and family as natural supports and important voices in the labeled person's life, and finally, identifying the support needed to achieve the goals listed by the labeled person (Mansell, et al., 2003). Using this approach, PCP has set itself apart from other forms of planning by placing the labeled person at the center of the discussion of their own lives.

PCP grew "out of the ashes" (Mount, 2016, 45:43) of how social services were proceeding during the time of normalization. Normalization was a concept that evolved through the work of Wolf Wolfensberger (originally coined by Bengt Nirje) during the time of deinstitutionalization and went on to be known as Social Valor Theory. Normalization was a concept that claimed devalued people deserved to live a typical life, advocating for smaller living arrangements, closures of sheltered workshops, true integration into communities, and acknowledging the past in order to move forward in services. Wolfensberger passionately argued that art, architecture, environments, and interior design all need to be critically analyzed in order to view how people are being treated. Once this is acknowledged, services that appear to be progressive are unmasked to actually be doing the bare minimum of maintaining health and safety versus allowing people to live their best lives.

Predictably, the term normalization was twisted to be understood as something more akin to Foucault's idea of normalization; many within service agencies and families 
believed normalization was a trend trying to make labeled people "normal," wherein the idea of normal was heatedly debated. Because of this, Wolfensberger delved into the minutiae of typical living standards in order to evolve the concept into Social Valor Theory; it had the same foundations of normalization with more statistics to truly analyze services. Wolfensberger still educated about historical social services and the context of oppression and stigma that surrounds labeled people and the services they use ${ }^{1}$. During a lecture series at the Millersville University in Pennsylvania in September 19982, Wolfensberger stated "...that we cannot understand human services of our day if we do not know where they come from and how they have gotten the way they are" (2:47-3:00). He emphasized the need to know our history, and he pointed to historical examples throughout his work; in the previously noted lecture series, for example, he began lessons in Greco-Roman culture. At this time, however, advocates of normalization had begun to splinter. Many opted for a much more intuitive (Mount, 2016, 44:55) approach called person-centered practice. Wolfensberger's attention to historical context was lost in the furtherance of normalization and the development of PCP.

PCP has dominated recent service provisions in the US and the UK, the latter shown through the adoption of principles stated in the 2001 White Paper entitled Valuing People (Mansell, et al, 2003; Bigby, et al., 2010). Manifestations of this approach are planning aids such as Essential Lifestyle Plan (ELP), Planning Alternative Tomorrows with Hope

\footnotetext{
${ }^{1}$ Please see the documentary "Valuing Lives: Wolf Wolfensberger and the Principle of Normalization."

2 The full lecture series is available on http://www.mn.gov/mnddc/wolfensberger/index.html
} 
(PATH), and Making Action Plans (MAPS). Each of these aids has a specific purpose based on how knowledgeable the supporters are about the labeled person or what the specific goals are as well as whose goals take priority. However, all of these aids are based on the basic principles of PCP listed earlier.

Some critiques that have arisen regarding PCP have come from the social work discipline and social administration. Bigby and colleagues (2010) noted the emphasis on family and friends does not translate to the experiences of many labeled people, who are historically socially isolated outside of paid support workers. PCP works for labeled people who have access to resources such as paid support, family and or friends, (Cambridge and Carnaby, 2005, as cited in Bigby, et al., 2010) social services, transportation, and community resources for employment and socialization (Bigby, et al., 2010).

The values that led to the creation of PCP, such as the "failure of services to put values into practice" (Bigby, et al., 2010, p. 141) have not changed throughout much of social services. Much of social service provision has been privatized (Bigby, et al, 2010; Villadsen, 2008), leading to services being costly and unattainable to those with limited income or resources. Similarly, in group settings, prioritizing an individual's goal may be difficult, such as in group home settings or roommate situations relying on limited staff assistance.

It is difficult to not notice the gap between rhetoric and reality when analyzing PCP in practice. Mansell and Beadle-Brown (2003) specifically call out reduced spending in social service provisions and lack of staff training in successful implementation of true 
person-centered planning (p. 6). This particular critique focuses on the UK, however, concerns about spending translate to the US in that we have block funding provided to states, which then determine how that money is unevenly divvied out based on a laundry list of requirements and assessments. The US also has a current debate involving fair wages for home health care workers. This debate is critical in the discussion of quality of care, quality of service, and employee turnover. PCP cannot happen if staff turnover is high, resources are not available, and services are privatized. These limitations are part of the inherent discourse of ID as one that posits labeled people as worth less than others regarding services and resources. 


\section{Chapter 3: Theoretical Overview}

Throughout my time researching the topic of sexuality and intellectual disability, I have found interesting ideas surrounding language and sexuality. Queer theory resonated with me early on with its focus on sexuality, but even more so with its emphasis on rejecting essentialism and binaries. Once I began to pick apart the foundational beliefs of these concepts, I found language and discourse to be powerful tools in the creation and maintenance of essentialism and binaries. Poststructuralism, with its focus on language and discourse, was therefore a natural fit. Surprisingly, when searching for sources discussing either theory, I often found crossover between the two, strengthening my belief that the two theories worked well together. Michel Foucault's archaeological and genealogical works appeared to work well with these theories without explicitly using either. Colin Koopman (2013) suggested that a Foucaultian genealogy can be viewed as a method for critique using critical inquiry (Queer theory) as a starting point, genealogy as methodology, and ending with a pragmatist approach to future work aimed at improving

the stated phenomenon. Specifically, poststructuralism focuses on text, language, and discourse, allowing the genealogical methodology to use these as grounding for historical texts.

\section{Queer Theory}

Queer theory is a lens to view normative practices and deconstruct these practices and call them out as limiting. Queer theory is generally located under the umbrella of critical theories. A hallmark of critical theory is the metanarrative that power is unequally distributed among populations. Queer theory challenges the accepted view of what 
constitutes normal regarding sexuality, gender, and sex. McRuer (2006), for example, has interwoven Queer theory with the study of disability to posit Crip theory, wherein ablebodieness is critiqued as invisible as heterosexuality within dominant discourse. Both heterosexuality and able-bodieness are viewed as normal, in other words. herising (2005) pointed out that Queer theory "disrupt[s] the normative, the naturalized, and the hegemonic" (p. 141) whereas hegemony refers to power of the state exerting control over others in a perceived "natural" way as to go unnoticed (Marinucci, 2010, p. 82). Queer theory also rejects essentialism, which is the belief that a pure core exists defining what, for instance, the gender "man" is. Instead, Queer theory supports the belief that categories believed to have a "true" core are, actually, socially constructed. What this means is that societies construct what "man" is, what it means to be a "man," and how to perform the gender of "man" correctly (for example, a man has a penis and is attracted to women). Instead, Queer theory claims binary thinking, which supports the idea there are two genders, is false and that these binaries are socially constructed. Since these manifestations are considered to be socially constructed it is possible, then, to perform and experience other genders, for instance. Marinucci (2010) explained this rejection of essentialism as:

Queer theory is capable of resisting essentialism while simultaneously affirming the experiences of people for whom the established categories are problematic as well as people for whom the established categories are relatively unproblematic (p. $61)$. 
While Queer theory rejects binaries and essentialism, instead embracing social constructionism, it is also respectful of the idea that the normative categories of "man" and "woman" (for example) can and do exist, but they are not the totality of gender expression. Grounding in Queer theory can create options to historically held notions of knowledge, or as herising (2005) stated, a "divestment of inherited knowledges" (p. 142).

Queer theory focuses on ideas of sexuality, gender, and sex, but can be translated to other areas, as well. For instance, Queer theory encourages questioning of what practices are considered normal; this can lead to questioning, or "queering," the idea that disabled exists as a dichotomous category from nondisabled. Applying Queer theory, one questions whether what is normatively considered a disability may only be a variation of human ability, calling into question what this label does for power imbalances in various social institutions, such as hiring practices and education. For instance, curb cuts are necessary for people who use chairs to access sidewalks. Under the normative perspective, people who do not use chairs are considered "normal" and those who do are "abnormal" or disabled. Therefore, specific allowances and changes occur in order to accommodate disabled people. However, through a Queer theory lens, these allowances and changes would occur as a way to promote and embrace all forms of movement without deeming them accommodations for one specific grouping of people (much in the same away an accommodation such as shoes or glasses have become normative and no longer markers of disability). By deeming them accommodations, a power imbalance occurs that gives priority to individuals who can walk (without assistance or who walk without a limping gait, for example) and names those who cannot as other or less than. 
Using this lens to begin questioning foundational beliefs led me to look at language and discourse. For this, I turned to poststructuralism as a way to focus specifically on and deconstruct discourse to identify power imbalances that occur in naming and whom is considered an authority when speaking. Poststructuralism also leads to a questioning of what knowledge is and where it comes from.

\section{Poststructural Theory}

Poststructuralism rejects grand narratives. Though this can appear to be combative with Queer theory because Queer theory's grand narrative maintains that inequity exists, I show how the two can complement in order to facilitate a genealogical perspective. Poststructuralism also rejects essentialism and emphasizes language and discourse (in the Foucaultian sense of the word) as the main tools in constructing and maintaining reality. The key concepts of poststructuralist theory are: discourse, subjectivity, and power (Strega, 2005), all of which are key in genealogy and complement Queer theory.

Poststructuralism claims reality is socially constructed. Primarily, this construction is facilitated and maintained through language and discourse. This is reiterated in the tenet that almost nothing exists without a discursive action. In poststructuralism, there is no such thing as a raw experience; all life occurrences are understood and experienced through the lens of one's history and understandings. Therefore, no two people can have the same experience, or have the same view or understanding of the experience. For instance, Strega (2005) stated language and discourse are not "transparent, functional, and progressive" (p. 216), but based on "history rather than progress, and [based on] workings of power and ideology rather than necessity" (p. 217). Also, power relations and hierarchies are socially 
constructed and maintained through history and interpretations of authority and power. For instance, medical doctors replaced midwives in the early $20^{\text {th }}$ century as authorities in relation to pregnancy and birth. Where did these replacements occur and what authority or power is inherent to medical doctors versus midwives? Poststructuralism can help deconstruct the discourse constructing this authority. In order to refrain from complete relativism (everything is socially constructed, therefore, nothing means anything), poststructuralism encourages reframing understanding so as to become aware of dangerous situations that could become oppressive by recognizing these socially constructed realities. Specifically, this theory brings to light the possibility of either being oppressed or becoming the oppressor, constructing social realities that can be dangerous wherein dangerous is viewed as domination.

Poststructuralism posits the subject is created and experiences through discursive practices; discursive practices can be understood as the action of discourse. For example, a person may understand herself to be a lesbian through the act of sexuality education. How LGBTQ identities are discussed (or not) in a sexuality education curriculum can create a concept of what a lesbian is. According to poststructural theorists, there is no essential core of self, the "self/subjectivity is an effect of discourse, historically and socially situated, constituted and constructed in discourse and discursive practices" (Strega, 2005, p. 222). This positioning does not remove choice from the subject but claims there are a limited number of choices from which to choose based on the discourse one experiences. Again, using the example of the person identifying as lesbian: a young teenager who also identifies as Black may not have many discourses available to her, 
leaving a limited number of choices she can choose from which to create herself as subject. Discursive practices can be understood as means in which discourse are relayed or reified, such as in what information the media reports or what historical facts are taught in schools (Strega, 2005, p. 219). These formations are tied to power.

Power, within poststructural theory, is viewed not as a commodity but an action or relationship. Power exists in constant motion. Similar to how choices are available to subjects, albeit limited choices, power is exercised by all. Also, power is not solely understood as oppressive or repressive; power can also be productive and positive. Important to the concept of power in a poststructuralist framework is the direction of power (government) and power in the use of domination, which is an attempt by one party to freeze interaction by others; because power exists in constant motion, the attempt to repress it could be viewed as dangerous, an act of domination.

Foucault paid special attention to the ways in which individuals constituted themselves via techniques of "power, knowledge, and ethics" (Koopman, 2013, p. 52). These techniques created the subject. However, the subject was also subjected to various power plays. In these power plays, subjugated knowledge was borne. By this I mean some knowledge was considered outside of the hegemony and lost to history. This subjugated knowledge is what Foucault deemed the "historical knowledge of struggles" (Foucault, 1980, p. 83). This knowledge was "local, specific,...[and] buried...disqualified from the hierarchies of knowledge and sciences" (Foucault, 1980, p. 82).

To summarize, poststructuralism focuses on language and discourse to identify subjugated knowledge and assess the location of the subject within these historically 
constructed discourses while paying attention to power relations. This is done through a rejection of essentialism and an acknowledgment of how power relations (including hierarchies and dichotomies) interact with discourse. 


\section{Chapter 4: Social Work and Foucault}

Michel Foucault (1926-1954) was a French philosopher whose work has had a lasting impact on society. He was active in the prison reform movement in France as well as other social justice movements of his time. His work focused on local relations of power, subjectivity, and ethics. Epstein (1999) stated she owed a debt to Foucault for his work deconstructing the social sciences as well as the inspiration he evoked in her research. I, similarly, feel my work has been transformed through and by Foucault's philosophy. I often feel Foucault's work is the "red pill" from the film The Matrix (1999), showing me how deep the "rabbit hole" goes. From using his framework in previous work in discourse analysis (Winges-Yanez, 2015) to my current undertaking of genealogy, I have found Foucault's philosophy to be both cutting edge and common sense.

What is genealogy? Koopman (2013) called it a form of critique capable of social change. Wang (1999) claimed genealogy is a form of resistance. My answer, the short version, is that societies must recognize and understand where problematization has come from before they can move forward from it. A metaphorical Greek Hydra exists within the construct of "people labeled with ID;" if we cut off (or identify) one head (or contributor) another two emerge that are just as big with just as much to contribute. Some examples of the Hydra heads are: labeled people are asexual, or they are perpetual children, or labeled people must be protected. We must identify as many of these heads as possible in order to know how to proceed, otherwise, we continue on the same path that has led us to where we are now: a discourse littered with paternalism, infantilization, and ignorance. History must be destabilized, if it was ever truly stable. The linear teleological history we know must 
be ripped open so the fissures and accidents are made visible. A genealogical perspective insists the present did not proceed in a linear, progressive manner, but instead proceeded based on power relations and subjugated knowledge. History is contingent; the present is not inevitable. Foucault emphasized this messy view of history throughout his work and most obviously in his genealogies.

\section{Foucaultian Genealogy}

Through what discursive actions and discourses have these themes of paternalism, infantilization, and ignorance come from? How did they emerge? In order to know this, I must identify the issue as a problem, one that is "regarded as a specific kind of problem for specific authorities at a specific point in time" (Garland, 2014, p. 378). This phenomenon is coined "problematization" by Foucault (Garland, 2014, p. 378). Dean (1994) further explicated problematization as a theoretical domain leading to a practice of "effective history," which opposes the "colonization of historical knowledge by these synthetic philosophies of history" (p. 4). In other words, the problematization is the first step in beginning the process of a genealogy.

Foucault unpacked the problematization of sexuality, this idea that it is "considered the privileged place where our deepest "truth" is read and expressed" (Foucault, as cited in Garland, 2014, p. 378) by identifying the

...great surface network in which the stimulation of bodies, the intensification of pleasures, the incitement to discourse, the formation of special knowledges, the strengthening of controls and resistances, are linked to one another, in accordance 
with a few major strategies of knowledge and power (Foucault, 1976/1990, pp. 105106).

These strategies of knowledge and power were: "the hysterization of women's bodies, the socialization of procreation, the pedagogization of children's sexuality, and the psychiatirization of perversions" (O’Brien, 1999, pp. 134-135). Foucault specifically laid out these four strategies in how they have created the modern "sexuality" through power relations and contextual knowledge. For instance, the pedagogization of children's sexuality involved parents diligently keeping children from sexual activities, including masturbation. Foucault analyzed the physical architecture of schools in how genders were stringently segregated to mitigate any sexual occurrences, with doctors and educators highly sensitized to indications of sexual curiosity or expressions. The contextual knowledge claimed children did not have or participate in sexuality without dire consequences, as noted by the psychologists of the time.

With these components in mind, it becomes clearer why a genealogical perspective made sense for my research. Koopman (2013) argued that Foucaultian perspectives be used from the standpoint of critical inquiry. He argued Foucault should be interpreted as offering tools for the purpose of altering our future. However, this alteration can only take place if we know where we stand. Koopman advocated for the use of Foucault to unravel our messy present by looking to the past and then using critical theory to forge forward with our findings. Koopman (2013) claimed Foucault "took up genealogy as a tool for inquiring into the historical conditions of the possibility of certain broad cultural formations that impact our ways of being in the present" so that we might transform our 
current ideas so they "might become less oppressive and more democratic" (p. 11) in the same vein as Dewey might propose. As Kendall and Wickham (1999) stated about using genealogy:

It is, in other words, a methodological device with the same effect as a precocious child at a dinner party: genealogy makes the older guests at the table of intellectual analysis feel decidedly uncomfortable by pointing out things about their origins and functions that they would rather remain hidden (p. 29).

Koopman (2013) described Foucaultian genealogy as:

...an approach that would seek to discern all of the various threads in their specificity so as to grasp the ways in which they had been woven together into a new singularity, or a singularly new problematization...[w]here others had searched for a single, searing explanation, Foucault looked for a network of multiplicitous strategies (p. 4).

Foucault (1997a) stated "you can't find the solution of a problem in the solution of another problem raised at another moment by other people" (p. 256). Foucault, in this statement, claimed his work was hyper vigilant in identifying dangers; by doing this, society becomes aware of these and changes, but the change is never the end solution because new dangers will always emerge. The point is to not look to history for solutions or look for the socalled silver bullet, but to continually pay attention. Using a genealogical perspective, I analyzed a current practice (person-centered planning). Most importantly, a genealogy takes into account the power relations and historical contingencies that create and maintain current phenomenon, marking the difference between a history and a genealogy. Foucault 
emphasized power relations are not inherently bad or negative, but that domination can be. Domination is defined as when various participants or groups are "blocked or frozen...in power relations...immobilizing them" (Foucault, as cited in Jenkins, 2012, p. 60). Foucault, in this example, discussed power relations wherein one group has domination, which leads to power imbalances that silence other groups.

Genealogy is conducive to critical inquiry (Koopman, 2013) and is a "critical engagement with the present" through the use of historical research (Garland, 2014, p. 367). This form of research means agreeing to implicate myself in these forms of domination as well as not engaging in normative arguments. For example, the intent of this research was not to identify practices or institutions that were "wrong" or "right," but simply to acknowledge their hand in creating what is now known as ID. However, I hope that social workers realize and acknowledge that sexuality is a human condition experienced by all people and needs to be addressed in any intervention hoping to progress equity for labeled people, especially given how much of a role sexuality has played in our current understanding of ID (illustrated in chapter 5). Koopman (2013) reiterated this claim with: "Foucault recognized that no matter how base or despicable...practices have been, we can neither reject nor legitimate these practices on the basis of the terms of their emergence alone" (p. 87).

However, a genealogical method is not meant to be value-free (Koopman, 2013). Additionally, a genealogical method allows the research to "present a series of troublesome associations and lineages - that... are actually more problematic and "dangerous" than they otherwise appear" (Garland, 2014, p. 372). By “dangerous," Foucault referred to practices 
and institutions that may or have already oppressed. In locating these dangerous practices and institutions, the researcher focuses not only on well-known historical moments, such as eugenics in my own research.

\section{Current Accounts of Social Work and Genealogy}

A genealogy is a huge undertaking that can only be adequately and effectively accomplished following years of work. I have provided a brief summary of some genealogies that have included social work in order to provide a basis for the application of the framework. I applied the framework to a reading of person-centered planning, which dominates current work with labeled individuals in education, housing, and employment.

The genealogy offers an alternative perspective of history without necessarily refuting the current one, allowing for multiple truths and multiple histories to exist (Skehill, 2008). This pluralistic history allows the disruptions and subjugated knowledge to emerge so the current problematization can be better understood "for those who fight, those who resist and refuse what is" (Foucault, 1980, as cited in Faubion, 2002, p. 236).

I have encountered many puzzled reactions to hearing I wrote a dissertation using Foucaultian philosophy. My elevator speech only works if I have at least 90 floors to ride with my audience. However, this apparent disconnect of social work from philosophy, specifically, Foucault, is not really so apparent. Social work scholars around the world have used and continue to utilize Foucault in their work. I summarized and highlighted this work for the purpose of illustrating current usage of Foucault in social work as well as future possibilities. I begin with a summary of two works that analyze social work's relationship with child welfare, followed by genealogical perspectives of social work and 
social work culture, and finish with a study analyzing the seniors' movement with an explicit statement naming genealogy as resistance.

Social work and child welfare. Caroline Skehill has used Foucault's works in her analysis of social work for years. Specifically, she used genealogy to analyze social work's place in child protection and welfare in the Republic of Ireland (2008). She discussed her reasoning for using a Foucaultian genealogical method in her work and what it has provided her. As with other social workers using Foucault, she cited Foucault's interest in the "objectification of the subject through professional knowledge" as pertinent to her work (Skehill, 2008, p. 450). In this project, she identified the ruptures within history that placed social workers as "experts" within the field of child welfare in Ireland. These ruptures are important since she noted social workers were struggling for "discursive space" within child welfare because the Catholic Church dominated most of the discourse up until two key social workers advocated for the inclusion of social work in the Health Act of 1970 (Skehill, 2008, p. 459). The first draft of this legislation did not include social workers at all in the outline of child welfare previous to the two key players advocating social work's expertise in the field (Skehill, 2008).

These findings were possible only through "detective" work that looked beyond the official archives, posed questions where others found answers, and sought to illuminate contradictory moments in history (Skehill, 2008, p. 450). She stated social work can benefit from a genealogical perspective because it offers:

Problematization in terms of its contradictory nature involving vacillation between reform, social control and the multi-faceted dimensions of practice within and 
around these general themes...[whereas social work is often conceived as] a contradictory practice, operating along dualisms of care and control; regulation and empowerment; deserving and underserving; need and risk; redeemable and unredeemable and so on...(p. 450).

By illuminating these contradictions and ruptures within history, Skehill (2008) claimed social work can be impacted in the way services are not only provided, but how they are conceptualized in the first place, allowing for "constructive transformations" within the practice itself (p. 461). Equally important is the hidden history that social work was not considered an option for child welfare work previous to 1970; however, now, social work is considered an expert in the field, receiving not only State funding, but also feeding into a discourse of social work that includes child welfare and safety as a main component. Skehill showed how genealogy uncovers some discontinuities in the perceived progression of social work in regards to child welfare. This acknowledgement of an alternative history provided a reframing of social work's perceived expertise in the field of child welfare. This revelation no longer allows social work to rest on laurels of "expertise" when discussing child welfare. Additionally, social workers are forced to identify what made their discipline opt for the label of expertise in this field: was it truly because of experience or was it because of professional idealization? These questions are important to answer if social work intends to proceed from a perspective of transparency.

Parton (1999) took a different entry point into the study of child welfare by including the Foucaultian element of government. Parton claimed new strategies are emerging within the field of social work that do not focus on child safety or needs of 
children, but instead on the idea of risk. In practice, these strategies take on the form of documentation of families, risk assessments, and mandatory reporting (Parton, 1999). Parton claimed he used a Foucaultian lens for the purpose of viewing the present not as inevitable, but changeable. By utilizing Foucault's work, Parton hoped to encourage "new and creative ways" of thinking about the present and forging ahead (Parton, 1999, p. 102).

Specifically, Parton (1999) acknowledged social work's key role as expert in the alliance of various institutions working together towards the government of the population. Rose and Miller (1992) referred to the domain of government as "inextricably linked to the activities of experts and their fields of knowledge in which human conduct is analyzed, rendered calculable, and administered" (as cited in Parton, 1999, p. 105). Social work uses risk assessments to calculate risk and prioritize scarce resource allocation.

Parton (1999) briefly traced social work's relation to child welfare through the rise of neoliberalism. He claimed during much of the $20^{\text {th }}$ century, the state encouraged the use of social work as social regulators for deviant youth (p. 111). Philp (1979) posited this connection between the respectable and deviant in his own analysis of social work. Both scholars identified social work's contested place between private and public, mediating a discourse among disciplines of psychology, law, and education. Through this mediation, social workers are able to "regulate" citizens (Parton, 1999, p. 112).

Following the politically conservative 1980 s, a time noted for its anti-welfarism, families deemed state intervention in the form of child welfare visits "actively and potentially abusive" (Parton, 1999, p. 117). This led to an onslaught of media spots showcasing the failures of the child welfare system in preventing the abuse and death of 
various children, illustrating ineptitude of state funded social services. One strategy, then, was to work with fewer resources while also developing "more wide-ranging preventative family support strategies," known as a risk assessment tool (Parton, 1999, p. 121). Via this new strategy, risk became calculable, allowing social workers to hierarchize cases through formulas.

Additionally, state policies mandate the risk assessments, altering how social work is practiced within child welfare. Parton (1999) noted the special attention this assessment places on the marginalized, including the

...poor, single parent[s]..., substance abusers, the homeless, and certain ethnic groups...The ordered world of social problems has been displaced by the fragmented world of the excluded (p. 123).

By singling out these groups as "high risk," social workers become the tools of normalization as understood by Foucault. This study used genealogy as critique, allowing a reframing of how a common practice in social work (risk assessment) can be prejudicial. By acknowledging this prejudicial stance within current assessments, social workers can also begin to acknowledge their own biases during the assessment, perhaps requiring different questions to be asked. Social work scholars and direct practice workers could work together to find other methods for gathering information that do not rely on "risk assessment," but look instead at systemic and institutional structures, leading to a political assessment versus a personal one. For a more in-depth analysis of social work, I turn to an article by Villadsen (2008). 
Genealogy of social work. Villadsen (2008) utilized a genealogy to analyze the history of social work to identify and critique current practices taking place that create "new kinds of subjects and new types of communities" (p. 93). The author also used this technique to:

“...strategically point out discontinuities... and unsettle the schematic breaks and epochs of mainstream history by describing disturbing continuities with pre-modern practices and institutions" (Villadsen, 2008, p. 96). The author claimed social work is revisiting philanthropic principles in modern day practice, evoking a subject that is responsible for current difficulties in his or her life. Villadsen (2008) claimed there are four major "historical strategies for governing the poor and abnormal" starting in the $18^{\text {th }}$ century and ending in the current "neo-philanthropic regime of social work" (p. 96). The author focused on historical Danish documents but claimed similarities across other developed welfare states.

The $18^{\text {th }}$ century was a time described as authoritarian, which transformed into a time of philanthropy during the $19^{\text {th }}$ century. He briefly described the friendly visitors that would visit the poor and assess living conditions. Villadsen (2008) noted the visitor would assess the state of cleanliness in the home in order to determine "whether...moral corruption of the soul had taken place" (p. 97). During this time, visitors began to provide "educative assistance" versus material assistance in order to foster autonomy and responsibility.

Towards the end of the $19^{\text {th }}$ century and the beginning of the $20^{\text {th }}$, an increase in the "classification and ranking of the poor and needy" took place, providing the basis for 
scientific investigation into the causes and cures of poverty in the latter part of the $20^{\text {th }}$ century (Villadsen, 2008, p. 98). During the early 1900s, a proliferation of scientific disciplines, including the psy- complex, "rendered knowable the normal and pathological functioning of humans" (p. 96). This proliferation created new methods and techniques for constructing and maintaining statistical norms and normalization in the Foucaultian sense (see chapter 1). Specifically, tests were available to identify and categorize deviants - mentally ill, feebleminded, weak blood lines, and so on - while institutions were erected to segregate the abnormal from the normal. Within the segregated groups, subgroups were created; a "never-ending specification of normality was going on, providing welfare state professionals [social workers included] with plenty of objectives to work for" (Villadsen, 2008, p. 99) which also elevated the level of professionalization and expertise of social work.

The final era Villadsen (2008) identified is neo-philanthropic. He illustrated this new movement via a statement from a former stateswoman who claims poverty stems from "clients' problems with their self-relations rather than from material conditions," which correlates with self-esteem and development (p. 100). Villadsen (2008) identified this particular strategy with the term "empowerment" (p. 100). Empowerment facilitates the client's journey in development and agency. From this, the client is supported in finding local communities and volunteer organization to connect with (p. 101). These clients are assessed as at-risk and in need of "raising self-esteem and self-knowledge" in order to become productive citizens, as envisioned in a specific form (p. 103), otherwise known as normalization. Villadsen (2008) called on social workers to: 
...stop calling themselves consultants and facilitators and rather openly communicate to the client that there is a power relation and that there is an objective about changing elements in the client's behavior and personality (p. 103).

Villadsen (2008) claimed there has been a reactivation of philanthropic frameworks in relation to social work, using new terminology and contexts. This reactivation veils the intense categorization and normalization occurring under the guise of empowerment. Looking at social work through a genealogical lens, what else, what other truths or histories emerge? Has social work focused primarily on categorization and normalization of the population? Laura Epstein continues this discussion by using genealogy to view the culture of social work.

Epstein (1999) articulately named social work within the ...human or social sciences that are the backbone of the technologies that have emerged as instruments by which the state can govern with minimal coercion, or, when coercion is employed...human science offers ways to support, ameliorate, disguise, and justify the state's carceral [sic] machinery (p. 8).

Epstein utilized Foucault's works specifically because he often centered his work on the human sciences. She used a genealogical framework because it is a "sharp critique of customary thinking" and a "creative way of analyzing problems in the human sciences" (p. 14). Epstein noted standard history does not effectively deal with the dominance of women in social work or how social work has been constructed and shaped mostly by women (p. 15). Epstein (1999) focused her attention on Charlotte Towle, a clinician and faculty member in the Social Work department at the University of Chicago beginning in 1932. 
Towle was key in developing the core ideas within the field of social work as well as "converting social work into $20^{\text {th }}$ century social therapeutics" (Epstein, 1999, p. 17). Towle's book, Common Human Needs (1945), was a key turning point for clinical social work. It marked the end of Victorian era views of the poor (moral deviancy) and, instead, highlighted the new priorities of basic human rights, basic individual rights, and an adherence to science (Epstein, 1999, p. 22). The theory framing this new perspective was "person in environment" incorporating Freud's psychodynamic personality theory, which provided development milestones and "a universal set of standards" (Epstein, 1999, p. 22). Here, the professionalization and reliance on science begins to take shape within social work.

Less than ten years following this book, Towle published another book (The Learner, 1954) encompassing current social work knowledge in a systematic way to be used in schools of social work. The book detailed the information needed for a "person in environment" analysis and how this work comprised the practice of casework (Epstein, 1999, p. 18). This particular book discussed human nature, how one develops social skills, and human growth in the industrialized society in the first half while the last half outlined principles constituting social work practice (Epstein, 1999, p. 19). This book was widely used within academic institutions training new social workers in the United States.

Epstein utilized genealogy as a method to uncover the history of women within social work and women's contributions to current social work practice. She stated women chose social work because they were "unwelcome" or marginalized from sociology, psychology, and psychiatry within academic institutions (Epstein, 1999, p. 15). She also 
identified particular points in history when social work began to turn towards professionalization and scientific knowledge as guiding principles.

Genealogy and senior activism. Wang (1999) provided a brief genealogical critique of the seniors' movement in the United States. He traces the first generation of the movement to the Great Depression, when the elderly were forced to "address and redefine" the stigma of old age as unproductive (Wang, 1999, p. 194). This stigma began during the turn of the $20^{\text {th }}$ century when industrialization flourished and required strong workers. Once the Great Depression hit the country, the elderly had even less resources available. Because of this, two different subjectivities were created: one of the old person as frail and in need of financial help and another of the old person assisting in the recovery of the nation through spending made possible by financial assistance (p. 200). Both required the acceptance of this negative discourse of the old person as frail and in need of financial assistance.

Wang (1999) identified these two subject manifestations because he was illustrating the innate power/resistance/subject model put forth by Foucault necessary for a genealogical critique, which analyze the histories of "the different modes by which human beings are made subject" (p. 193) and allow for the "dialectic relationship between power and resistance" to become clearer (p. 191). This leads to a powerful discourse that not only enables the senior movement, but also constrains it.

Once the senior movement accepted the subjectivity of frailty and dependence, it gained legitimacy and public support. This "negative discourse" prevented the movement from "militant approaches" because of the accepted subject of old and frail (p. 199). Post 
the Great Depression, the Social Security Act came into play and laid "the basis for the second generation seniors' movement" by creating the discourse of the "pensioner" (Wang, 1999, p. 199). Again, this discourse became both enabling and constraining because the SSA was a "universal measurement" that genders, races, and classes the senior movement by ignoring various communities within the elderly population, such as low-income minorities, women, and homemakers (p. 200). Again, Wang (1999) illustrated the power relations inherent in a resistance that creates, maintains, or resists a specific subject, in this case, the pensioner.

Wang (1999) followed the movement with the creation of various organizations such as the National Retired Teachers Association (NRTA), which later became the American Association of Retired Persons (AARP). The founder of the NRTA, Ethel Percy Andrus, was a retired principal upset by her low pension. Key to this discussion, according to Wang (1999), was the fact that Andrus did not frame the issue as a women's issue or even a patriarchal issue, but one of the "low level of pension for retired teachers" (p. 202). This is key because Andrus was limited to the available discourses in 1947, which were capitalism, pluralistic politics, and the "work-achievement-oriented welfare state in which she was located" (p. 202). Specifically, this speaks to Foucault's emphasis on the local and subjugated knowledge that illuminates an alternative history.

Wang (1999) briefly touched on the socially constructed intergenerational conflict "created by the media, politicians, and economists" of the "greedy geezer" pensioner (p. 207). This construction aims to shift the social responsibility of care from the state to the privately funded. Again, the subject of the senior changes from embracing old age as a 
fulfilling segment of life to one of greed and identity politics. Left out of this generalization of old age are the marginalized, local, and historic stories such as the elderly Chinese woman who chooses suicide as a form of culturally legitimate resistance (p. 210). This story is not a part of the current discourse of Western old age, but neither is the part time worker who is also a homemaker. As Wang noted, "the meaning of resistance can be fully appreciated only in its local and historical contexts" (p. 211).

Wang (1999) called out genealogical critique for its capacity to reconstruct history by focusing on local and specific situations to better understand power relations, points and patterns of resistance. This form of analysis uncovers a history previously unknown, or at least under acknowledged, so that social workers are able to "participate, observe, and intervene in the operation of power relations" on the local level (p. 214).

\section{Conclusion.}

Though social work scholarship doesn’t routinely utilize Foucaultian methods, these studies have shown it is not only possible, but useful. They illustrate genealogy as an alternative way to view the past and the future. Both Skehill (2008) and Parton (1999) offered genealogical frameworks to reframe the status of child welfare practice within social work. By doing this, social work's perceived historical expertise in the field of child welfare is brought into question as well as providing a critique of how this perception came into being. Secondly, Villadsen (2008) and Epstein (1999) provided very different perspectives on social work history, using genealogy as critique (Villadsen) and to uncover hidden truths (Epstein). Finally, Wang (1999) utilized genealogy as critique as well as a 
tool of resistance, providing insight into where social workers can insert themselves into a specific situation to initiate or assist in social change. 


\section{Chapter 5: Research Design}

The previous chapter illustrated various ways social work research has utilized genealogy. Some implications arising from these studies focused on reframing a wellknown story so as to uncover some lesser-known truths, such as how child welfare became a part of social work expertise (Skehill, 2008) or how influential female social workers have been to the discipline of American social work (Epstein, 1999). Other studies brandished genealogy as a form of critique, illuminating spaces within social work where activism can take place to change the current trajectory of a discourse (Wang, 1999). Genealogy must begin with a present problematization. Intellectual disability provided the starting point for my genealogical exploration to show ID has not “....kept its meaning,...ideas retained their logic" and instead has "...known invasions, struggles, plundering, disguises, [and] ploy” (Foucault, 1998b, p. 369).

The medical and social models are currently the dominant models of disability in social work. Academics and advocates have assessed and critiqued both models innumerable times. Because of this wealth of information, I only briefly described these models and how they are used within current service provisions. These models are necessary to understand in order to move into an alternative viewpoint.

Similar to how one can utilize different models to view a phenomenon, such as using either the social or medical model to view ID, I suggest a theoretical model of genealogy in order to use as a lens when analyzing person-centered practice. To my knowledge, such a model does not currently exist, so I provided the theoretical background for a genealogical model of ID and outlined the basic tenets. I relied on Foucault's works, 
including History of Sexuality, Volume I (1976/1990), Abnormal (1999/2003), Psychiatric Power (2006), as well as excerpts from interviews and essays. Additionally, I interwove Shelly Tremain's and Ladelle McWhorter's complementary works throughout.

I drafted a genealogical framework to view the concept of ID, articulating the dispositif of sexuality, mainly using the works of Michel Foucault. Foucault eloquently and effectively illustrated the genealogy of sexuality in his The History of Sexuality: Volume I (1976/1990). The dispositif illustrated in this work precedes the $20^{\text {th }}$ century, specifically, the knowledge of medical practices and the social sciences as they intersect with power strategies of social control seen through normalization, biopower, and government.

After laying out this network, I constructed a genealogical model of intellectual disability. Using this model as a lens, I carried out a discourse analysis of person-centered practice. This discourse analysis elicited a clearer understanding of implications of personcentered practice as it relates to people labeled with ID.

Genealogy identifies the emergence of knowledge-power structures throughout history, elucidating fluidity within history that does not strictly adhere to progress and linearity. Instead, genealogy aids in the discovery of "how that which existed emerged into being...discern[ing] transformations" versus just describing what existed statically (Koopman, 2013, p. 40). I used the genealogical framework as a lens to facilitate my discourse analysis of texts related to person-centered planning by various authors (2002), an online training program for direct support workers, and a person-centered thinking training I attended in September 2017. The primary object of study, Koopman (2013) 
stated, is "no longer either power or knowledge in isolation, but power-knowledge taken as an intersection...formed at the twain of power-knowledge" (p. 41).

\section{Framework of Genealogical Model of Intellectual Disability}

Sexuality as dispositif. Foucault wrote The History of Sexuality, Volume 1 (1976/1990) to provide a genealogy of sexuality. This genealogy eventually identified sexuality as a dispositif, utilizing power-knowledge structures that constructed a normal sexuality by addressing what was/is deemed abnormal: children's sexuality, women's sexuality, perversions versus normal, and procreation. Sexuality was identified as somehow becoming a person's deepest truth and identity, a view that did not exist prior to the $17^{\text {th }}$ century. Additionally, this view came about through the myriad of knowledgepower relations that included the Catholic Church and the human sciences, specifically psychology and psychiatry.

In my research, I highlighted how sexuality is a dispositif of intellectual disability using historical texts, such as historical definitions of intellectual disability (then known as imbecility, idiocy, etc.), historical interventions (such as gender segregation within institutions, institutionalization, eugenics, etc.), policies and laws policing who could marry based on cognitive labels, up through current interventions.

By doing this, I created a lens through which to view ID, a genealogical lens, or framework. Using this framework, I propose a new way to understand ID through current practices, namely PCP. I used a Foucaultian discourse analysis to analyze the texts of person-centered practice to show applicability of this lens and what new, if any, insights can be provided using this framework. Specifically, my research questions were: 
1.) What does a genealogical framework reveal about ID in PCP?

2.) What implications do these findings hold for sexuality education? For social workers working in I/DD services?

Genealogical framework of ID. In History of Sexuality, Volume I (1976/1990), Foucault laid out a genealogy of sexuality that illustrates iterations of our current understanding of the concept; he articulates how sexuality is a dispositif, in other words, "...a network of power and knowledge that generates sexual identities and sexual subjects" (McWhorter, 2009, p. 11). For example, sexuality, Foucault posited, began to change in the $17^{\text {th }}$ century within the Catholic Church. This change was not widespread, but instead, set the stage for the coming changes. Within the church, priests and others in service followed a doctrine for confessions, paying special attention to the flesh and acknowledging the pleasures of the flesh, thoughts of flesh, desires, and so on. This doctrine became dogma. In Foucaultian terminology, this dogma set the foundation for a new set of enunciations; during this time, where and when it was possible (and appropriate) to discuss sexuality became more strictly defined (Foucault, 1976/1990, p. 18). Similarly, the domains and discourses began to grow exponentially, creating and morphing objects of the discourses (Foucault, 1976/1990, p. 18). This is important because Foucault named authoritative figures (the Church) who begin to establish their station as "expertise" in the domain of sexuality. From this discursive formation of the confession, this dogma specifying how to discuss the flesh, a knowledge/power network begins to take shape. Those with the knowledge of desire and sin are those with the power to navigate the discourse. Within this dispositif, those confessing and those who know they are supposed 
to confess (the lay Catholics) begin to identify what they are supposed to discuss during confession and pay attention to these thoughts and actions, exhibiting their own form of power in the confessional transaction.

As Foucault moves through history, he identified other authoritative figures entering the framework who start to define their own enunciations and objects. Such figures included alienists (early psychiatrists), doctors, educators, and public health officials. Foucault highlighted the early public health campaign surrounding masturbation, specifically children's masturbation. Because masturbation was a universal concept, various manias and sicknesses were linked back to this one behavior everyone shared; by doing this, the discourse flipped and instead identified children's masturbation as a possible cause of future sicknesses and manias. I would like to dwell on the topic of masturbation a bit longer using one of Foucault's other genealogies -a genealogy of abnormality contained in a lecture course from 1975: Abnormal: Lectures at the College de France 1974-1975 (1999/2003).

Abnormality was constituted from three concepts: the monster, the onanist, and the recalcitrant child. Foucault used the story of a man named Jouy to explain the concept of the recalcitrant child. Foucault touched upon the story of Jouy in History of Sexuality: Volume I (1976/1990) momentarily; however, a fuller discussion occurs in Abnormal: Lectures at the College de France 1974-1975 (1999/2003). Tremain (2013) does a fantastic job parsing out the details of this story to highlight the context of what Foucault was trying to articulate: a conflict between idiocy or child-likeness and the concept of abnormal in terms of sexuality. At this point, society began to see a connection between 
sexual deviance (which was being defined at this time as abnormality) and idiocy. This connection has lasted through current times, as with portrayals of individuals being unable to control or understand instincts because the person is too close to childhood.

Foucault provided the story of Jouy (1999/2003) to

...show the quite precisely compound and mixed figure of the monster, the little masturbator, and, at the same time, the recalcitrant individual, or anyway, the individual who cannot be integrated within the normative system of education ( $\mathrm{p}$. 291, emphasis mine).

Jouy, a 40-something year old man, was taken in by the local police for sexual interactions with a minor (this girl is identified as a young teen in this lecture, but other accounts state her age as six). The case occurred in 1867, and Foucault stated that during this era, children played a game called "curdled milk" wherein boys were masturbated by others. It was a common game, but this incident led to an arrest because the "boy" was a man in his forties - the story becomes a demonstrative case for the intertwining of sexuality and ID. Foucault's genealogy of sexuality summed up how sexuality became the definer of subjects; sexual selves were indicative of a person's nature. Certain sexualities were then linked to pathology or perversity, such as homosexuality, which was listed as a mental illness until 1973 in the Diagnostic and Statistical Manual of Mental Disorders (DSM). Keeping this pathology in mind, we delve into the story of Jouy.

Once the local police picked up Jouy, he undergoes a battery of psychological tests by two psychologists. During this time, psychology had transformed itself into a legitimate science, its domain that of the abnormal individual. The field shifts from the alienist, who 
believed mental disorders (delirium) were incurable, to the psychologist, who believed individuals, with the correct identification and help/training, could become functioning people. Additionally, psychology attributed the cause of these sicknesses and manias to behaviors that were linked to "instincts." Subjects were identified and labeled based on behaviors, specifically childhood behaviors. It is also during this time society sees the emergence of forensic psychology.

Jouy undergoes several tests, including:

...to measure the brainpan, study the facial bone structure, and inspect for possible signs of degenerescence [sic] the anatomy of this personage who up to that moment had been an integral part of village life; that they made him talk; that they questioned him concerning his thoughts, inclinations, habits, sensations, and opinions. And then acquitting him of any crime, they decided finally to make him into a pure object of medicine and knowledge-an object to be shut away till the end of his life in the hospital at Marèville, but also one to be made known to the world of learning through a detailed analysis [that was later published] (Foucault, 1976/1990, pp. 31-32).

The doctors examined his history and identified him as an illegitimate child; his mother died when Jouy was a small child; he was poorly educated (asked to leave school) and did the most menial jobs in town for less pay than other laborers (Foucault, 1999/2003; Tremain, 2013). Foucault (1999/2003) identified him at this point as "the village idiot" (p. 292). Foucault (1999/2003) reiterated that there is "no illness intrinsic to instinct" but there is a possible imbalance, wherein these instincts either function "normally" or "abnormally" 
(p. 299). In Jouy's case, the doctors identified a sort of "arrested development" that took place (Foucault, 1999/2003, p. 299). To this, Tremain (2013) restated Foucault's own stated goal for the 1974-75 course:

...to study the emergence of the power of normalization, the way in which it has been formed, the way in which it has established itself without ever resting on a single institution but [rather] by establishing interactions between different institutions, and the way in which it has extended its sovereignty in our society (p. 810).

This statement leads to a view of normalization of people and sexuality. The local expert of the town wrote to the magistrate that Jouy was unable to "resist animal instincts" and this was a case of a "dimwitted person who can be forgiven because of his abstruseness" (Foucault, 1999/2003, p. 296). From these accounts, I agree with Tremain (2013): what is being described is the emergence of "imbecility" (p. 810). Jouy had existed in this town his whole life and integrated as much as he could (while, notably, living on the margins of it), but he is not identified as a danger until his being is fully analyzed by the burgeoning science of psychology/psychiatry during a time that sexuality, specifically, children's sexuality, is under great surveillance. The fear of children's masturbation and its future consequences laid heavily on parents and guardians, as illustrated by the pamphlets, public health discourse, and medical shows of the time demonstrating physical and psychological issues that were said to be related to childhood masturbation (Foucault, 1976/1990; Foucault, 1999/2003). 
At this point I would like to interject a warning: in reading this story of Jouy, it is easy to commit a genealogical error wherein one reads this account using current contexts of appropriate and legal sexuality (regarding victimization, age of consent, etc.). I state this so that the audience is aware that this debate has occurred/is occurring amongst academics. Tremain (2013) actually addressed these concerns in her essay, so I will not repeat them here. Foucault was citing this case while also noting that the game "curdled milk" was a common game during this era as were various relationships. When Jouy saw the girl of this story playing the game with other boys, he included himself. Though we, as a society and as a profession, have many concerns about this type of relationship and power differential, these were not the topics at hand of this particular case.

Returning to the story, we see sexuality and ID collide in a landmark way. Imbecility had not necessarily been a domain of psychology/psychiatry inasmuch as it was here. Tremain (2013) summarized that Jouy could only be psychiatrized at this point in history because:

$[\mathrm{h}]$ is infantile sexuality reflects his arrested development; and...he cannot be taught right from wrong, or at least not in the standard way... [but] only by establishing that Jouy remained extremely close to and almost fused with his own childhood... (p. 810).

From this summary, ideations of ID become apparent: infantile sexuality (infantilization, sexual perpetrator/victim); cannot be taught wrong from right (incapable, sexual perpetrator/victim), or at least not in the standard way (need for Special Education); and fused with his own childhood (infantilization). This story highlighted a discourse that 
continues through to current times, but also illustrated a moment in history when abnormality was acknowledged in a specific way, through specific enunciative modalities and discursive formations. From this story, a better understanding of how society and experts treated those diagnosed as abnormal takes shape. Though the treatment of idiots began in the mid $19^{\text {th }}$ century, the story of Jouy adds an important layer to what was happening.

Foucault (2003/2006) clearly differentiated between madness and idiocy in his lectures at the Collège de France in 1973-74 in a collection titled: Psychiatric Power. This splitting off was the point in which psychiatrization of the child began to occur. Foucault (2003/2006) stated "...psychiatrization of the child came about through...the imbecilic child, the idiot child, the child who will soon be called retarded, that is to say,... he was not mad..." (p. 203), and this is where madness and abnormality began to differ. The child/childhood was the basis of psychiatry as discussed earlier. Jouy illustrates abnormality in that he was too closely fused with his childhood, but he was not mad. In history, the imbecilic child becomes the symbol of what is abnormal but not mad.

In the mid $19^{\text {th }}$ century, Edouard Seguin, a French psychiatrist, believed development could become arrested, or halted, which meant it could be restarted with the right practice or tools (McWhorter, 2009, p. 129). As Foucault had stated, abnormality was conceived as a matter of "instincts." Foucault (2003/2006) stated that according to Seguin, "instinct is an indefinite series of small refusals opposed to any will of the other person" (p. 215) and that the treatment is a confrontation of wills, in which the psychiatrist is the "absolute master" of the idiot (p. 216). 
Seguin immigrated to the U.S. in 1850 to work with the idiot population where other psychiatrists had already begun to employ Seguin's techniques in their schools for idiots (McWhorter, 2009, p. 131). The basic tenet of Seguin's techniques included arrested development and that "idiots were not lunatics; they were children [developmentally], and if not helped would remain children for the rest of their lives" (McWhorter, 2009, p. 132).

Seguin was active in the work of idiots from the mid $19^{\text {th }}$ century through the early $20^{\text {th }}$. During this time, a great deal of social reform and State policy began to happen. Moving forward, it is important to keep in mind the basic points of Seguin's work: 1) idiots were not mad due to instinct, which was unbalanced; 2) idiots were stuck in an arrested development, where their development had been halted and psychiatrists had to work to restart this development; 3) the psychiatrist had to become the total master of the idiot, which included institutionalization.

Seguin is generally considered to be one of the first experts of idiocy (Tremain, 2013), but many others followed using his foundational works. One such person was the American R.J. Patterson, a medical superintendent of the Ohio Asylum, who in the 1850s posited that idiocy was caused by "physical rather than mental origin" (McWhorter, 2009, p. 132). This belief led many doctors to treat idiocy within a medical model as a pathological issue and advocating for asylums to resemble hospitals rather than schools (McWhorter, 2009, p. 132).

In 1838 , France passed a law mandating that lunatics be confined in an asylum due to the financial burdens placed on family for caring for them. In 1840, the law was expanded to include idiots. The cost for caring for the confined people then fell onto the 
community, creating a different financial burden. Because of this, psychiatrists were hesitant to diagnose someone as a lunatic or an idiot. For someone to be confined, a doctor had to claim the person was not only a lunatic or an idiot, but also dangerous. Doctors complained, from 1840-1860, that they were being forced to write false reports to appease financial concerns of families (Foucault, 2003/2006, p. 220). Conversely, at the same time, a subset of reports began to appear claiming idiots and lunatics really were dangerous, offering up case studies to prove it, such as "...they are dangerous because they masturbate in public, commit sexual offences [sic], and are arsonists" (Foucault, 2003/2006, p. 223). Finally, in 1895, Dr. Bourneville published an account of a young girl "who was an idiot who had become a prostitute" was raped, ending with the statement: "Criminal anthropology has demonstrated that a high proportion of criminals, inveterate drunks, and prostitutes are, in reality, imbeciles at birth whom no one has ever sought to improve or discipline" (Foucault, 2003/2006, p. 220).

Similarly, in the U.S. during the 1860 s, asylums were being framed as necessary for several reasons, including the idea that "untrained idiots [are] passionate, filthy, selfabusive, animal-like, gluttonous, given to irrational behavior, and intemperate" (McWhorter, 2009, p. 133), echoing the early characteristics of unbalanced instincts within psychiatry. Foucault (2003/2006) reiterated this, saying that at the center of this discovery of the mad child is the

...retarded child...through these practical problems raised by the idiot child you see psychiatry becoming something infinitely more general and dangerous than the 
power that controls and corrects madness; it is becoming power over the abnormal, the power to define, control, and correct what is abnormal [normalization] (p. 221). Dangerous, within Foucault's terminology, refers to a system or power structure that attempts to oppress another group. Foucault (2003/2006) called out the power/knowledge relationship that is the human sciences, specifically psychiatry, for how it forced a culture of normalization onto society to:

...give the psychiatrist's power a particular stamp, to give it an additional, supplementary distinction; in other words, the psychiatrist's knowledge is one of the components by which the disciplinary apparatus organizes the surplus-power of reality around madness (p. 233).

The stories that doctors began to publish in the late $19^{\text {th }}$ illustrated this, as we saw most emphatically in the story of Jouy, which occurred about two decades following Seguin's immigration to the U.S. and approximately 60 years prior to the landmark court case of Buck v. Bell (1927). Through these incidents and classifications, the element of danger occurred explicitly within the definitions of idiocy and implicitly through the enunciative modalities/subjective positions that defined them.

On this note, Patrick McDonagh (2008) made an interesting contribution via his book Idiocy: A Cultural History. During the mid-19 $9^{\text {th }}$ century, literature often illustrated the "idiot" as a "childlike Christian innocent" (p. 226). However, during this time asylums were seeking funding and legitimacy, and they needed a different representation. Some asylums were utilizing a pedagogical approach, which necessitated a different type of idiot, 
while others were making the diagnoses to commit individuals and ease the burden of poor families. McDonagh (2008) states:

[T] he choice of which representational approach was to appear in a particular document seems to have depended on the intended audience, with, as a broad rule, the "innocent" appearing most often in general fund-raising efforts written by those outside the professions directly related to asylum management - that is, pedagogues and medical men. On the other hand, the reclaimable, semi-bestial idiot is a stock character in early descriptions of continental institutions, as well as in professional writings and focused fund-raising attempts in Britain (p. 226).

With this added element of danger and criminality, which psychiatrists had usually defined in a sexual manner (rape, prostitution, masturbation, etc.), new techniques emerged. McWhorter (2009) efficiently summed up the current knowledge of the mid $19^{\text {th }}$ to early $20^{\text {th }}$ century surrounding idiocy:

Idiots and imbeciles were arrested in their development. They were stuck at a certain stage of childhood where the basic principles of morality are not grasped. Whatever caused this arrest in development, whether the sins of their mothers and fathers or some unavoidable accident in utero or at birth, the fact was that imbeciles were not to be trusted. Regardless of how capable some of them might at times appear, they could not handle civic responsibility or freedom any more than could the average eight-year-old child (p. 135).

These apparatuses clarified a concept (idiocy) much more specifically and interwove ideas (dangerousness, instincts, etc.) that continue through today. The 
enunciative modalities that came into being (psychiatry) or became entwined (medical doctors) at this time were the key figures that later work with other enunciative modalities (social workers) relevant to this study.

Returning to the end of the $19^{\text {th }}$ century, when idiots and imbeciles were being touted as dangerous, most explicitly in sexual terms, and institutionalization was pushed as a solution, we see biopower really enter the scene. Previously, I mentioned biopower as integral to understanding ID, specifically taking into consideration the dispositif of sexuality. I now bring in this concept to move forward in the genealogical model of ID.

Biopower, as I defined previously, is a system that has, through statistics, medical knowledge, and economics (among many other methods) created an "average," or concept of "normal" that is not only statistical but also normative and value-laden, while simultaneously creating a normative and value-laden concept of "abnormal." Biopower is a regulating and normalizing power structure. A technology of this system was the institution, be it asylum, indoor relief, or hospital; the goal was to "partition the random element of populations from the collective at large in order to maximize the conditions conducive to life" (Tremain, 2005, p. 5). Schools for idiot children had existed for some decades, but the framing changed at the end of the $19^{\text {th }}$ century from one of training to one of protection. This reframing occurred following the published cases of "dangerous idiots" from French and American doctors.

Biopower is the manner where a (normal) population can thrive once those deemed abnormal or dangerous are codified and categorized. Bringing into this discussion the psychiatric idea of degeneracy, the institution (by whatever name is popular at this time) is 
what supported this thriving of the healthy normal population. Degeneracy, according to Foucault (2003/2006) was "the effect of abnormality produced on the child by his parents...it is the sign on the child of his ancestors' madness" (p. 223). Though Foucault stated this idea of degeneracy had been removed from psychiatric vocabulary by Freud in 1894 (2003/2006, p. 223), the idea continued to manifest within the concept of ID, at least in the U.S in the early 1900s. The best example of this is Henry Herbert Goddard's The Kallikak Family (1912), which tells the story of a "degenerate family...illiterate, poor, and purportedly immoral" (Smith \& Wehmeyer, 2012, p. 169). The twist of this story is that the "progenitor" of this family, a soldier, had a "dalliance with an allegedly feebleminded barmaid" before righting his "moral ship" and marrying an upstanding moral woman (Smith et al., 2012, p. 169). The family that was the object of the report was the offspring of the barmaid, illustrating quite dramatically the consequences of feebleminded people (though women of childbearing age were much more dangerous).

During the last few years of the $19^{\text {th }}$ century and the beginning of the $20^{\text {th }}$, professionals were solidifying their own brand of expertise through the creation of taxonomies regarding ID. I will not cover the litany of taxonomies they used but will instead focus on which ones lasted: idiot, imbecile, and moron. These were classifications of severity of feeblemindedness (the umbrella term then used instead of idiot). Idiot and imbecile referred to persons who would require lifetime custodial care due to their disability. Moron referred to a person who was morally weak, dangerous because he/she was capable of "propagating" and a "threat to racial hygiene" (Wehmeyer, 2013, p, 133). Beliefs began to lean towards the idea that the feebleminded were hopeless cases, 
"understood as menaces to society" (Wehmeyer, 2013, p. 136), therefore making education useless and custodial care necessary. Cohen (2016) noted:

In 1904, 17.3 feebleminded people were institutionalized for every 100,000 people in the population. By 1921 the number had nearly tripled, to 46.7...the main purpose...was to remove a group deemed to be a threat and to segregate them: lock them up in secure facilities where they could not reproduce. "The ultimate aim of the school," said the head of the newly established North Carolina School for the Feeble-Minded, "is the elimination of feeble-mindedness from the race by segregation" (p. 25).

Additionally, many states enacted marriage laws that restricted the marriage of labeled people (State Laws Regulating Marriage of the Unfit, 1913). These laws restricted marriage amongst a host of people deemed abnormal. Some, like the Michigan law, remain on the books today. These laws were meant to be less invasive than sterilization but had the same goal of a disability-free population.

Institutions had become necessary within society to ensure a thriving healthy population, first by separating out feebleminded (generally male) who could be dangerous by committing rapes or public masturbation, but also separating out feebleminded (female) who could become prostitutes, be raped, or lure men into sexual relations and therefore, bear children who would most likely be degenerate. This brings us to the early $20^{\text {th }}$ century, when a strong scientific movement took hold in much of the Western world with the support of doctors, psychiatrists, and institutional supervisors working with the 
feebleminded population - the Eugenics Movement. This became one of the most extreme forms of biopower to intersect with the ID population.

On two separate fronts, those labeled were being picked out as targets. In the fight for women's rights, Margaret Sanger was tirelessly working to improve access to contraception for women. During the early 1920s, Sanger gained a new ally: the eugenicists. Leaders from this movement were interested in improving the stock of the population by reducing poverty, illiteracy, and feeblemindedness (Eig, 2014). In order to do this, the movement encouraged certain women to refrain from reproducing. This movement was mostly led by a group of scientists with backgrounds in genetics and animal breeding (Cohen, 2016), lending a level of credibility Sanger had previously lacked. In their minds, these leaders believed the "women most likely to produce poor, feebleminded, or criminally included children should be prescribed birth control - or sterilized- to keep them from reproducing" (Eig, 2014, p. 53).

The superintendents and doctors working in the institutions headed the other front, still siding with the eugenicists. The professionals working with the feebleminded population had become "experts" in their field. As noted earlier, taxonomies abounded from these professionals because "elaborate classifications of inmates became a powerful demonstration of professional legitimacy" (Wehmeyer, 2013, p. 107). Through these creations of categories and power structures, these professionals became the experts who identified an object and subject. For example, a phenomenon, or object (ID), was exhaustively categorized so that subjects were then created; a person who was previously only a prostitute would now be labeled as feebleminded, specifically as a moron possibly 
needing to be confined until the expert deemeed that person fit to reenter society. This prostitute would also (theoretically) take on this new scientific label and integrate it into her own identity. These experts rallied for more institutions, created the curriculum, decided whom to admit, and supported state laws allowing sterilization of inmates. Sterilization became a battlefield in many states, culminating in the infamous Buck v. Bell case of 1927.

For over 20 years, sterilization laws had been passed and repealed throughout the United States. Arguments for repeal included the claims that sterilization laws were “degrading," "humiliating," and would "inflict cruelty upon a helpless class" (Cohen, 2016, p. 68-9). Justice Oliver Wendall Holmes Jr.'s opinion in Buck v. Bell had lasting effects on the discourse of the "feebleminded" and opened the floodgates for sterilization laws. As this is a well-known case, I only outline the basics. Carrie Buck was a young woman who was raped by her adoptive mother's nephew. She became pregnant and was sent to an institution for those labeled as feebleminded. Despite a lack of supportive evidence in the form of school records or behavior reports, Carrie was admitted as feebleminded. Her mother had also been previously admitted due to solicitation and homelessness. Because Carrie was pregnant at the time, the professionals could clearly establish a line of "degenerates," laying the groundwork for a call for sterilization for the betterment of society. Justice Holmes' opinion concludes:

It is better for all the world, if instead of waiting to execute degenerate offspring for crime, or to let them starve for their imbecility, society can prevent those who are manifestly unfit from continuing their kind (as cited in Cohen, 2016, p. 2). 
In 1927, when Buck v. Bell was decided, support for eugenics had greatly waned. Though many working within the institutions had rescinded their support for eugenics, they still considered sterilization a necessary procedure if a patient was to be released. During the trial of Carrie Buck, a witness for the prosecution, Dr. DeJarnette, explained the need for sterilization stating, "feebleminded women were more likely to reproduce...[and] were easily over-sexed" (Cohen, 2016, p. 188). This is an important statement in that many superintendents were now envisioning patients who stayed a short while before being released into work placements after treatment and sterilization. The looming economy of World War II would change this.

Following Buck v. Bell, sterilization was nationally upheld, and patients within institutions were sterilized before being released (paroled) into the community. By 1932, approximately 16,000 people were sterilized (Wehmeyer, 2013, p. 174). After Buck v. Bell, the ratio of women to men being sterilized was 2:1 (p. 174). Those who were deemed feebleminded and women were seen as much more of a threat to society. This perceived threat grew during the Great Depression, when the economic crash caused many institutions to see a surge in admissions without additional dollars. Wehmeyer (2013) cited author Philip Reilly (1992):

Prior to the market crash of 1929 , the primary purpose of the forced sterilization programs was to prevent the birth of children with supposedly genetic-based hereditary disorders. After the crash, the emphasis moved to preventing people who were thought to be unable or incapable of raising and caring for children from doing so, as a means to reduce the state's financial liability (p. 174). 
Unfortunately, during the crash, many parents were unable to care for their disabled children and saw no other choice than to admit them to an institution. Additionally, with large co-ed populations, superintendents viewed sterilization a necessary procedure in order for patients to lead "as normal lives as possible" and because "patients of both sexes dance together, view movies together, work and play together" (Arnold, 1938-39, as cited in Wehmeyer, 2013, p. 170). During the Depression, admittance into the institutions had increased to the point of having patients sleeping two to a bed or in hallways. Due to overcrowding and fall in workforce that came with World War II, older patients deemed higher functioning cared for younger and lower functioning patients. One superintendent stated "girls [were] being held solely to protect them from the depravities of mankind" (Wehmeyer, 2013, p. 169), but were also caring for other patients.

The deplorable state of many institutions at this point in history is greatly known. Overcrowding, understaffing, and lack of federal/state money to pay for improvements or even maintenance plagued these institutions. Families were told to decrease their own suffering, financially and mentally, by admitting "defective" children to institutions and then not mentioning them. This particular narrative continued until the $1950 \mathrm{~s}$, when a revised narrative appeared via the confessional stories of parents.

Foucault (1976/1990) claimed confession within the "Christian West was the first technique for producing the truth of sex...nearly one hundred and fifty years have gone into the making of a complex machinery for producing true discourses on sex" (p. 68). This production was the coupling of extensive confessions intertwined with the scientific interpretation of the human sciences. Through this coupling, sexuality as we know it today, 
with diagnoses, fetishes, and such, embodies a truth of humanity. Similarly, through taboos, the medical model, and confessionals by parents, we see another truth emerge that is the truth of intellectual disability, one that equates ID with innocence. While the various discourses of ID have evolved and changed over time, there is no demarcation, necessarily, between them. From the mid $19^{\text {th }}$ century, doctors and human service workers were referring to labeled people as "pets" and "kids" regardless of age. Jouy was treated as a perpetual child, unable to leave childhood, according to doctors of the time. Though this narrative became a backdrop during the raging battles of sterilization and eugenics, it never ceased. This idea did come forefront, however, during the 1950s when parents began to be vocal about their labeled children. It was also during this time that a different narrative associated with sterilization began to emerge.

Again, we see a mirror in the history of sexuality proposed by Foucault wherein the confessional led to our current understanding of sexuality. Here, parents brought the shame of having a "defective" child out of the shadows by naming them as perpetual children, as seen in the influential work by Pearl Buck, The Child Who Never Grew (1950).

Pearl S. Buck had a daughter who lived in an institution, though she lived in a cottage built specifically for her. Buck had not publicly announced she had a daughter with a disability until staff members published a plethora of abusive accounts within various institutions in the mid to late 1940s (Trent, 1994). Buck advocated for parents to keep their disabled children at home until the children begin to "experience the stress of peer rejection" (Trent, 1994, p. 232). Buck also reassured parents that having a child with a disability was not their fault, which was in direct conflict with earlier narratives from 
doctors and other media sources regarding "bad genes" or "immoral" behavior (Trent, 1994, p. 232). Buck stated that disabled children were "forever children" (Trent, 1994, p. 232). Despite the ongoing troubles that many institutions were continuing to face, celebrity parents still advocated for institutionalization. However, they were also encouraging society to view labeled kids not as "over sexed" or dangerous, but as "forever children" that required extra care. Roy Rogers and Dale Evans Rogers added to this discourse by claiming children with disabilities were gifts from God, a characterization that continues for many today. They had a child with Down syndrome who died at the age of two (the death was unrelated to Down syndrome). The Rogers' advocated for parents to find "transcendent meaning in mental retardation" (Trent, 1994, p. 235).

At this point in history, we see components of Foucault's view of sexuality in how sexuality was policed for both children and deviants. Children, as discussed previously, were to be protected from sexuality lest it physically or mentally harm them in the future. Additionally, deviant sex was to be discouraged, as discussed from the monster and recalcitrant child of Foucault's work. With the previous history of eugenics and sterilization, though eugenics was no longer supported, a set truth had emerged that those labeled feebleminded or having mental retardation (MR) should not reproduce. Also, if this population were perpetual children, as had been believed and now reiterated through parental confessions, then this population should not be having sex or expressing sexuality at all. If the new narrative was to be taken as true that those deemed mentally retarded were gifts from God, this brought in a whole new complication of religious oversight and dogma in that sex was foremost for the purpose of reproduction. 
During this pivotal decade, parents all over the U.S. (and internationally) began to band together to inform one another and create support networks. Organizations such as The A.R.C. (Association of Retarded Children) were created in 1950 by parents with children labeled mentally retarded (www.thearc.org). Ironically, during the period from 1950-1968, populations in institutions for the retarded (the new term for feebleminded) increased at the fastest rate ever in America (Trent, 1994, p.266). Trent (1994) eloquently sums up this time frame as such:

Thus, in the midst of the popularization of the "retarded child," the incarcerating of retarded people (children and adults) increased as middle- and upper- class Americans found it respectable and even therapeutic to institutionalize their retarded children. What the "menace of the feebleminded" in the first quarter of the century had only partially accomplished, the infantilizing of retarded people in the 1950s finally achieved...The parents' confessional literature sustained this new popular image of mental retardation and of the residential institution (p. 266).

However, times were quickly changing with a plethora of civil rights' movements happening all over the world. In 1966, Senator Robert Kennedy visited the Willowbrook State School in New York. When he emerged from his visit, he was "obviously shaken" (Wehmeyer, 2013, p. 223) by what he had seen and called for reform. Unfortunately, reform would be slow. For comparison, across the world in Sweden that same year, The Parent's Association for Mentally Retarded Children held a public debate entitled: "The Mentally Retarded and the Sexual Question” (Kulick et al., 2015, loc. 960). Medical 
doctors, legal experts, institutional staff, and parents agreed the time had come to look at the "deeper concerns" of mental retardation such as:

...sex education...whether gender segregation in institutions was justified, whether staff working in institutions had the right to intervene to break up romances, and what parents should do when their intellectually impaired children start talking about love and sex (Kulick et al., 2015, loc. 971).

A similar debate occurred in Denmark a year later with differing results; Denmark chose to move forward with including sexuality in the normalization movement (Wolfensberger's normalization) while Sweden was much more passive (Kulick et al., 2015). In the US, society embraced the theory of normalization through a movement out of institutions and into community living. Normalization, as put forth by Wolf Wolfensberger and Bengt Nirje, emerged from a Swedish law in 1968 stating those with mental retardation should “obtain an existence as close to the normal as possible" (Wehmeyer, 2013, p. 227). This principle was meant to guide society into changing their viewpoints and beliefs about how to treat and interact with labeled people.

In partnership with this new progressive vision, deinstitutionalization was enforced throughout the US. Following the highly publicized story of Willowbrook from journalist Geraldo Rivera in 1972, states began to funnel money into community living options. With community living came a host of other issues that had previously been dealt with unevenly across states, such as public education. In 1975, Education for all Handicapped Children (later named IDEA) was passed, mandating all public schools receiving federal funds must educate all children, regardless of ability. 
Organizations, such as The A.R.C. (which had changed its name to the Association of Retarded Citizens) began advocating for community services for all ages of those labeled mentally retarded. At this point in history, involuntary sterilizations in institutions were still occurring. With deinstitutionalization, though, doctors, family, and staff needed to approach the reality of sexuality head on. With prototypes in Denmark and Sweden, the birthplace of normalization, the US had some guidelines. The US, however, would not follow suit.

Journal articles with titles such as "Parental views on sexual development and education of the trainable mentally retarded" (Alcorn, 1974) began appearing in peerreviewed journals. Even in 1974, research was lacking in the fact that people labeled with MR matured physically at the same rate as someone not labeled with MR (Alcorn, 1974). Birth control was cited as important, though little was discussed in these reports regarding healthy sexuality or rights (Alcorn, 1974; David, Smith, \& Friedman, 1976). Many parents encouraged sterilization for their offspring, with approximately half in Alcorn's (1974) study considering it a possibility. This was consistent across other studies (Hammar et al., 1967). Food had historically been (and continues to be) used as either a reward (Levin \& Simmons, 1962; Lovaas, Freitag, Kinder, Rubenstein, Schaeffer, \& Simmons, 1966; Redl \& Wineman, 1951) or a way to deter sexuality of labeled people, as described in Alcorn's (1974) study: "Another couple wrote that they had let their girl get fat and unattractive, so they would not have to worry about men taking advantage of her" (p. 127). 
A dissertation from 1977 succinctly summed up the current trends of the time, while also acknowledging the United Nations decree in 1970 that all people, regardless of ability, had the right to marry:

The debunking of the misconceptions that the mentally retarded are asexual, sexually animalistic, and the realization that the retarded have a need for and right to sensual contact throughout their lives and sexual relations in adulthood, if they are capable, has placed a great responsibility on parents and caretakers of the retarded. Whereas once the expression of sensuality and sexuality on the part of the retarded could simply be ignored or punished [within institutions], now the retarded must receive training as to appropriate behavior in these spheres, just as in the intellectual and social spheres, if the rights of the retarded in these areas are to be upheld (Mitchell, 1977).

It also must be kept in mind that though all children were now required to receive public education regardless of ability, sexuality education was not required. Indeed, it is still not federally mandated, and programs for labeled students are still severely lacking. Advocacy efforts are still trying to argue the myths Mitchell (1977) mentioned in her work, even today (Winges-Yanez, 2015).

Throughout the 1980s, social service funds were greatly slashed while, at the same time, a worldwide pandemic took over headlines, causing fear and mistrust. Deinstitutionalization continued, slowly. Infrastructure, such as community support, livable wages for staff, training, and legal oversight, continued to grow at uneven rates across the country. The state institution in Oregon, for instance, didn't finally close its 
doors until 2000. State institutions, or State Supported Living Centers (SSLCs), in Texas continue to operate today. Efforts to close them continue to fail, in large part due to families advocating institutionalization and employee unions working in the SSLCs.

In 1990, the US passed the Americans with Disabilities Act (ADA) following decades of advocacy. The ADA established disability as a protected class, thus preventing prospective employers from discriminating. Though, labeled people are still one of the least employed groups and continue to fight against wages that are pennies to the dollar. It also required many buildings to be accessible to those with physical disabilities. Signage and websites, though, do not need to be accessible through use of plain language or screen readers. Although, accessibility requirements regarding websites are currently forthcoming.

In the 1990s, US social services adopted a British concept concerning people with disabilities called the social model (discussed earlier), which promoted person first language and interventions, such as person-centered practice. Person first language states a person is more than their disability; therefore, according to this method, the correct way to refer to a person with Autism is "a person with Autism" versus an Autistic person. More recently, many within the disability communities have disagreed with this, instead opting to choose how they want to be referred to as a person. During this time, person-centered practice also proliferated in ways to create life plans for labeled people, such as Essential Lifestyle Plans, Individual Support Plans, and so on. These plans have teams, usually involving the person, their social worker, staff (if any), family and doctors. The team 
creates a plan for daily living information as well as goals for the person, as chosen by the person.

Finally, in the early years of the 21 st century, progress continued to be made for labeled people through employment programs and Universal Design in Learning, but progress regarding sexuality continues to lag. Some countries have worked to close this gap. Canada (http://www.griffincentre.org/about.php) and Australia (http://www.cbchs.org.au/files/nrteUploadFiles/262F042F2016113A083A00AM.pdf)

provide community programming for labeled individuals who identify within the queer spectrum and the UK provides comprehensive sexuality education for labeled people (http://www.changepeople.org/projects/sex-education-for-adults-with-

disabilities). Unfortunately, as previously discussed (Winges-Yanez, 2015), stereotypes that have proliferated since the late $19^{\text {th }}$ century continue to plague labeled people today.

With scientific knowledge expanding rapidly, new medical interventions have entered the discussion of intellectual disability, including prenatal testing for Down syndrome and other developmental disabilities. One specific intervention, dubbed Ashley's Treatment, called growth attenuation therapy, came into the public sphere in 2006. According to the AAIDD:

The intervention consists in giving a [person] high doses of estrogen and progesterone to chemically alter her growth patterns to force her bones to fuse (and therefore stop growing) abnormally early. This would lead, theoretically, to a smaller adult size, which would also theoretically lead to increased ease of care for individuals who are subjected to this intervention, which would theoretically lead 
to their staying in a family's home for a longer period of their adult lives (AAIDD, 2012).

Additionally, this treatment, as it's being used on people with I/DD, removes secondary sex characteristics (Ashley had a hysterectomy and her breast buds removed per her parents' request). It would appear that in the 21 st century, treatment of labeled people has not improved much past semantics.

As of 2010, under proclamation by President Obama, Rosa's Law came into effect. This law states all materials referring to a labeled person must use the label "intellectual disability" versus "mental retardation." Again, this is not universal and many state agencies continue to function under the title of Mental Health/Mental Retardation (MHMR) services.

Conclusion. This brief genealogy of intellectual disability paints a picture in which sexuality has heavily influenced the way society understands, interacts with, and intervenes with labeled people. This genealogy has provided a basis for a model with which to view ID as opposed to the social or medical models. With the genealogical model, ID is shown to have static characteristics that have been reiterated over time in different ways. For example, a person with ID, as in Jouy's story, is incapable of knowing right from wrong in the field of sexuality. Currently, this thinking continues in arguments against comprehensive sexuality education for students labeled with ID (Winges-Yanez, 2015). This, then, leads to a sustaining belief that labeled people are incapable of selfdetermination when it comes to issues of sexuality, which is in direct violation of many of the tenets of person-centered practice. Additionally, throughout much of the history of ID, 
queer identities or expressions are all but ignored. If sexuality is acknowledged, it is most likely within a heterosexual framework, leading to justifications for gender segregated housing and workspaces. When sexual relationships are discussed within heterosexual frameworks, contraception of some sort is generally included and emphasized (https://vimeo.com/joshuatate/guestroom), harking back to the fear of propagation of labeled people as well as the belief that a labeled person is unfit to parent (despite the caretaker role many fulfilled in the institutions during staffing crises to reduce costs).

\section{Foucaultian Discourse Analysis}

The methodology I used for this analysis is Foucaultian discourse analysis. The genealogical framework previously outlined guided my analysis of PCP. The genealogical framework replaced the medical, social, and/or rights-based models as my lens to view current practice (in this case, person-centered practice). This framework provided a more authentic understanding of ID, a much more transparent one that explicitly places sexuality as a construction tool in the making of the concept "intellectual disability." I used this framework to analyze a popular current practice with labeled people: person-centered practice, using works from Hook (2005), Garrity (2010) and Graham (2011) to guide my analysis. In the following discussion, I also identify and speak to concerns of validity and reliability.

Discourse analysis enables us "to question the intelligibility of truth/s we have come to take for granted" (Graham, 2011, p. 665). Discourse is a fluid notion, meaning anything from a discussion to an overarching ideology. The text from which one can analyze discourse can also range from a TV commercial to written words in a book. 
Discourse in this context is the overarching ideology expressed by person-centered practice. I used criteria laid out by Garrity (2010) as well as Foucault (1969/2010, 1998a) to analyze the discourse reflected in and reinforced by person-centered practice. Specifically, I used four categories to analyze the overall discourse: object, enunciative modalities/subjective positions, concept, and strategies (Foucault, 1969/2010; Garrity, 2010).

Foucault discussed a method for identifying and analyzing discourses using archaeology to describe discursive formations, with the purpose to study the present through historical statements (1969/2010). He sought to uncover that which is believed to be common knowledge: "the manifest discourse, therefore, is really no more than the repressive presence of what it does not say" (Hook, 2010, p. 25). Foucault looked for the relation, or the connection, of statements as they "do something" (Garrity, 2010, p. 202). This "doing something" is defined as discursive formation. Through the analysis of discursive formations, we begin to understand discourse as a social practice that demonstrates how knowledge is constructed and maintained. For example, when I present to students, I often ask how they would informally define intellectual disability; the answers are generally the same: physical appearance, the need for an assistant, and a lower IQ score. None of these students claimed to have studied ID, yet, they all named these definitions of ID. These definitions are maintained and then passed on because they are considered common knowledge; this represents a discursive framework. According to Foucault, there are four categories that identify and specify the limits of a discourse (Foucault, 1998a). 
The first category is object, which is understood to be manifest through discourse. Through discourse, a phenomenon is described, named, and classified as an object of knowledge. Foucault (1998a) has described this as a law that can define the unity of an ensemble of statements. For example, Foucault spent much time analyzing "madness." He stated that although different disciplines, such as the medical and legal fields, may use different terms and definitions, they both speak of "madness" using the same rules (Foucault, 1998a, p. 313). These rules are what constitute the object "madness"; they dictate how madness is recognized, codified, spoken of, and treated. These include talking of mental health, neuroses, deficits and diagnoses, and diagnostic tools that can measure a person's mental health state.

Secondly, enunciative modalities, which I labeled as subjective positions because Foucault uses enunciative in varying ways, names how statements referring to objects are made (Garrity, 2010, p. 204). Subjective positions take into account that certain subjects are sanctioned to make certain statements; for instance, only a medical doctor can make a medical statement and be taken seriously (Garrity, 2010, p.204), such as when a doctor proclaims a patient to have a diagnosis of schizophrenia. A relationship of power is recognized in the subjective position; the speaker(s) has the authority to make the statement while the audience becomes subject to the statement and the object becomes subject. In other words, when a doctor is discussing schizophrenia, the audience takes this information as a truth while those who identify or recognize themselves in this proclamation become subject to it and take on these truths as their specific truth. 
The third category, concepts, describes the existence of a series of permanent and internally consistent ideas in a group of statements (Foucault, 1998a, p. 316). The analysis must show a connection between concepts to identify an individualized discourse. Foucault uses the term "theoretical framework" to describe concepts, in that all the concepts "appear interconnected, intersect, interfere with and follow each other from...one and the same theoretical framework" (Foucault, 1998a, p. 318). For instance, when Foucault discusses "madness," the theoretical framework could be a medical, deficit-based model; encompassing "madness" using diagnostic measurements that place a deficit within a person, who needs help (e.g. medicine, therapy, etc.) to become "normal." Alternately, a framework using a social model would use concepts of stigma, misrepresentation in media, and over medication to discuss "madness" in society.

I used the concepts of biopower, normalization, government, and subject (as previously defined in chapter 1) throughout my reading of PCP. By using preset concepts, concepts that aided in the creation of the genealogical model, the analysis had greater focus and provided a clearer roadmap for the audience to follow. I previously identified the basic assumptions of the social model, which are fairly transparent in a reading of PCP. Identifying areas in PCP relevant to the concepts of government, normalization, biopower, and subject shows an alternative view of person-centered practice.

Finally, the category of strategy is the "rule of formation of all operational eventualities" (Foucault, 1998a, p. 320); meaning, there is a common theme arising out of this discourse. Strategy is a law of formation of all possible options, all possible points in the same strategic field of possibilities. For instance, a strategy, also called a theme, 
emerges from the relation of the object, subjective positions, and concepts that individualize a particular discourse. From the discourse of "madness," possible strategies that may arise would then be sickness, weakness, or even fear.

Integrating Foucault's work into an analysis is complicated. Describing this process of integration is even more difficult; I summarize it here for clarification. The genealogy I constructed highlights the concepts of biopower, normalization, subject, and government and how they have contributed to the maintenance of society's understanding of intellectual disability. I used these four concepts as a jumping off point when beginning my discourse analysis. However, once I started the analysis, I realized I needed to first ascertain if the texts were related to each other and all were a part of the same discourse (in this instance, the discourse of PCP). This relationship analysis incorporated different concepts, objects, strategies, and subjective positions. Once this relationship was established, I continued with the Foucaultian discourse analysis using the predetermined concepts of subject, normalization, government, and biopower. These predetermined concepts acted as a jumping off point for the discourse analysis, but they remained the identified concepts during the final analysis.

Using this methodology, I analyzed some specific texts of person-centered practice, based on their referenced usage within the literature as formative, using a genealogical framework to identify the major strategies, subjective positions, and concepts surrounding and integral to the object of ID. I used a genealogical framework that posits a dispositif of sexuality to identify the emergence of ID as a modern phenomenon. Using current literature and practices, particularly person-centered practice, these concepts, strategies, 
and subjective positions highlight a discourse with historical ties. By using a dynamic framework (genealogy) to illustrate how historical concepts and practices have affected current understandings of and practices associated with ID, a fuller picture of intellectual disability as a phenomenon emerged.

I read the text Person-centered planning: Research, practice, and future directions, which includes formative writings on PCP edited by Holburn and Vietze (2002). This text incorporates writings from O'Brien and O'Brien, the early adopters of PCP, as well as writings from current leaders in the movement, including Michael Smull and Helen Sanderson. I also analyzed material from the online course from Cornell University ILR School of Employment and Disability Institute (http://www.personcenteredplanning.org/courses.cfm). This site has 7 courses to choose and includes the major person-centered template plans (PATH, MAPS, ELP, Circles of Support) that are currently used in social services for labeled people. Additionally, these courses also have foundational readings discussing the emergence and basic tenets of PCP. Some texts are not readily available through the site; however, given the audience of these courses are paraprofessionals working in the field, these adequately cover the knowledge base of people working in the field and facilitating these plans. Direct support workers (DSW) (including nursing care facilities, home health care, personal and home care, residential care, community and vocational, psychosocial rehabilitation, and addictions) "receive the least amount of training and have the least education...rely[ing] solely on employer developed and delivered training post hire" (The Lewin Group, 2008, p. 16-17). Additionally, 
[h]igh turnover rates among DSWs are widely known...by administrators, researchers and advocates as a problem and a key barrier to the delivery of quality services and supports in community health and human services (The Lewin Group, 2008, p. 11).

This turnover also speaks to inconsistent training amongst staff and varying standards between organizations. I specifically chose these texts because the authors from the edited book brought PCP to a larger audience. I also analyzed a training I participated in in September 2017 on person-centered thinking I received from the Person-Centered Thinking Institute housed at University of Texas' Texas Center for Disability Studies. Using the genealogical model, I used discourse analysis to analyze these texts in order to answer the following research questions:

1. What does a genealogical framework reveal about ID in person-centered practice?

2. What implications do these findings hold for sexuality education? For social workers working in I/DD services?

Through multiple readings, I utilized the criteria discussed previously to analyze the texts. I used a matrix to thematically organize the analysis. For each text, I read and analyzed using FDA to find examples of biopower, subject, government, and normalization within the analysis. These examples highlighted the building blocks of the discourse (identified by Foucault as object, subjective positions, strategy, and concept) and showed the overall discourse of ID emerging from a text. However, I also read for examples that highlighted contrary concepts in order to fully examine the discourse. These contrary concepts emerged as paradoxes, discussed more fully in the final chapter on implications. My analysis additionally used the genealogical model to provide the lens so that categories 
were preset. My goal was to identify the discourse that emerged through the help of these categories. The table below illustrates the matrix, which began as starting point of a complex analysis. I allowed the matrix to evolve as needed with my reading.

\begin{tabular}{|l|l|l|l|}
\hline Object & Subjective Position & Strategy & Concept \\
\hline & & & Biopower \\
\hline & & & Subject \\
\hline & & & Normalization \\
\hline & & & Government \\
\hline
\end{tabular}

Figure 1. Discourse analysis format.

Once each text was analyzed, I then did a meta-analysis to discuss the overall discourse that emerged. Additionally, I utilized a voice-recorder (and transcribed my notes, which acted as a reflexivity journal), peer debriefing, and an audit trail to enhance trustworthiness and credibility. I have outlined the tenets of these methods for the reader.

Peer debriefing "...is the process whereby a researcher calls upon a disinterested peer - a peer who is not involved in the research project - to aid in probing the researcher's thinking around all or parts of the process" (Thi Nguyen, 2012, p. 604). This process enhances the "credibility and trustworthiness" of the project, similar to internal validity with quantitative works (Thi Nguyen, 2012, p. 604). Finally, peer debriefers "...may help to clarify interpretations and challenge researcher assumptions contributing to the credibility of findings, analyses, and conclusions drawn" (Thi Nguyen, 2012, p. 605). Throughout the project, I referred not only to primary and secondary texts for fidelity, but 
to my peer debriefer as well. This person is a psychoanalyst and philosopher and is knowledgeable and familiar with Foucault's works.

Secondly, I voice-recorded my thoughts and reactions as I analyzed the texts. Verbalizing (and then transcribing) these thoughts provided a form of a reflexivity journal. This process is especially important to me as a researcher because of my positioning and complicated relationship with ID. Most of my professional experience has centered on working with people labeled with ID and most of my research has, as well. My personal experience is that my sister is labeled and I have never known a world without this phenomenon. I have been transparent regarding my own experiences and thoughts around ID and understand the necessity to consistently acknowledge this complicated relationship throughout the process of critical analysis of the findings and data. Reflexivity is a way to continuously interact with the data in order to interrogate my own biases and interpretations of the findings. Dowling (2012) states that some researchers use reflexivity to not only journal about the process, but also to examine the "...political and social issues that inform the research process" (p. 748). Due to my epistemological standpoint and adherence to poststructuralism, this form of reflexivity works well with a Foucaultian framework. This model and analysis not only showed sexuality is integral to an understanding of ID, but also identified different power and knowledge relations that have created and maintained the concept in a way as to be limiting and normalizing.

Finally, an audit trail traces the steps I took throughout the process. My oral recordings helped to identify and trace my thinking processes, but I also used a whiteboard to list important parts of texts and thoughts related to it. Using my smartphone, I regularly 
took pictures of the white board and uploaded them to my computer in order to keep a recording of the board. This photographic trail, which I have used with previous projects as well, also allows me and others to reconstruct the process. See Appendices A and B for my notes from my voice recorder and photographic trail. 
A Foucaultian Discourse Analysis 101

\section{Chapter 6: Discoveries}

I've chosen to use the term discoveries versus findings because the term findings has a concrete finality ring to it whereas discoveries holds the door open for additional views. There are incalculable discoveries to be made about PCP using a Foucaultian discourse analysis method, but I will only discuss mine. Throughout this analysis, I was surprised to find productive and positive parts of PCP. I have worked with PCP as a direct support worker for many years; however, reading through the texts, I discovered I really knew very little about PCP and its history. I was surprised at the room for growth I saw in PCP, room for resistance to occur and progress to happen. Because of these possibilities, I decided to begin training as a PCP facilitator. This room for growth appears to be possible because of the tensions that exist between productive and oppressive forces, which began to crystalize as paradoxes. For instance, PCP emphasizes the role of the labeled person as the center of PCP discussions and also heralds labeled people as the experts in their lives; however, the role of the labeled person is never fully addressed by PCP concerning the historical stigma and oppressions that have occurred and created societal understanding of ID. Specifically, a labeled person has little experience with healthy sexuality because many are intentionally censored from learning information or being seen as sexual beings, yet labeled people are tasked with advocating for what is important to them and what relationships are important to them during the PCP process. However, within this push for self-advocacy from a place of intentional censorship exists the possibility to advocate for inclusion in sexuality education. These paradoxes exist throughout my analysis. In this chapter, I identify the major paradoxes for later discussion during the implications chapter. 
Regarding the discoveries and implications of this analysis, I begin with a description of the preliminary analysis, wherein I assure the texts I am analyzing are, in fact, part of the same discourse and this discourse is PCP. Given Foucault's emphasis that a provided structure (such as a book) does not mean all within the structure (the book) is part of the same discourse, I would have been remiss had I not done this preliminary step.

Following this discussion, I move into the analysis of the texts using my genealogical framework. This analysis utilizes the predetermined concepts of biopower, government, subject, and normalization that emerged out of the disability literature and helped form my genealogical framework. I will delve into this analysis and provide statements (Foucault, 1969/2010; Graham, 2013) as examples of the discursive formation that emerged. From here, I then answer my first research question of what a genealogical framework reveals about ID in PCP. In the final chapter, I answer my second research question and discuss implications for sexuality education and social workers working in the I/DD field.

\section{Relationship of Texts}

As I collected my texts and began reading them and attending the training, I realized the first step of this process should be to first identify if these texts are, in fact, related to the same discourse (and therefore, to each other) and that the discourse is PCP. Foucault admonished assuming a single discourse exists simply because the text is confined by the structure of a book or an ouvre of an author (Foucault, 1969/2010). A discursive formation provides the boundaries for the discourse, or more clearly, the boundaries of the functioning of a discourse, creating a single discourse. Because of this oversight, I began 
to analyze my texts to ensure they were all part of the same discourse of PCP. The four classifying headings of object, enunciative modalities, strategy, and concepts were described in Archaeology of Knowledge (1969/2010) for discerning a discursive formation.

I began by reviewing the four headings via Foucault's Archaeology of Knowledge (1969/2010). After reviewing Foucault's descriptions, I chose to rename enunciative modalities to subjective positions because enunciative was used in varying ways throughout Foucault's introduction and was not adequately capturing the term. Instead, enunciative function appeared to describe a form of speech versus a classification to identify a part of discourse. Therefore, I changed the term to better reflect the purpose of the heading, which highlights the authoritative institutions surrounding a discourse: subjective positions (p. 72).

Following my review of these headings, the rules of formation of a discourse became much clearer, in that this specific analysis needed to identify the boundaries of the discourse of PCP in order to be sure the three texts were related. I began this relational analysis by using my previously identified concepts of normalization, subject, government, and biopower. However, I quickly realized that this specific analysis would not work with these predetermined concepts. I initially identified those predetermined concepts because they were associated with the overall discourse of ID as seen throughout the literature and in the construction of the genealogical model. The concepts, therefore, were not specific to PCP viewed without the genealogical model. This glaring mistake became noticeable only when I acknowledged that the normalization prevalent throughout PCP was not that of Foucault, but of Wolfensberger. Foucault's concept of normalization involves: 
elucidating...norms and then determining the means and extent to which normal curves could be altered to maximize whatever was identified as the good...identifying abnormal bodies and then, to the extent possible, disciplining abnormal bodies to approximate the existing norms (McWhorter, 2009, p. 199200).

Normalization from Wolfensberger's framework, as discussed earlier, emphasizes that labeled people (also termed devalued people) deserve to live a typical life (e.g., life similar of those without disabilities), meaning smaller living arrangements, wage earing jobs, and authentic integration into communities. An example of normalization comes from the edited book (Holburn, et al., 2002) I analyzed:

One of the core values of person-centered planning is that the preferences of the individual with the disability should be honored and the person should be supported in making choices in all aspects of his or her life... The purpose of this chapter is to describe how to include people with mental retardation [sic] in the process of selecting a place to live and in the development of a support plan that accompanies that selection (Davis and Faw, 2002, p. 203).

Additional examples (Figures 2 and 3) come from the workbook I received during the PCP training: 


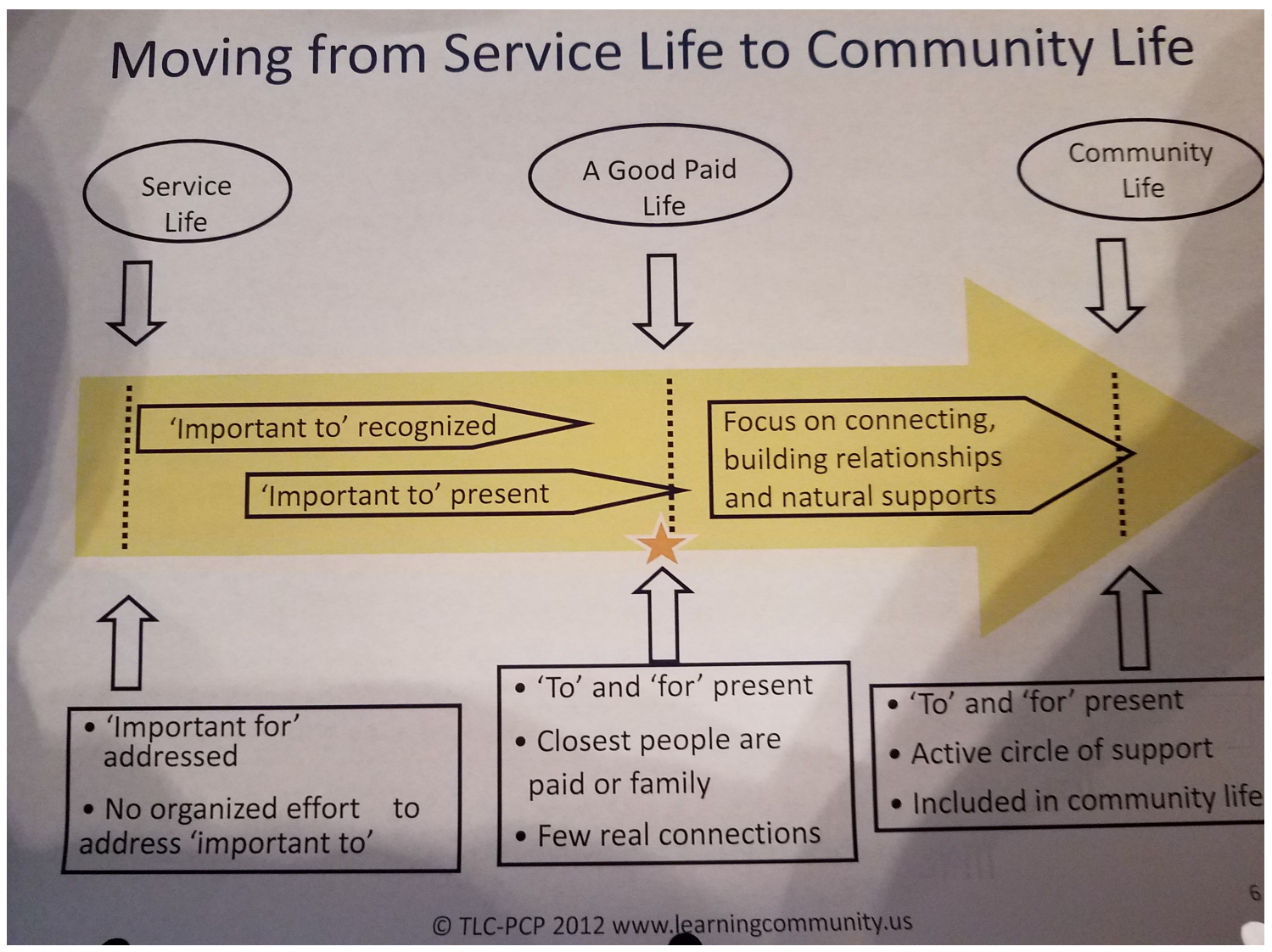

Figure 2. Community life map illustrating where many people in services may be (service life) and what community life may look like. Institute for Person-Centered Practices, 2012. 


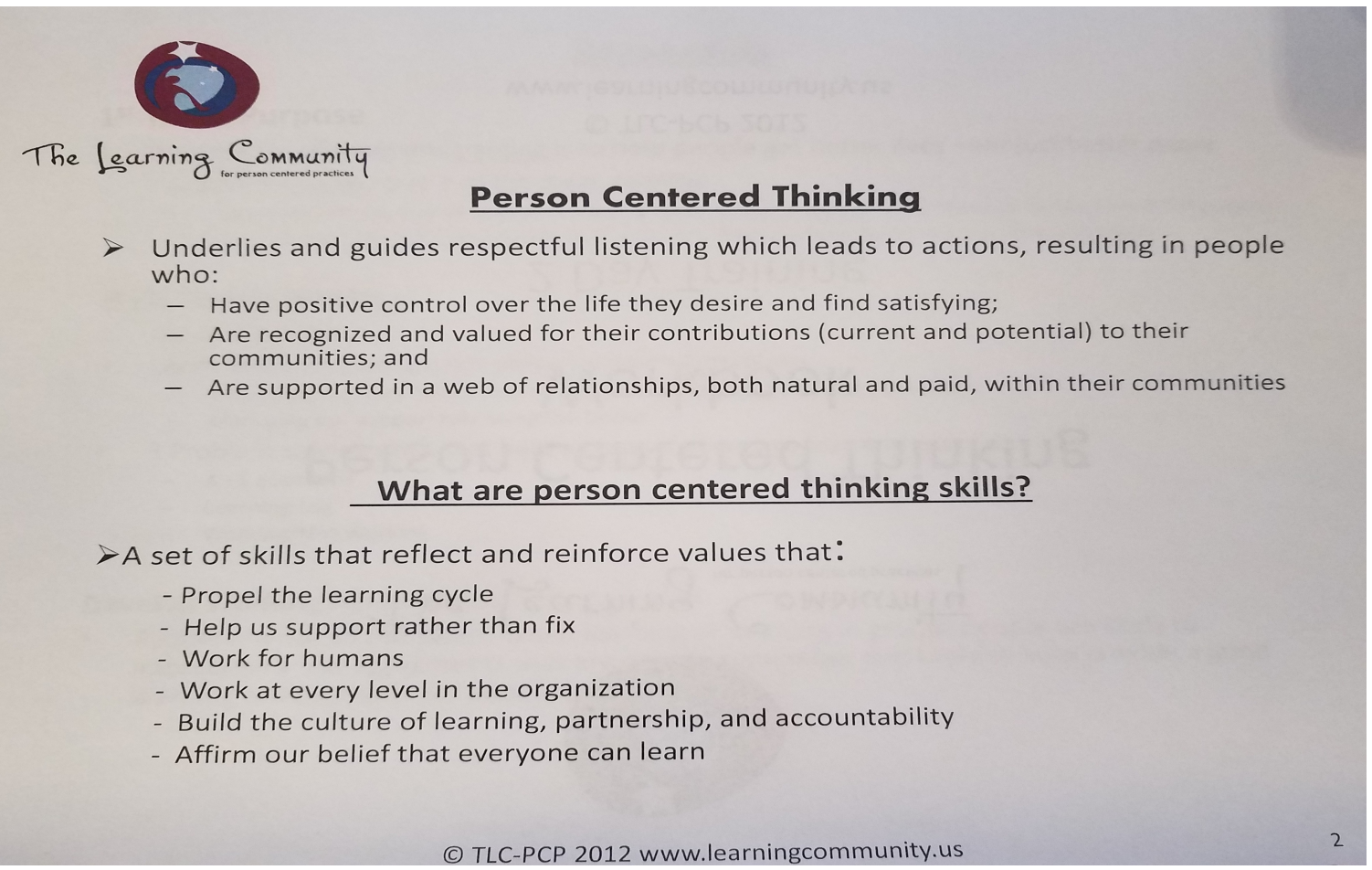

Figure 3. Person-centered thinking. Introduction of person-centered thinking training. Institute for PersonCentered Practices, 2012.

Both examples highlight the importance of a labeled person living a typical life and contrast this tenet explicitly with how most labeled people currently experience life in services. A typical life, as illustrated in Person-Centered Thinking (Figure 3), is one where individuals have positive control over the life they desire, are recognized and valued for their contributions, and are supported in a web of relationships. An exercise in the PCP training I attended asked all of the participants whether they would place themselves under Community Life (Figure 2) and whether the people we supported would also be placed under this heading. Again, this heading was representative of what a typical life looks like, according to PCP. 
In fact, the boundaries of PCP are not those of ID and my analysis was not using my genealogical framework to analyze the discourse. The boundaries of PCP are conducive to creating a path forward for labeled people and their advocates to envision and pursue a typical life whereas the boundaries of ID include limitation. Similar to a layer cake, I was looking at only the first level of analysis.

All three texts did share the same objects: labeled person and plan. The plan is an obvious product of PCP, so obvious that I almost did not see it. PCP is an approach to move forward towards a desired life with a plan in place. All three texts identified this goal and discussed, in different ways, how this plan could be achieved and understood. Additionally, the object within these texts was always, though less obviously, the labeled person. Generally, the person labeled with ID was discussed as a co-creator and the person being supported; however, through this description, a person emerges as the historically understood object of a person labeled with ID. Specifically, the process of PCP includes an intervention targeting the labeled person so that this person is capable of living a typical life, the "ideal life...to consider what is possible and positive" (Kincaid \& Fox, 2002, p. 34) with supports. This historically understood object of a person labeled with ID includes an expert or team of experts working to improve the labeled person's current situation through intervention.

The subjective positions of this discourse emerged as: parents, service providers, experts, and the labeled person. Again, this analysis only viewed these texts without the genealogical model, so the subjective positions that emerged are those that exist as blatantly stated throughout the texts. Those deemed with authority to speak and be heard 
are the subjective positions. For this process, it was difficult to not use the genealogical model and trouble the subjective position of the labeled person as authentic. However, this examination occurs during the secondary analysis.

The strategies that emerged from this discourse were shared across the texts: creativity, humility, and support. These strategies guided how the subjective positions disseminated information. Throughout the texts, creativity was referred to constantly as a way to view difficult situations or in looking for ways to attain goals for the labeled person. For example, Kincaid and Fox (2002) stated:

Person-centered planning is a creative process that does not accept the status quo...As a result, the supports and solutions to identified problems need to be diverse and creative (p. 34).

Additionally, the training provided outlines of person-centered skills. One in particular, the Donut sort, is discussed later in the analysis. The description of this skill is as follows according to the training:

\begin{tabular}{|l|l|l|}
\hline \multicolumn{1}{|c|}{ SKILLS } & WHAT IT DOES & \multicolumn{1}{c|}{ POSSIBLE USES } \\
\hline $\begin{array}{l}\text { The } \\
\text { Donut } \\
\text { Sort }\end{array}$ & $\begin{array}{l}\text { Identifies role-specific responsibilities. } \\
\text { (Core responsibilities; use judgment and } \\
\text { creativity; not usually a paid responsibility) }\end{array}$ & $\begin{array}{l}\text { Help people get clear about their } \\
\text { responsibilities regarding specific situations } \\
\text { Develop job/volunteer descriptions } \\
\text { A structure for feedback and evaluation }\end{array}$ \\
\hline
\end{tabular}

Figure 4. Skills reflection form. The Donut sort. Institute for Person-Centered Practice, 2012.

Those working with the labeled person and their family were encouraged to be humble in progressing through this work, stepping away from the stance of "expert" and into a role of "co-creator." This creates tension with the already stated subjective position 
of expert, but this is a tension that exists in the discourse. An example of this tension is illustrated in the following quote:

Providing preferred activities to people with developmental disabilities is critical for several reasons, including the obvious ethical and moral obligations. Another important reason is that providing preferred activities may have corollary effects on challenging behaviors. That is, providing opportunities to engage in preferred activities, in lieu of formal interventions targeting behavior reduction, may result in a reduction of challenging behaviors (Klatt, Juracek, Norman, McAdam, Sherman, Sheldon, 2002, p. 315).

These statements illustrate the expert emphasizing the importance of asking a person what their preferred activity is and working towards achieving that because it is the "ethical" obligation, while also citing the benefit of reducing challenging behaviors, highlighting the stance of behavioral expert. This humility does rub up against expertise of traditional behavioral interventions, exhibiting the tension that exists in PCP and is innate to its structure.

The concepts that emerged from this analysis were individual, community, selfdetermination, normalization (Wolfensberger), and organizational change. Selfdetermination needs to be a part of the discourse so the labeled person can be a co-creator of the plan, which, at times, may require humility, support, and creativity on the part of the other subjective positions. The declarations of this process highlight assisting labeled people to live their lives as similar as possible to those without disabilities, which speaks to normalization (Wolfensberger's version), again, utilizing the stated strategies. The texts 
often discussed organizational change; in this analysis, I placed it in the concept category because it is really discussed as something that needs to be in place in order for this process to work, which requires the same strategies. Organizational change moves to a different category in the next analysis with the genealogical model in play. In summary, the concepts that emerged mirror those that were listed as defining PCP. When describing PCP, Kincaid and Fox (2002) cited a passage from O'Brien, O’Brien, and Mount (1997):

Person-centered planning is rooted in the values, goals, and outcomes that are important to the person, but it also takes into account other critical factors that have an impact on the individual's life, including family and agency views, funding issues, and the person's disability and community (p. 30).

The concepts that emerged in this first level of analysis were part of the boundaries cited as important in this passage. The objects of this discourse are the labeled person and their plan for a typical life, a life that requires creativity, humility, and support to envision and attain with self-determination, normalization principles, community and organizational change.

I sent my findings of this preliminary analysis to the facilitators of the PCP training I attended in September 2017 (and who are state, national, and international level trainers). I did explain the categories and that I was identifying whether the texts I was analyzing (one of the trainers also contributed to the edited book) were representative of the discourse of PCP. They agreed with my findings with the caveat that "expert" is not as important of a role regarding subjective position. The caveat given was that the important subjective positions were the labeled person, their friends, and their community (wherein community 
may be institution, group home, day habilitation, or support worker) because those views were the true experts. Two of the trainers cited their positioning as parents as their true expertise versus their professional expertise. Given they are all experts and parents, I do disagree with this caveat, but it is important to note.

This critique of expert is further discussed in my second level of analysis, specifically when I look at the concept of government. I use my genealogical framework to analyze the PCP texts as well as the predetermined concepts of normalization (Foucault's), subject, government, and biopower. I also begin to name the paradoxes that exist in PCP through this lens. 


\section{Discourse Analysis Using Genealogical Framework}

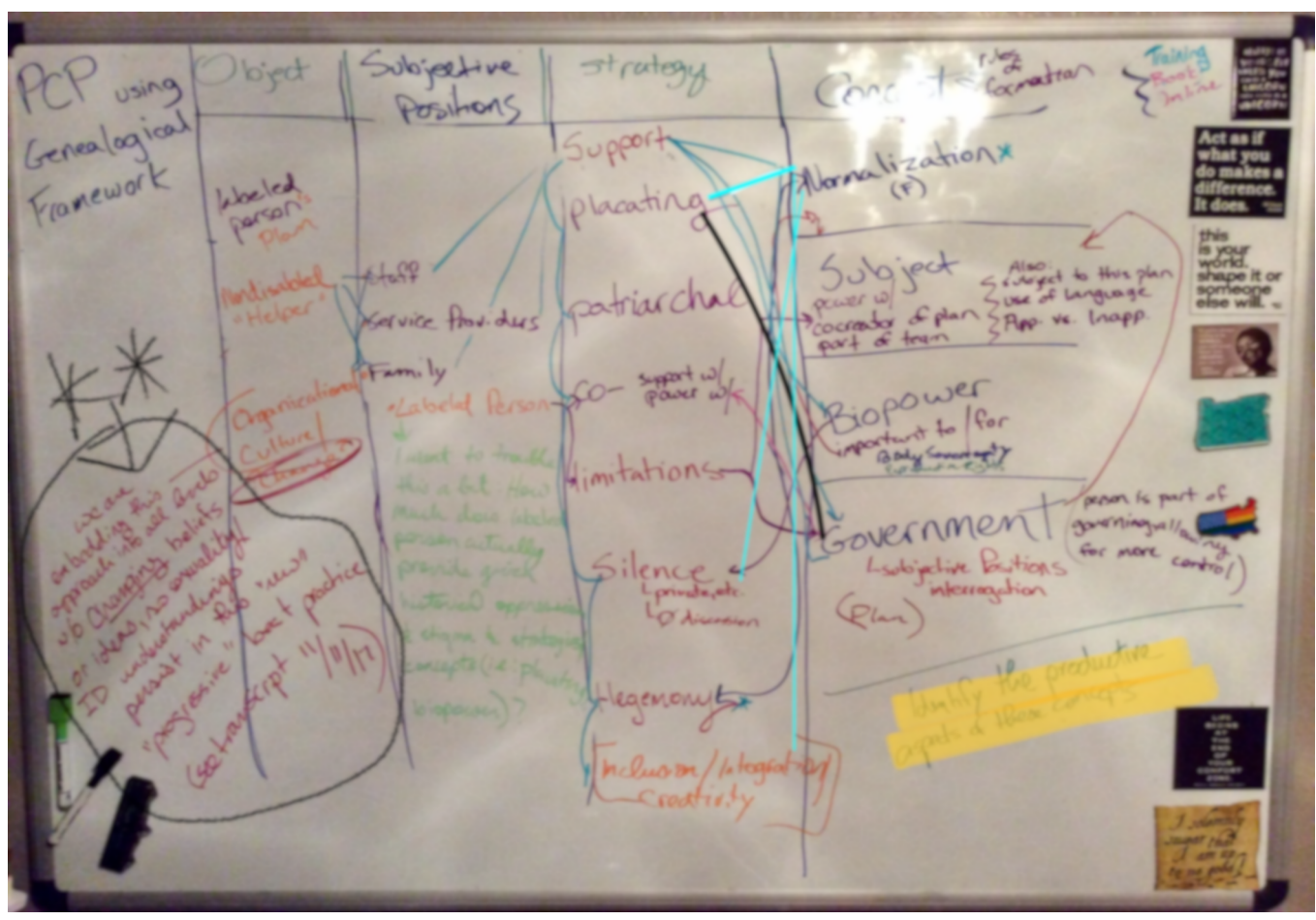

Figure 5. Discourse analysis of all three texts (together as one discourse) using predetermined concepts of normalization, subject, biopower, and government. (A larger version is on page 231)

I start by providing a photo of the final version of the white board during this analysis to provide a guide for the following connections and terms (Figure 5). Additional notes are written on the sides of the board. The key discovery shown in this photo is the interconnectedness of these terms and categories. Together, they provide the boundaries of the discursive formation while also illustrating a viewpoint of PCP only possible utilizing the genealogical framework. Important to note is that this viewpoint would not be possible with a discourse analysis as done in the preliminary stage; the preliminary analysis utilized a static analysis (without the genealogical component). The genealogical framework allows for a historical approach that opens the door to various futures, upsetting 
the view of an inevitable future. Showing the many factors that have led to our current understanding of ID also shows the many inlets to effect change. Foucault (2000b) stated, "[w]e need a historical awareness of our present circumstance" (p. 327) to understand our conceptualization of an issue. The predetermined concepts gleaned from the literature, and which helped form my framework, speak to a complex discourse existing in PCP.

Throughout my discussion of discoveries, I attempt to specify the connections between concepts and the complicated roles these concepts play in discourse, both productive and oppressive, and the paradoxes these forces create. It is this complex relationship between productive and oppressive that I found especially interesting; I will refer to it from here on out as a paradox. Several paradoxes exist, but I will highlight the major ones that emerged throughout this analysis: 1) Intimacy/Normalization; 2) Support/Government; 3) Co-creator/Subject; and 4) Biopower/Normalization. Within these paradoxes exists room for growth and sites for resistance to continuing the status quo for labeled people. Yet the paradoxes also highlight some of the oppressive aspects of PCP; for instance, PCP utilizes a plan that governs labeled people's lives and provides a guide to how staff and family can provide this life. This plan also shows how participants can advocate for a goal of sexuality education or pursuing an intimate relationship, thus, providing a guide for seeing the labeled person as a sexual being.

Finally, I provide statements to illustrate the discursive formation that emerged. Statements, as described by Foucault (1969/2010) are "the atom[s] of discourse" (p. 80). Graham (2011) explained this idea further: 
The statement as "function" can be theorized as a discursive junction-box in which words and things intersect and become invested with particular relations of power, resulting in an interpellative ${ }^{3}$ event...(p.6).

Concepts. Following the analysis to assure all of the texts were related and were describing PCP, I analyzed the texts (as a single unit from this point on) using my genealogical framework. For this analysis, I used the predetermined concepts of normalization, subject, government, and biopower. Because these concepts were predetermined and helped form the genealogical framework by emerging out of the disability literature, this is where I begin the discussion of the analysis. Starting from the concepts will also aid in describing how they connect with the other categories. However, a discrete description of each concept is almost impossible. To do so would sterilize the analysis and leave out the rich overlap that exists in the discourse. To separate the concepts would also lose some of the meanings in them. In the following passage from Tremain (2005), she explicates the complexity and interconnectedness of these concepts:

These practices, procedures and policies have created, classified, codified, managed, and controlled [normalization] social anomalies through which some

\footnotetext{
${ }^{3}$ To describe "interpellation" in a way that makes sense, I sought the support of a friend, Dr. Daude Laurents, Dean of Liberal Arts and Humanities at Austin Community College:

Althusser came to the view that subjects are constituted by intersecting social forces, rather than conceiving subjectivity as metaphysically independent "units" that interact. For this reason, when in a social context we are "addressed" and "respond," our subjectivity is constituted in that moment of interaction and thus becomes subject to the ideological structures informing the social engagement. Take for instance hearing a love song on the radio: It is as if the song addresses me, and if I respond, I become a subject in that moment of engagement, but that engagement brings with it the heteronormative ideology "embodied" in the song's mode of production and communication. In that case, my subjectivity is both posited by my engagement with the song and also my identity as a subject is defined/constrained by the ideological structures implicit in the song (personal communication, November 22, 2017).
} 
people have been divided from others and objectivized [normalization] as (for instance) physically impaired, insane, handicapped, mentally ill, retarded, and deaf. Foucault argued that in recent times, practices of division, classification, and ordering around a norm [normalization] have become the primary means by which to individualize people, who come to be understood scientifically, and who even come to understand themselves in this mode [subject]. Indeed, the power of the modern state to produce an ever-expanding and increasingly totalizing web of social control [biopower] is inextricably intertwined with, and dependent upon, its capacity to generate an increasing specification of individuality [government] in this way...in order to make [subjects] more governable [government] (p. 6, words in brackets are mine).

Due to this overlapping, I use statements to highlight a specific concept during my discussion. At no time will a concept exist without the presence of another concept, but the statement may highlight the explicitness of one concept I am attempting to describe at the moment.

Normalization. Foucault's concept of normalization refers to how institutions identify what is normal, or as Chambon and Wang (1999) describe: "processes by which society (specifically, the human sciences and the helping professions) acts upon individuals and groups to regulate, shape, or make them conform to a norm" (p. 276, emphasis mine). Throughout my analysis using my genealogical framework, Foucault's normalization (as opposed to Wolfensberger's) emerged through the interplay of the other categories. To better understand how normalization emerges in PCP, I also identify the strategies that 
emerged in concert with normalization, specifically: hegemony, support, silence, and inclusion/integration/creativity.

Hegemony. The easiest place to begin is with the term hegemony. Hegemony refers to the power of the state exerting control over others in a perceived "natural" way as to go unnoticed (Marinucci, 2010, p. 82); however, the

...weight of normalization has remained on fine-tuning the deviant person to make her or him more "normal" in his or her "normal" environment; the good health of the "community" has uncritically been taken as a given (Trent, 1994, p. 275).

Keep in mind that present day Westerner hegemony privileges White, cis-, heterosexual, traditional gender role stereotypes. When examining normalization in PCP through the genealogical framework, it becomes clear that hegemony plays a large role in how labeled people should lead their lives when living typical lives. For example:

It is "life-giving" to affirm these needs and wants [relationship, love, and intimacy] of people, and to do what may be reasonable to assist with these challenges. These are deeply personal matters and should rarely be the public work of organizations and professionals (Kendrick, 2001, para. 34).

This passage in particular resonates with the concept of normalization and hegemony because keeping intimate relationships private and taboo (taboo for labeled people) is a hegemonic ideal, but this is unrealistic given PCP is about creating a plan for labeled people to live their best lives, which would, as stated, include these "considerable part[s] of being human" (Kendrick, para. 33). According to this passage, though, labeled people would 
follow the hegemonic response of keeping intimacy private and not a part of the discussion during the PCP process. It is this tension that creates a paradox.

Given that labeled people have historically been viewed as asexual, sexual victim/perpetrator, or perpetual children, sexuality is already seen as problematic. In the interaction of hegemony and normalization, we can also see sexuality as taboo in relation to labeled people. Wherein hegemony reifies what is appropriate and preferred in a given culture, normalization statistically identifies these aspects and names them as productive for a healthy society. The vague references PCP makes to sexuality and intimacy throughout the texts emphasizes the importance of discourse analysis in determining "why it is that certain statements emerged to the exclusion of all others and what function they serve" (Graham, 2011, p. 5) because as Foucault (1969/2010) claimed: "there is no subtext" (p. 134). Specifically, from the above passage, what emerges is "intimacy is private and not the business of organizations" and in the absence of any discussion of sexuality, it (sexuality) is to be avoided or ignored altogether.

I want to draw attention to this first paradox. In this example of normalization through hegemony, a paradox occurs wherein the labeled person is expected to fall into line with the idea that intimacy is private. In contradiction, the PCP process requires a team of professionals and advocates to gather together to envision and create a plan that provides a typical life for the labeled person. Because of this process, intimacy cannot be private. Part of the PCP process also involves following up with staff, family members, and the labeled person regarding if the plan is working (usually through documentation). This process would then require discussion and monitoring of goals. If the labeled person 
had noted that intimacy was a goal and a priority, this would need to be monitored. This leaves room for an oppressive force, hegemony and normalization, to be manipulated by the very PCP process if intimacy is noted as a priority; intimacy would then, by the PCP process, become a talking point and part of the discourse. This first paradox is labeled the intimacy/normalization paradox and will be discussed further in the implications section.

Not only does this passage encourage silencing intimacy for labeled people, it is illustrative of an explicit absence throughout all of the texts I read; there is no discussion at all of queer relationships. Another example, one that will continue throughout the discoveries discussion, comes from the edited book wherein the author discusses a case in which two labeled individuals who live together take part in PCP. The individuals were identified as a man and a woman and "viewed as and, thus, treated as a couple...[1]ittle was known about them as individuals, and they were perceived as having few interests" (Sanderson, 2002, p. 102). This passage comes from the author working with an agency to begin embedding PCP throughout the organization and into team meetings. I use this passage, though, to highlight that these individuals were viewed through the hegemonic lens of heteronormativity (they are opposite sex and living together, therefore they must be a couple), which leads to normalization (a productive couple is heterosexual). Interestingly, throughout this chapter, this assumption is never reviewed. By not reviewing this assumption, normalization again emerges because, for the health of the population, it is better to not discuss or encourage intimacy amongst labeled people for reasons such as limiting the reproductive possibilities of labeled people as discussed in the genealogical framework (eugenics). Additionally, this "couple" is not described as showing affection 
or intimacy towards each other, thereby begging the question: why are they assumed to be a couple? Lacking any signs of affection, this also speaks to the normalizing techniques of assuming labeled people are not interested in sex. The chapter is about improving each person's life and truly embedding the PCP principles into the organization but interrogating the assumption that these individuals were a couple was never addressed during the process of discovering who each person was as an individual. The question becomes, would this assumption have happened had the two individuals been same sex? Or, would this assumption have been revisited had the individuals been having sex; meaning, would a discussion regarding health and safety supports have been addressed?

Support. Support is a strategy that is related to all the concepts in this analysis. The entirety of PCP is based upon effective support. Support as a term could have been placed almost anywhere in this analysis, but I chose to place it in the strategies category because through support, the subjective positions and these concepts emerge from PCP. Support in this context refers to the organizations, support staff, and family that are responsible for support services for labeled people. A mantra of PCP is "power with" not "power over" (Institute for Person-Centered Practice, 2012), meaning we (as support professionals and/or family) are here to support them (labeled people) and work with them on their plans and achieving their goals. How does support as a strategy work with normalization?

Support professionals and family members work to create a plan for labeled people to live their best lives. In doing this, support is needed to fulfill these goals and plans. With the understanding that many family members, often parents, are disinclined to discuss sexuality (Foley 2012; Lofgren-Martenson, 2004; Rogers, 2009; Swango-Wilson, 2008; 
Winges-Yanez, 2014), much less queer sexualities, does support exist for exploring sexuality? Instead, the discussion of employment options and housing options trumps any discussion of sexuality throughout the PCP texts I analyzed.

In Western society, we value living independently and having a paying job versus communal living. However, the productive aspect of support and normalization can be seen in society providing housing for labeled people in the community versus in institutions and advocating for fair wage employment (as opposed to sheltered workshops that pay pennies on the dollar). On the flip side, the "normalizing techniques that facilitate the systemic objectivization [sic] of subjects as" (Tremain, 2005, p. 8) intellectually disabled in the types of housing and employment that are available to labeled individuals; this also illustrates the concept of government in that by providing these "choices" of different employment and housing options. There are limited choices, creating a direction of conduct that is "limiting so the consolidation of more hegemonic structures" are made possible (Tremain, 2005, p. 8). Meaning, the strategy of support exists to advocate for better housing and employment options without critically examining the options available.

Bringing this discussion back to sexuality, support is seen as integral to the PCP process and often associated with the improvement of daily life. Throughout the texts, though, the mention of support regarding sexuality was absent. A story included in the PCP training I attended discussed a labeled person named "Harry" (the example of Harry will be revisited throughout the discoveries discussion) who wanted to buy a shirt that stated "I like my sex like my coffee - hot, strong, and on the table" in which he is excited to wear this shirt to the administrative offices of his service provider because he views it 
as a "chick magnet" (Institute for Person-Centered Practice, 2012). The story illustrates the importance of support staff in this situation knowing what their roles as support staff are and what their ethical duties are; the exercise is to define what the support staff's role in this situation is. See Figure 6 for answers provided.

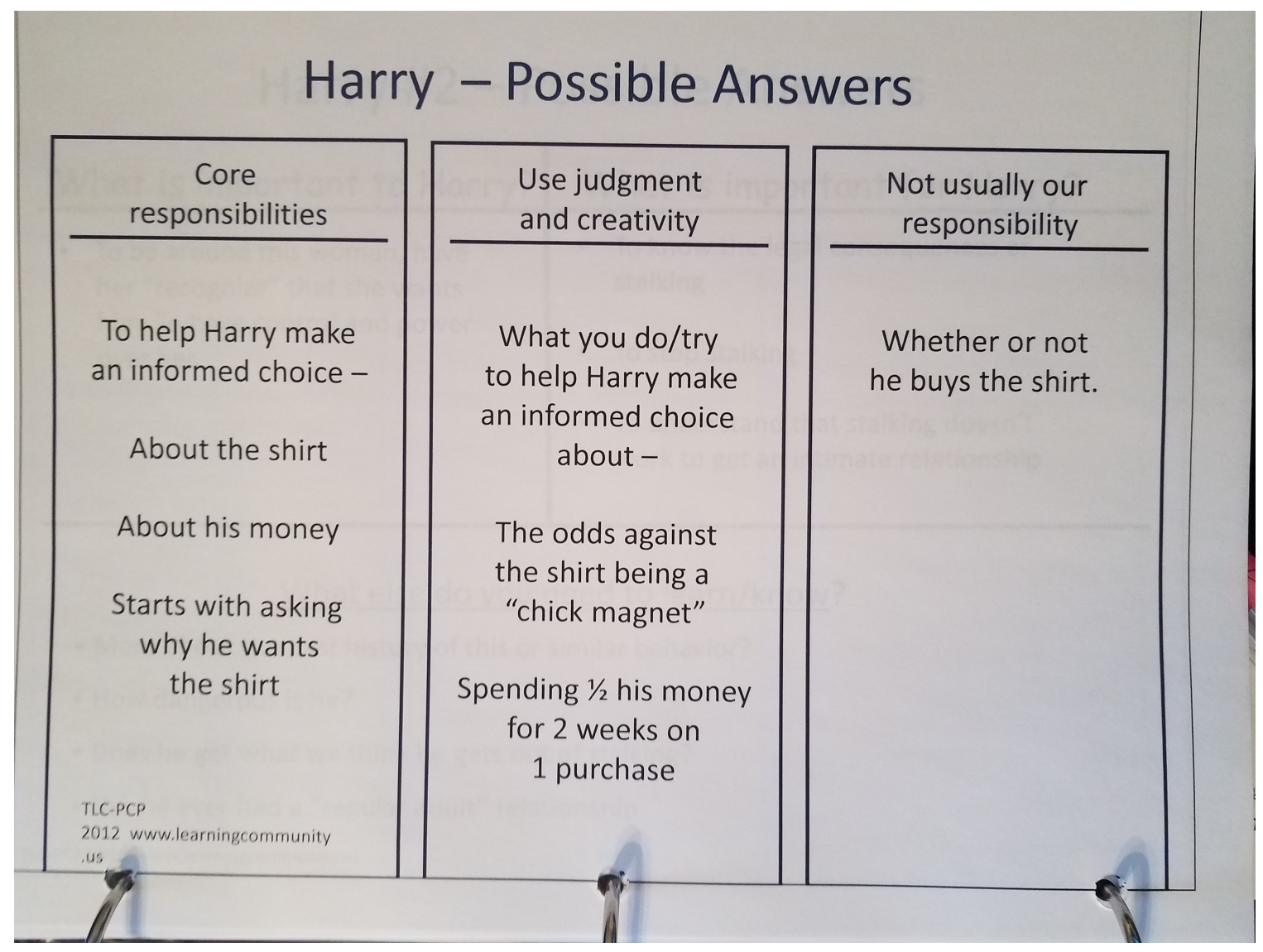

Figure 6. The Donut exercise to help identify core responsibilities of support staff; pictured is Harry's staff's donut. Institute for Person-Centered Practice, 2012.

The following statements pertain to a skill identified in the training I attended as the Donut exercise (see Figure 6) or as the "water line experiment" in Sanderson's (2002, p. 121) article from the edited book. This skill engages the staff (or family member in some cases) to identify what their core responsibilities are to the labeled person, what are 
secondary, and what may fall outside of their scope of responsibility. The support that is provided (as described in these possible answers) includes discussing money concerns and "odds against the shirt being a chick magnet" (Institute for Person-Centered Practice, 2012). There is no discussion regarding knowledge of sexuality, what this message conveys to people in terms of objectification, Harry's desire to be seen as attractive or sexual, or anything really associated with sexuality despite the explicit sexual reference. The answers do allow for the labeled person to practice self-determination in that there is no discussion of whether or not Harry can or should buy the shirt, implying that the support role is about discernment, not a foregone values-based decision. However, the eventual conclusion of the story unveils that Harry has a history of stalking women, which ultimately changes the role of the support staff (Institute for Person-Centered Practice, Harry \#2, 2012). In the end, the stereotype of labeled people being sexual perpetrators is reinforced and perpetuates the normalization techniques of censoring or ignoring the sexuality of labeled people because of this. This story also reinforces supports encouraging these normalizing techniques for the safety of everyone else and touches on the strategy of inclusion/integration/creativity and the object of nondisabled helper.

Inclusion/integration/creativity and placating. For the next strategy of my analysis, I include creativity in inclusion/integration because creativity is necessary when navigating inclusion/integration (often these terms are used interchangeably in the PCP literature). For the concept of normalization, the strategy of placating also emerges. How do inclusion/integration/creativity and placating provide strategies for normalization? This is where a discursive object emerges: the nondisabled helper. I had trouble naming this 
particular object/term because it has manifested over time in many ways: the teacher of Seguin's work, the staff in institutions, the direct support professional of group homes, the family member, and the contracted assistant hired via federal and state funding. At most times throughout the genealogical framework, a nondisabled helper exists; in PCP, a nondisabled helper is generally associated with staff members but can also be contractors, volunteers, or family members. For the labeled person to navigate the world, a nondisabled helper is usually viewed as necessary.

Here, again, Harry's story emerges as a statement that also pertains to inclusion/integration/creativity and normalization: Harry's staff's donut was used as an example of core responsibilities, none of which included discussing sexuality or engaging in analysis of the shirt. Instead, the donut states the staff should possibly discuss how the shirt might not be a "chick magnet". The inclusion/integration/creativity becomes a silent acceptance of hegemonic beliefs around sexuality, specifically around the objectification of women and viewing sex as humor versus an educational opportunity. Instead, this staff person encourages a placating version of self-determination that actually mitigates inclusion by avoiding a difficult conversation about sex. If the staff person had engaged in a conversation, a discussion of dating, intimacy, and attraction may have led to future goals to be included in the PCP regarding social opportunities as well as a discussion about boundaries (referring to Harry pt. 2 wherein it was discovered much later that Harry has a history of stalking behaviors).

In Sanderson's (2002) article about embedding PCP into their organization through working with the perceived heterosexual couple, the staff are charged with identifying 
activities out in the community that may interest the people they support using PCP. Through this process, specific staff identify areas they are more inclined to be excited about, such as a staff person who enjoys gardening will help one of the labeled individuals with gardening while another staff person who enjoys going to church volunteers to take the shift that includes attending church. In a similar process, the Institute for PersonCentered Practice (the training I attended) provides a chart for identifying staff that have matching interests with the labeled person in order to provide feasible inclusion/integration/creativity (see Figure 7). 


\section{A Matching Profile}

For each person - what are ...

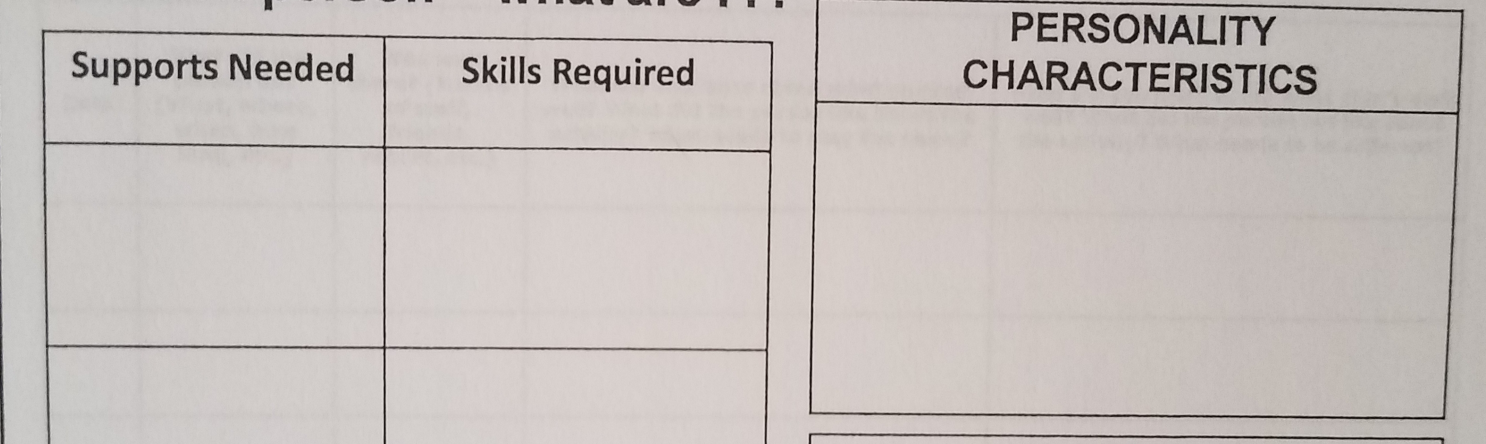

\section{NICE TO HAVE} (SHARED INTERESTS)
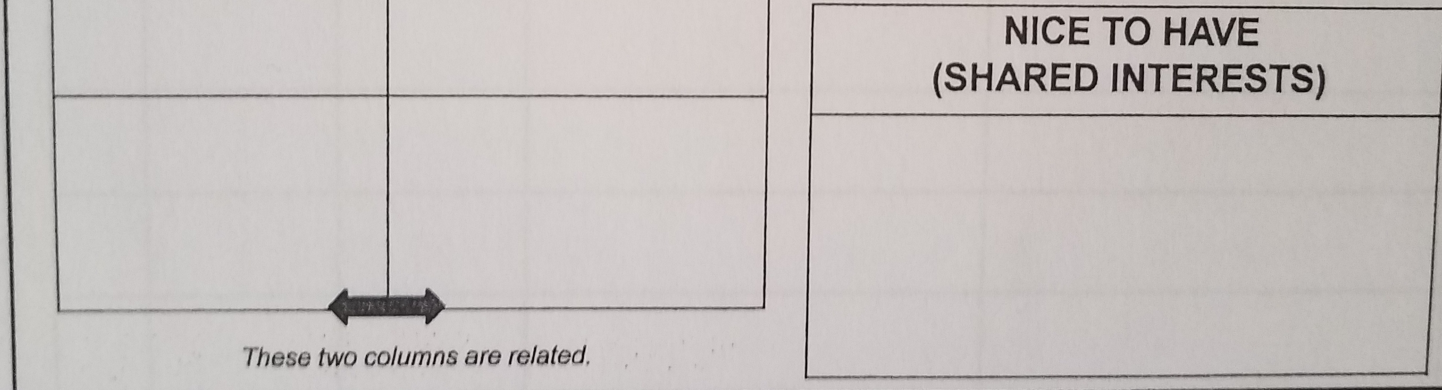

Insituic for

Person-Centered

PRACTICES

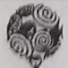

Figure 7. Matching profile; a tool to assist in finding staff (nondisabled helper) for labeled person. Institute for Person-Centered Practice, 2012.

In Sanderson's (2002) article discussing the process of embedding PCP into an agency by working with a perceived heterosexual couple, the issue of whether or not the labeled people in this project are a couple is never revisited, the placation of staff ignoring this assumption and moving into "more important" community issues such as gardening and church is concerning and echoes the concept of normalization. In the matching profile pictured above (Figure 7), given the previously stated disinclination to discuss sexuality and the present myths associated with labeled people and sexuality, is it likely to seek out 
a match for sexuality education or assistance in community activities that encourage dating and exploration (while also considering the high turnover and minimal training)? This is unlikely, especially given the almost complete lack of discussion of sexuality throughout any of the texts I analyzed. As McWhorter (2009) states: "Normalizing management amounts to harnessing developmental force and bending it in the direction desired" (p. 200). The desired direction, as laid out in the genealogical framework, is to censor or ignore sexuality for labeled people; for community inclusion/integration/creativity, this includes no explicit acknowledgement of sexuality in lieu of other "safer" activities (gardening, attending church) or placating the labeled individual so that one tenet is encouraged (self-determination) while dismissing sexually problematic language or actions (e.g., Harry and his shirt) which actually prohibit true inclusion/integration/creativity.

Government. Speaking of harnessing force and directing it in the desired direction, the next concept I present is government, while reiterating the caveat that none of these concepts exists alone. Subject and government overlap and their interconnectedness makes it such that separating them would diminish their respective importance in my analysis of PCP. However, I will highlight government in the statements I present for this section.

Government, according to Foucault, is "any form of activity that aims to shape, guide, or affect the conduct of some person or persons...the conduct of conduct" (Tremain, 2005, p. 8). Already, direction of conduct has manifested some in the discussion of normalization. As I focus on government, the strategies of support, placating, co-support, and limitations provide context for its emergence in PCP. 
Support. As previously stated, many staff and family members are reluctant to discuss sexuality. This poses a problem when considering the role these staff and family members (subjective positions) play in creating or fulfilling PCP goals. Many of the texts I've analyzed show the need for support as integral to living independently in the community:

Coordinated efforts among formal and informal supports are necessary components of successful planning, as well as the achievement of a quality life in the community for the focus person (Malette, 2002, pp. 151-152).

These supports are described as necessary for housing, employment, and daily activities. Intimate relationships are often glossed over or sidestepped in the texts. This is important to pay attention to when discussing the support family, staff, and service providers provide in the creation of a person-centered plan. The genealogical framework highlights the discomfort and unwillingness to acknowledge labeled people's sexuality so that in the analysis of these texts, the absence of discussion relating to sexuality from support in the form of the subjective positions becomes glaring. In this way, we can see how support governs the person-centered plan; if family, support staff, or service providers are not engaging in discussions of sexuality, it is left to the labeled person to advocate for this to be a part of their plan. In this way, government is innate to PCP by the very process of PCP. The role support plays in facilitating this government so that sexuality is sidestepped is also built in simply by points laid out in the genealogical framework, such as viewing labeled people as asexual or as victims/perpetrators incapable of understanding the nuances of sexuality. 
Looking at the strategy of support, the subjective positions of family, service providers, and direct support staff really guide the direction of how the person-centered plan manifests (the labeled person does, as well, but this position will be discussed more fully when analyzing the concept of subject). As key stakeholders in the labeled person's life, these subjective positions are integral to the process of creating a plan. Government aptly names this process when taking into consideration the above definition as well as noting "activity" can refer to "one's relation to oneself, interpersonal relations that involve...control or guidance, and relations within social institutions and communities" (Tremain, 2005, p. 8).

What is interesting in this particular analysis is that while the strategy of support governs the plan (discussed above), the plan also governs support. It is here that another major paradox occurs; I name this paradox support/government and discuss it more fully in the implications chapter. Once this plan has been created, it remains a living document. Those supporting the labeled person carry out these goals and priorities noted within this plan, so that these processes become almost circular. The plan provides the blueprint for the labeled person's best life and staff, service organizations, and family use this plan as a blueprint for how to support the person. Again, noting the lack of sexuality discussions in the texts, it is possible to infer that plans provide a blueprint for staff, service providers, and family to support the person in everything listed (i.e., not sexuality). Kincaid and Fox (2002) noted some universal goals of PCP regardless of which planning method one uses, including "gain and maintain satisfying relationships" (p. 32). They described this goal as: 
The individual with disabilities is supported in pursuing and maintaining satisfying relationships, including family, friend, community, and romantic relationships. In addition, person-centered planning identifies methods to support the individual in achieving healthy interactions with friends and family, who can provide the person with opportunities to give and receive love and affection (pp. 32-33, emphasis mine).

I emphasize "support the individual in achieving healthy interactions" because this illustrates the importance family, staff, and service providers have in providing support of plan goals (and creation) and how subjective this phrase is given these subjective positions as posited in the literature. This is an important excerpt also because it does list relationships as a universal tenet of PCP (and is noted throughout the texts); however, the methods to support individuals achieving this goal are never expounded upon or described while other tenets such as housing, employment, community life, and self-determination are the topics of chapters in the book, noted in the training, and highlighted throughout the online course. Predictably, relationships, as explicitly discussed in the PCP texts, appear to refer to platonic relationships only. This is illustrated through Sanderson's (2002) example of the perceived heterosexual couple that exhibited no intimacy and Harry's story wherein explicit sexual behaviors were discussed in a problematic framework (stalking), both of which encourage a platonic view of labeled people as normal and safe.

Objects. From these two examples of government and support, two objects emerge: the plan and the nondisabled helper. The plan emerges as an identifiable object in that it is defined as the outcome of the person-centered process, listing goals and priorities of the 
labeled person. This plan is created through support by the subjective positions and becomes the object from which the subjective positions navigate how they support the labeled person. Interwoven throughout this discussion is the nondisabled helper. The nondisabled helper is the "support" person who is necessary to planning and goal achievement mentioned by Malette (2002). All of the texts highlight the importance of service providers, staff, and family members in creating the plan and being part of the person-centered process, implicitly inferring the nondisabled helper as necessary. In Figure 2 (Service Life to Community Life, 2012), a good paid life is noted as one that includes "few real connections" and the "closest people are paid or family". However, in the section labeled "community life," there is a "focus on connecting, building relationships, and natural supports". In both of these examples, the nondisabled helper (e.g., natural supports or paid staff) is viewed as integral to a labeled person's successful navigation in life.

It is also possible to see the beginning emergence of the object organizational culture at this point. Staff and service providers exist within organizations; to use PCP, the process becomes either an in-service training or an embedded principle within the organization. Staff and service providers co-create these plans and then work off of them to provide services and supports to labeled people. However, the distinction (training versus principle) begins to emerge at this point because it is key to moving forward in this analysis and paying attention to the strategies of placating, co-support, and limitations as they relate to government and subject. 
Placating and co-support. This leads to the strategies of placating and co-support, which truly exist in tandem when discussing the concept of government. Co-support refers to the strategy of including the subjective position of the labeled person during the personcentered process. In the training I attended, co-support was repeated throughout (see Figure 8).

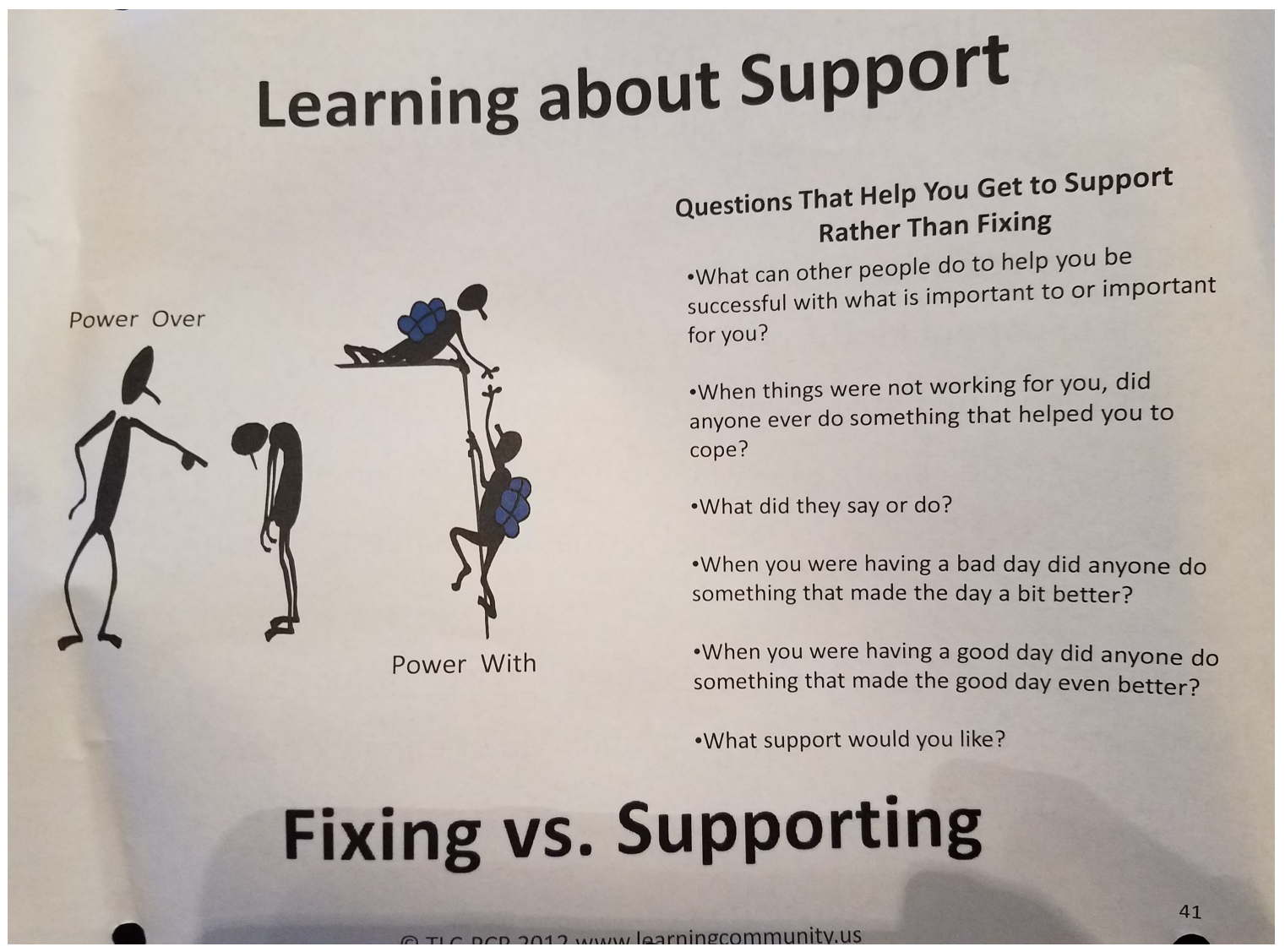

Figure 8. Fixing vs. supporting. Institute for Person-Centered Practices, 2012.

Person-centered planning centers the labeled person. The labeled person is essential to the process of creating a plan and various chapters in the book I analyzed are dedicated to the 
concept of self-determination and ways to assure the participation of labeled people. For instance, Kincaid and Fox (2002) identify PCP as empowering:

Person-centered planning is an essential component of self-direction and selfdetermination for individuals with disabilities. Individuals learn how to express their preferences about their futures, as well as how to collaborate with other people and to assume a leadership role in fostering a positive and possible future (p. 35).

Given the historical oppression and stigma labeled people face in expressing their sexualities, and given the resistance of staff, service providers, and family to provide education or space for expression, how possible is it for labeled people to learn how to "express their preferences" and "assume a leadership role in their futures"? For example, a labeled person who may want to "express their preference" for a queer sexual identity may have difficulty doing this during PCP because of service providers refusing to "acknowledge or discuss" queer identities (Duke, 2011, p. 44) or they may not "know when, where, and how to effect queerness; they are often uninformed about safer expression of sexualities" (Thompson, 2007, p. 40). To revisit the excerpt from Kincaid and Fox (2002) about universal tenets of PCP, co-supporting someone to engage in healthy relationships would require additional reviews of methods of support as well as engaging with sexuality discourse, both of which are missing from most of the analyzed texts. The minor acknowledgements take on the strategy of placating versus true co-supporting. All of this analysis comes into play as we consider the concept government.

The labeled person works with their team to co-create the plan for living their best life. However, given the problematic status of co-creator previously described, Tremain's 
(2005) interpretation of government as “one's relation to oneself, interpersonal relations that involve...control or guidance, and relations within social institutions and communities" (p. 8) acknowledges an issue: how does a labeled person authentically cocreate given these oppressions and stigmas without taking them on as governing their own desires, expressions, and behaviors to match those of the co-supporters? In this way, how does a labeled person resist interpellation, a seemingly natural phenomenon occurring in the moment of social interaction in the context of hegemony? The ability to resist becoming subject to narratives that place labeled people as asexual or incapable of healthy sexuality within interactions with authoritative figures (teachers, clergy, parents, media, etc. who historically have negative views of labeled people's sexuality) or during PCP meetings (a public forum) with case managers, doctors, parents, and vocational rehab specialists is daunting. Throughout the analyzed texts, the labeled person was identified as the co-creator of all person-centered plans; however, the acknowledgement of labeled people working from a deficit - years of stigma and oppression that have been historically normalized as discussed in the genealogical framework - in their own subjectivity is never addressed. This leaves a large gap between being an authentic co-creator and simply placating labeled people by addressing them as co-creators without addressing their current subject status in society. This gap creates the third paradox termed co-creator/subject, which will be discussed further in the implications chapter.

Limitation. In fact, much of this discussion dovetails into the strategy of limitation. By creating the person-centered plan (the living document and the process) and ignoring the subject status of labeled people (interpellation), the government of services and labeled 
people again highlights the object of organizational culture. Specifically, MagitoMcLaughlin, Spinosa, and Marsalis (2002) list barriers organizations face in fulfilling plan goals: managing conflicting priorities, individualizing plans while serving large numbers of people, providing adequate staffing, ensuring adequate transportation, and coordinating services across teams and environments (pp. 128-130). Service coordinators and staff brought up these same barriers time and again during my training in September 2017. What these barriers speak to is the limitation in which goals cannot only be envisioned, but also achieved. The conduct of labeled people and their goals and visions are limited by the barriers listed, speaking to much deeper levels of coordination involving organizational culture and their commitment to PCP as a governing principle versus a skill training. It is this imbalance the online training on PCP describes:

People attend training in order to become "person-centered" in the delivery of services to people who have disability labels. So common has the language of person-centered practices become that there is a danger of the "same soup in a different cup" syndrome. What this means is that we run the risk of putting the newest trendy label on what we have always been serving! (Yang Tan Institute, 2017, p. 1).

These limitations act as a strategy to what goals can be envisioned and achieved; who has final say on plans; how conflicts between institutions are managed (or not); how conflicts between the labeled person and agencies are managed (or not); and approval of what a "desired life" is or if it is deemed appropriate. We begin to see how limitation acts as a strategy with government and subject through subjective positions that then lead to 
behemoth objects of organizational culture and plan that exist in a circular reality with the previously discussed concepts.

Subject. Foucault speaks of limitations when discussing how a person is subject to a limited number of narratives, therefore leaving a limited choice of the subject created. Also, limitations exist in how the subject than governs themselves in society based on these limited narratives. Foucault (1997b) states, "[t]he subject is either divided inside himself or divided from others" such as "the mad and the sane, the sick and the healthy" (p. 326), or in this case, those with ID and those without. Those without ID do not necessarily need a plan to live their best lives and are assumed to be sexual beings, whereas those labeled with ID are assumed to need a plan and not to be sexual beings, or if they are viewed as sexual, this sexuality is deemed problematic (e.g. Harry). Subject refers to being the subject of discourse as well as being subjected to the discourse, wherein interpellation occurs and the person takes on these "truths" known within society. Foucault (1997b) also touches on the concept of subject in relation to power relations by citing the "totalization and simultaneous individualization" that occurs through the modern state and its institutions (p. 336). In fact, this is on display when analyzing the PCP process.

A person cannot exist in society without knowing certain ideas; Butler (1993) talks of this when describing the social construction that occurs the minute a baby is born and deemed either a girl or a boy (p.17). The same can be said for people labeled with ID. As laid out in the genealogical framework, an understanding of ID forms. From this, we must infer people labeled with ID understand these constructions as well. Yates (2005) 
highlights these constructions of the self as "learning disabled" (British term for ID) in his work:

The first thing to notice in Anne's and Paul's accounts is the way that they talk about themselves in relation to things in relation to things that they can and cannot do and the way that they are expected to behave (p. 72).

I discuss the concept of subject prior to its direct relevance to PCP because the analysis is more reliant on the genealogical framework; how ID has been constructed and understood over time must be acknowledged. A labeled person knows these constructions, but PCP discusses the person as an equal co-creator of the plan. As a co-creator of this plan, authors then highlight how self-determination and self-advocacy are innately practiced and improved (Dumas, et al., 2002; Wehmeyer, 2002). Still, how can labeled people authentically practice these skills given interpellation that has occurred? Specifically, how does a labeled person view their self as a sexual being given formal sexuality education is less likely to have occurred in Special education (Barnard-Brak, Schmidt, Chestnut, Wei, \& Richman, 2014) or from parents (Foley, 2014; Rogers, 2009; Sinclair, Unruh, Lindstrom, \& Scanlon, 2015)? It is unlikely a labeled person can or will advocate for better sexuality education or to express their sexuality given the overwhelming silence on the topic throughout their life.

Additionally, knowing a labeled person holds a less valued place in society (as illustrated in the genealogical framework and literature), is it likely they can equally share in the creation of their person-centered plan or in the process? By overlooking or ignoring 
the history of oppression and stigma that continues to affect labeled people, PCP overlooks the authentic participation of labeled people, instead reverting to lip service.

For example, Dumas, De La Garza, Seay, and Becker (2002) discuss efficacy perceptions while using PCP in their article from the book I analyzed. In it, they discuss:

...many participants believed that person-centered planning gave them [labeled people] more control, albeit limited, because they also still believed that they had to accept whatever services and supports were offered to them (p. 237).

And even then, "most participants were still giving control to their service coordinators" (p. 240). This example is especially interesting given the member checking I did with the facilitators regarding the discourse of PCP in the first level of analysis. The example clearly acknowledges labeled people having difficulty truly taking control of their services and choices, yet, the authors (one of whom is a colleague involved in the member checking) describe this process as "beginning to provide preferred outcomes" and labeled people were "beginning to display potential for self-efficacy" (Dumas et al., 2002, p. 240). The expert status in this study did not, therefore, lie with the labeled person, but with the service coordinator. This is an ongoing discussion and to brush it aside and claim the labeled person is the expert here is a disservice to PCP and to labeled people.

The labeled person has constructed a subject that is, as interpreted from Foucault's work, labeled with ID and must default to staff or parents or some other authoritative figure. Tremain (2005) refers to another scholar, Ian Hacking, to further the discussion of subject in the following passage: 
Hacking argues that the "human kinds" that are supplied by "human" sciences such as psychology, psychiatry, and sociology differ from the "natural kinds" that physics, astronomy, and other "natural" sciences claim to discover insofar as, in many cases, the people who are classified as members of a kind come to have knowledge of the relevant kind, which changes their self-perceptions and behavior, motivates them to forge group identities, and often forces changes to the classifications and knowledge about them (p. 7).

During my own training in PCP, I asked a labeled person what she likes and dislikes. Though she easily answered what she likes, she found it incredibly difficult to answer what she does not like. From the literature (and experience), the subject this person has created is one who is "compliant" and exhibits "good behavior" (infamous social service terms from the disability field). This woman very easily identifies that she is "special" and that she cannot do certain things because she is special. Given this is not an unusual encounter or response, I would argue that to dismiss the reality of historical oppression and stigma labeled people face when advocating for PCP as a way to "level the playing field" is to dismiss the reality of the labeled person's very existence and undermines the potential for PCP to effect change in the labeled person's life.

However, perhaps this erasure of oppression and stigma is needed in order to facilitate PCP, at least in its present iteration. I refer to the practice of providing a limited number of choices for the purpose of providing choice, thereby fostering positive reinforcement of self-determination while also limiting the field of possibilities and true self-determination. Explicitly avoiding conversations of sexual self-advocacy and healthy 
expression while simultaneously advocating for a more integrated and inclusive life; a life that is possible through the assistance of nondisabled helpers and service organizations working on a tight budget with a large number of clients. Fostering a better life, using strengths available in the system (nondisabled helper) which encourages family support and participation as well as buy in of PCP can be considered a mode of power that is "letting live" a large population (those labeled with ID). This leads to the final discussion of biopower.

Biopower. Biopower is one of the more elusive Foucaultian concepts. As I have interpreted it, biopower refers to a mode of power acting on the level of population (versus individual or family level) using normalization as a guide to foster life (as opposed to disciplining practices used to control life). Biopower also incorporates techniques that “classify, codify, manage, and control social anomalies through which some people have been divided from others and objectivized..." (Tremain, 2005, p. 6). One such technique is the label of ID. Labeled people are able to receive financial support, therapies, education, and other support services by receiving this label. Also, this label has instructed many families with a labeled member and social services that a plan is necessary in order to successfully navigate social service systems. However, the flaws of this plan, PCP, have illustrated historical stigmas perpetuated through the absence of any authentic discussion of sexuality. In fact, the texts I have analyzed for this project have either reinforced negative stereotypes (via the Harry story), perpetuated sexuality as platonic, or avoided the discussion altogether. 
Support. The strategy of support is used to reinforce biopower in a few different ways. Service organizations serving labeled people often need either a diagnosis or completed functional assessment in order to provide services. Once this label is confirmed, those using PCP support the labeled person by supporting what is important for the person (needs, such as medicine, etc.) balanced with what is important to the person. As discussed, many labeled people have little experience with discussing sexuality or engaging in healthy expression of it. Therefore, if sexuality is important to them, have they internalized their understanding of sexuality and explored this or sought out information on this in order to present this information to the planning team or to their identified advocate? And does this advocate then support sexuality as a priority? The literature states no.

Looking at biopower as a mode of power in PCP, the importance of medical information, the classification label of ID, the inclusion of labeled people within a community that supports them, the emphasis on choice and self-advocacy - PCP appears to foster life in a way labeled people have historically not experienced. Biopower, in this view, appears to be a productive form of power that has allowed labeled people to use the classification and codification system to benefit their quality of life. Here, then, is the final major paradox of the analysis to be discussed in the implications section more: normalization/biopower. Through the literature, extensive assistance can be found on how to include discussions of housing preference, employment possibilities, and behavior supports in ways that best support labeled people and respects their voice. However, it is the silence on sexuality and the lack of assistance in how to effectively include this in the 
PCP process that fosters life for the nondisabled community so that as a population, norms are maintained.

Biopower, then, aids in constituting an understanding of ID, an understanding of a population needing a plan in order to succeed and live their fullest lives. It also aids in constituting a population of human service organizations that work with labeled people (with confirmation of label) and a population of parents and family members, all who understand ID through current knowledge that has emerged through classification, codification, and interventions (such as PCP).

An important realization is that biopower is a mode of power that classifies, manages, and fosters support of the population. Specifically, labeled people are labeled in order to then receive specialized medical care and services; managed through the existence of support services such as Special education and social work, supported through employment of social workers and other disability support professionals, and needs and desires are supported wherein families feel heard and supported and labeled people are theoretically listened to. What is problematic is the missing piece of how to support labeled people holistically, including their sexuality. Supporting part of the population, the part that is normalized, to be sexually healthy while avoiding this discussion and support with labeled people 4 is what mitigates the productive aspect of biopower in this specific context while acknowledging that biopower is productive for much of society in this context.

\footnotetext{
${ }^{4}$ Given the caveat of "normalized population," it should be understood that anyone who falls outside of this is also included, such as queer people, teenagers, and people of color.
} 


\section{Conclusion}

This analysis shows the interconnections of Foucaultian concepts of biopower, subject, government, and normalization throughout the intervention of person-centered practice. Labeled people are subject to normalization and create their own narratives based on these techniques. PCP provides a technique of government through the utilization of a person-centered plan and also models how labeled people govern themselves and interact with other institutions. Finally, through the mode of power known as biopower, labeled people become classified, codified, and managed through social services, and in return, service organizations and families are given encouragement that PCP is the way to encourage self-determination and success in labeled people. However, as discussed in the genealogical framework laid out in chapter 5 , sexuality has played a major role in how society's current understanding of intellectual disability is constituted and maintained.

Regarding PCP, ID continues to be constituted by an explicit silence on the topic of sexuality as well as a lack of resources available to incorporate healthy sexuality into PCP. The analyzed texts refer to the importance of relationships, supposedly in all forms, for labeled people. What is missing is any supportive information on how to include the discussion of intimate relationships in PCP, whereas acknowledgement of intimate relationships do occur in the article by Sanderson (2002), it relies on heteronormative assumptions and stereotypes associated with ID (asexuality). The acknowledgement is limited in that the author never revisits the assumption regarding a perceived relationship. The main focus of this article is how to embed PCP ideals into an organization so that all staff subscribe to them; but how does this authentically happen when a major facet of 
someone's life (an intimate relationship) is never explored? The first paradox is identified here as intimacy/normalization. The implications of this paradox will be discussed in the following chapter on implications.

This tension may be reduced if family members or staff are willing and able to advocate on behalf of the labeled person, using their own place at the table, the strategy of support, to model an art of government that is inclusive. The PCP process produces a plan that is a living document that guides staff and family to support the labeled person while also using this process to add to or change the plan. However, throughout the texts, this model did not emerge. A model of how to intervene into a difficult conversation regarding sexuality is illustrated by how to sidestep this thorny discussion and instead discuss finances (e.g. Harry). This paradox of support/government becomes the second major paradox to be discussed in the following chapter via implications.

Throughout the texts, self-determination and self-advocacy are heralded as benefits and effects of PCP. Labeled people are expected to have a seat at the proverbial table to speak up for what they want for their desired life goals. They are encouraged to govern their lives with agency. Referring back to the genealogical framework, though, this seat at the table becomes problematic given the historical oppression and stigma associated with not only ID, but also sexuality as it relates to ID. Labeled people have not had the opportunities in public education, in social services, or in families to explore and express healthy sexuality. Therefore, is it realistic (or fair) to place the onus of sexual selfadvocacy onto the labeled person? Have labeled people constructed their identities to include sexuality when they are subjected to the narratives that labeled people are asexual, 
victim/perpetrator, or childlike? A genealogical framework reveals that ID continues to implicitly hold tension with sexuality through the process of PCP and its touted benefits. This third paradox of co-creator/subject and its implications will be discussed more fully in the following chapter.

Finally, biopower envelops this analysis by naming the power that service organizations, family members, and direct support workers have in avoiding the conversation of sexuality for the priorities of productive living; namely: housing, employment, and behavior supports. The importance of natural supports and relationships are emphasized, creating a fostering community that includes labeled people. PCP provides guidance on how to name what is important to the labeled person and what is important for the labeled person. However, all of this information is collected and collated by a service organization (or facilitator), all of whom benefit from PCP through employment as experts, leaving labeled people to possibly continue this circular existence of interpellation, governing, and normalization as asexual, victim/perpetrator, or eternal child. The final paradox normalization/biopower will also be discussed in the final chapter via implications for sexuality education, social work, and social services. 


\section{Chapter 7: Implications}

Throughout the previous chapter, an overall theme emerged: paradoxes. Using a genealogical framework and Foucaultian discourse analysis to view person-centered practice, certain paradoxes emerged as highlighted in the previous chapter. I named these paradoxes: intimacy/normalization, support/government, co-creator/subject, and biopower Inormalization. These paradoxes have implications for sexuality education, social work, and social services. I separate social work and social services because licensed social workers do much of the policy and administrative work while direct support workers provide much of the front-line work, often dictated by social workers. Much of the direct support work that happens occurs within social services and I wanted to acknowledge the two areas while differentiating between some of the specific supports and roles. Implications are different depending on whether someone is a social worker or social service provider, although not always, as will be discussed in the biopower/normalization paradox.

The paradoxes show the analysis and named the tension of productive and oppressive forces that exist in PCP and illustrate unique opportunities to critically view possible futures. Foucault's work highlighted the ruptures that exist throughout history and how these tensions in power relationships have led to a much more nuanced understanding of history, the present, and the future. Foucault (2000b) stated:

Every power relationship implies, at least in potentia [sic], a strategy of struggle, in which the two forces are not superimposed, do not lose their specific nature, or do 
not finally become confused. Each constitutes for the other a kind of permanent limit, a point of possible reversal (p. 346).

I examined power relationships in PCP and identified tensions as paradoxes, wherein a struggle of two forces exists and ways to reverse the path towards oppression becomes visible. This struggle speaks to the concepts I identified and analyzed (normalization, government, subject, and biopower) and I discuss how reframing these paradoxes can change the conversation. With this understanding of Foucault's work and my analysis of PCP, I move into the implications for sexuality education, social work, and social services.

\section{Intimacy/normalization}

PCP is a process wherein the labeled person is at the center - the person for whom a plan and blueprint are created. Those who are often part of this process (aside from the labeled person) may be family, support staff, friends, administrative staff (from job sites, residential sites), and other professionals (such as psychiatrists, medical doctors, etc.). The process identifies goals and priorities. One of the tenets of PCP states:

The individual with disabilities is supported in pursuing and maintaining satisfying relationships, including family, friend, community, and romantic relationships. In addition, person-centered planning identifies methods to support the individual in achieving healthy interactions with friends and family, who can provide the person with opportunities to give and receive love and affection (Kincaid et al., 2002, pp. $32-33)$.

Throughout my analysis of PCP, this emphasis on relationships emerged as hegemonic understandings of relationships as they pertain to people labeled with ID. Hegemony refers 
to what is deemed appropriate and preferred in a given culture. In Western society, relationships are generally understood to be private and heteronormative. In relation to labeled people, relationships are also perceived to be non-sexual. This understanding was highlighted by Sanderson's (2002) article describing two individuals of the opposite sex who lived together and were perceived to be a couple, despite a lack of intimacy displayed by either person or any shared interests. Throughout Sanderson's article, this assumption was never revisited even with the work the author did to embed PCP principles into the agency that supported this "couple."

From this same example, another question emerges: would this assumption have been made had the two people been the same sex? Throughout all of the analyzed texts, no discussion or mention of queer identities or orientations existed. Again, the assumption that any relationships between labeled people that do exist are heterosexual is reified.

In another example (from the training I attended), the story of Harry shows a labeled person with problematic sexual behaviors (stalking), lending to the stereotype that labeled people's sexuality is dangerous. In this story, discussions of self-determination were mentioned as a way to mitigate discussions of sexuality. Harry's desire to appear attractive and sexual was ignored, as was the problematic message of his shirt; instead, the staff person was told to be creative and discuss finances or how the shirt's message may not be perceived as a "chick magnet."

Normalization refers to "processes by which society (specifically, the human sciences and the helping professions) acts upon individuals and groups to regulate, shape, or make them conform to a norm" (Chambon et al., 1999, p. 276). Particularly looking at 
normalization in this discussion of paradox, the framing of normalization emphasizes relationships, but reduces their complexity to remove intimacy from the concept, either through default or for safety. We see this in the perceived heterosexual couple from Sanderson's (2002) article and in Harry's story. In the framing of normalization, the norm to which labeled people must conform is that of platonic, heteronormative relationships.

In both of these examples, an incongruity emerges wherein PCP is advocating facilitators, family, and staff to adhere to the tenet of supporting labeled people to find and maintain relationships, including romantic ones, while simultaneously reifying stereotypes pertaining to labeled people's sexuality. This paradoxical teaching has implications for sexuality education, social work, and social services.

Sexuality education. In a textbook on sexuality education, Bruess and Schroeder (2014) define sexuality education as:

A lifelong process of acquiring information and forming attitudes, beliefs, and values about our identity, relationships, and intimacy. It encompasses sexual development, reproductive health, interpersonal relationships, affection, intimacy, body image, sexual orientation, and gender. It addresses the biological, cultural, psychological, and ethical dimensions of sexuality (p. 15).

Based on the literature, sexuality education is much less available in Special education and fewer options of effective curricula exist (McDaniels \& Fleming, 2016). As discussed in a previous publication (Winges-Yanez, 2015), discussions of queer orientations and gender identities as well as healthy sexual relationships are missing from even the most comprehensive sexuality education curricula. The Sexuality Information and Education 
Council of the U.S. (SIECUS) provides guidelines for age-appropriate content in sexuality education as well as best practices for teaching it. Nowhere in these guidelines does it state labeled students should not receive sexuality education or should receive censored versions. Within sexuality education, the paradox of normalization and intimacy can be explored.

Frawley and Wilson (2016) noted that young women who are labeled had confusion about healthy sexuality:

Another strong theme from the young women's focus groups was being told how to say "no" to sex. There was no discussion about the pleasure of sex or sex and relationships being a positive experience, leaving women a bit scared about the whole topic (p. 480).

Michael Gill, author of Already Doing It: Intellectual Disability and Sexual Agency (2015), was quoted in a recent story by National Public Radio (NPR) saying through education, labeled people "become empowered in what is sexuality and what they want in sexuality" (Shapiro, 2018). This assumes understanding of intimacy in relationships exists for labeled people as well as for teachers facilitating sexuality education. As I noted, curricula targeting labeled people that include in-depth discussions of orientations, gender, and healthy relationships in the context of intimate situations are difficult to find. Yet, sexuality education can be a site of resistance that can begin to chip away at current understandings of ID that are perpetuated through PCP; sexuality education can and should include discussions of intimacy for labeled people. Sexuality education provides the foundation for 
having discussions about healthy relationships and intimacy for young people; this should be no different for labeled young people. Leslie Walker-Hirsch (2010) states:

Colleges and universities typically do not include sexuality education of children and teens with intellectual disabilities in the required preparation of special education teachers, or social workers and psychologists either for that matter. While special education teachers are well-versed in the aspects of addressing the unique learning styles of their students and the variety of teaching methods that have proven successful, they are not equipped, not comfortable, and often not permitted by their school boards to provide sexuality education to their students (p. 4).

This highlights the tension that many working in and advocating for sexuality education experience: parents and advocates want students to have information and be safe, but the desire to protect labeled students from "being victimized" (Walker-Hirsch, 2010, p. 4) supersedes. Staff, educators, and parents are either unprepared or unwilling to provide this information. Sexuality education provides foundation and guidance in navigating the complicated world of sexuality; more curricula need to address these foundations for labeled students, and educators need to be trained in order for the intimacy/normalization paradox to be addressed and the path towards oppression reversed.

Social work. Chambon (1999) states: social workers do not really start from "where the client is at. Clients do not exist outside of the historical activity of social work; they are the result of that activity" (p. 53). Through this lens, labeled individuals (as well as family, advocates, and allies) also become a part of this regime of truth associated with a discourse that is unique to social work. Social workers frequently become a part of 
labeled people's lives early on, usually through Individual Education Plans (IEPs). Social workers often serve as the case managers, school counselors, or administrators working to create person-centered plans through IEPs. As labeled people age, social workers continue to play a role in the person-centered process. Specifically focusing on social workers licensed through the National Association of Social Workers, I am going to use the Code of Ethics they are obligated to follow to guide the discussion of the intimacy/normalization paradox.

Social workers adhere to a Code of Ethics to guide practice. This Code is based on six core values: service, social justice, dignity and worth of the person, importance of human relationships, integrity, and competence (NASW Code of Ethics, 2008). I have discussed some of these core values in a previous work as they relate to sexuality education and ID (Winges-Yanez, 2015). These core values tend to closely mirror the main tenets of PCP. The paradox of intimacy/normalization has important implications for social work; the field would benefit from more advocacy and recognition of labeled people as sexual beings and the dismantling of stereotypes related to sexuality and ID that have persisted for so long.

As Chambon and Wang (1999) noted, normalization refers to "processes by which society (specifically, the human sciences and the helping professions) acts upon individuals and groups to regulate, shape, or make them conform to a norm" (p. 276). Social workers, then, are integral to this process of normalization. The Code of Ethics specifically provides guidance forward in this paradox discussion. 
Referring to the example of Harry's story, social workers should refer to the Code of Ethics when using the Donut exercise. Under the values of recognizing the importance of human relationships and integrity, social work would view the discussion of Harry's shirt as an opportunity to parse out the importance of this shirt and its message. Harry is exhibiting a desire to be viewed as a sexual being and attractive to someone at the administrative offices. By recognizing this desire, social workers could begin the conversation of boundaries and ascertain Harry's understanding of relationships. By having these conversations, Harry's integrity is respected and acknowledged, a core tenet of the Code of Ethics as well as PCP. Social workers have the tools and blueprint available to guide PCP into a more person-centered approach by unpacking the intimacy/normalization paradox.

Additionally, as noted by Walker-Hirsch (2010) and Ballan (2008), college social work education programs rarely discuss intellectual disability and sexuality. Social workers, therefore, lack critical coursework to work with labeled people in a socialecological framework because sexuality is not being addressed or even acknowledged. By referring to the Code of Ethics as a true guideline, social workers should start where the client is at and acknowledge the labeled person as a whole (sexual) person.

Social services. As discussed in chapter 5, direct support workers (DSWs) facilitate much of the direct support work done in social services, such as group homes, vocational rehab sites, independent contractors, and nursing homes. Especially in these services, the faux dichotomy of private versus public comes into play when addressing the intimacy/normalization paradox. 
DSWs face this paradox constantly, illustrated by the direction given by trainers such as Kendrick (2001), who stated "deeply personal matters...should rarely be the public work of organizations and professionals" (para. 34). Normalization frames intimacy as taboo for public discussion but also frames it as non-sexual and heteronormative. DSWs work in labeled people's homes and assist at their work sites and accompany them to social opportunities, all of which provide context for relationships to exist. The question then becomes, how do DSWs navigate this paradox given the normalization techniques in place (hegemony, for instance) while still providing person-centered services and supporting labeled people in their lives?

Perhaps mandatory conversations with the labeled people they serve can set expectations early on in working relationships, setting a course for DSWs to handle privacy and intimate matters while remaining professional. Their role is critical and already rife with blurred lines that they must manage. DSWs provide support in all aspects of life for some people, from daily living skills to social skills. In an article providing pointers to DSWs on the topic of sexuality and support, Arnold and Vincent-Pennisis (2010) write:

Direct Support Professionals (DSPs) have a rewarding, though at times challenging, role to fulfill. Challenges can be found particularly around support relating to sexuality. Perhaps this is because sex is often still a taboo topic for many people, and because of the contrasting values and beliefs different people have towards sexuality. And perhaps it is also due to the many myths regarding sexuality and disability, such as beliefs that people with disabilities are asexual or are incapable of having an intimate sexual relationship (p. 20). 
While the onus of policy falls onto organizational administrators, DSWs also hold power over how intimacy is addressed. Again, the tension that exists between intimacy and normalization can be addressed through written policy or by DSWs demanding a policy in order to effectively fulfill their duties. Perry Samowitz, senior director of education and training at the Young Adult Institute, states:

In order for an agency that serves people with ID/DD [sic] to provide the necessary supports for the social and sexual dimensions of life, there needs to a written social/sexual policy that clearly state the agency's philosophy and how it is specifically going to be implemented by staff. Careful plans are written so there is consistent treatment. Yet the issue of sexuality is often avoided, which allows staff to fill the vacuum with their own values and prejudices $(2009$, p. 18).

This discussion dovetails into the next paradox discussion of support/government. The issue of support as a DSW is complicated by the concept of government, both in the policies that are (or are not) provided by the support agency and in the government inherent to the person-centered plan.

\section{Support/Government}

Throughout the PCP process, a strategy of support is integral to governing the plan because various subjective positions help to create the plan, but the plan also governs support by creating a blueprint for staff, social workers, and family to follow. This reciprocal governance creates a paradox. Government names the process of conducting "one's relation to oneself, interpersonal relations that involve control or guidance, and relations within social institutions and communities" (Tremain, 2005, p. 8). The 
implications of this paradox extend to sexuality education, social work, and social services, too. Specifically, I looked at the tension of providing support to labeled people regarding their sexuality while acknowledging the government that simultaneously occurs in these areas.

Sexuality education. Sexuality education follows guidelines about what information is presented and how it is presented depending on the type of program offered. Educators use three types of school-based programs: abstinence only, abstinence plus, and comprehensive. Different regulations guide the information in these programs. The organization SEICUS provides an overall guideline for these programs. Special education and sexuality education programs for labeled adults use the same guidelines regarding information, but often use specific Special education teaching techniques to provide the information in a way that is effective. For instance, to be most effective for labeled learners, information needs to be repeated and concrete examples used (Walker-Hirsch, 2010).

Unfortunately, there are few effective curricula available (McDaniels et al., 2016), and many Special education teachers are not trained in providing sexuality education (Walker-Hirsch, 2010). Sexuality education aims to support people in knowing their bodies and navigating relationships through communication and education. In other words, support in the form of this education helps govern how successfully people navigate "one's relation to oneself, interpersonal relations that involve control or guidance, and relations within social institutions and communities" (Tremain, 2005, p. 8). Importantly, the 
existence and impact of actual support will depend on how the curricula and/or educators govern the information.

Students with disabilities are "entitled to free and appropriate education that meets their specific needs in the least restrictive environment, include[ing] sex education" (Barnard-Brak et al., 2014, p. 87). However, studies show that teachers are uncomfortable providing sex education and perceive the need for it as unnecessary for many students labeled with ID (Barnard-Brak et al., 2014). This reality shows how, here, government leads to a lack of support: teachers governing what information is relevant (for example, not sexuality education) means the support provided for healthy expression of sexuality is low. Combine this information with the dearth of effective curricula available for labeled students, and the government of labeled people's sexuality is one of protectionism and silence.

In a literature review on barriers to sexuality for labeled people, authors cite utilizing person-centered practices as a method to provide the "most educated and informed plans so that individuals can feel supported in searching for and maintaining healthy relationships" and align with "the sense of citizenry, self-control, and equitable access advocated by disability studies theorists" (Sinclair et al., 2015, p. 14). The authors also advocate for teachers to search through curricula to find appropriate programs for their students and to provide information to parents because "research shows that with education [labeled people] can make more informed sexuality related decisions, producing positive outcomes" (Sinclair et al., 2015, p. 14). In this example, the authors advocate for government of parents by teachers to better support their students through sexuality 
education. In this specific example, PCP is framed as a way to navigate the support/government paradox productively, emphasizing the holistic approach PCP tenets advocate for to include labeled people in sexuality education because sexuality education aids in labeled people successfully governing.

Social Workers. As discussed in my analysis, supports are necessary for living in the community, navigating community life, and creating a plan, as stated by Malette (2002):

Coordinated efforts among formal and informal supports are necessary components of successful planning, as well as the achievement of a quality life in the community for the focus person (pp. 151-152).

Social workers embody the formal supports of this description. However, the paradox of support/government is highlighted because in most work with labeled people (including PCP), the supports described necessitate government. Social workers theoretically meet clients where they are; meaning, social workers do not lead the process, but start from wherever the client is starting from. For example, a labeled person may advocate for getting a paid job. The case manager (social worker) does not choose the job but goes through a process of excavating information from the labeled person and their supports in order to find a suitable job that the person would be successful in and enjoy (theoretically). Social workers emphasize self-determination and advocacy. From this viewpoint, support/government work in harmony. A paradox emerges when social workers default to a belief of meeting the client where they at without taking into consideration historical stigma and oppressions. For example, a labeled person may not have the vocabulary to 
advocate for expressing a queer orientation or identity. In this situation, how would a social worker successfully advocate for queer socialization and opportunities given the lack of information and the lack of support social workers have in knowing these resources? The field of social work should better support workers in education and continuing training so that language, exposure, and opportunities can be based on to the labeled individuals they serve.

Referring to the research citing discomfort many feel in discussing sexuality with labeled people, social workers are not encouraged to advocate for healthy sexuality given the "well-being of society" and the "well-being of the individual" (NASW Code of Ethics, 2008) because of the hegemonic versions of well-being wherein labeled people are asexual or dangerous with their sexuality. By defaulting to a societal version (discourse) of wellbeing, social workers support labeled people to fulfill historical stereotypes and maintain these oppressions through governmental techniques, such as case management and uncritical facilitation of PCP. Given this default discourse, how can social workers support labeled people to live whole lives with integrity and self-determination? As evident in so many instances over history, the field must question the stereotypes and understand the context of their work.

Social services. Social services support labeled people through services such as vocational rehab, residential settings, and independent contractors. Through this support, though, social services govern labeled people to conform to appropriate societal norms. To use an example from the discourse analysis, Harry showed a desire to appear attractive and as a sexual being by wanting to buy a sexually explicit shirt. The support staff Harry was 
with was advised to discuss financial responsibilities instead of treading on Harry's right to buy the shirt (self-determination). However, the support staff (a DSW) could have helped Harry govern himself had he asked Harry about his knowledge of boundaries and intimacy. This support could have provided Harry the opportunity to effectively govern himself and his interactions with multiple people while also allowing the staff person to govern the situation as dictated in Harry's plan (allowing self-determination) by using effective support.

This example provides opportunity to analyze the paradox of support/government specifically looking at PCP, but it is not necessarily unique to PCP. Social services do, for the most part, proclaim to adhere to person-centered practices, but they may not use a specific plan. Regardless of whether the services have a plan in place, social service workers constantly walk the line of support/government. DSWs often support labeled people in a myriad of ways, whether that is financial management support or bathing. DSWs and social services must acknowledge this paradox of supporting people while simultaneously governing conduct of these same people or their attempts to support will always be clouded by the oppression of implicit governance. Again, are social services defaulting to a hands-off approach of self-determination instead of engaging in discussions that allow labeled people to truly govern their own conduct? Are social services willing to offer support that utilizes sexuality education and refuses the stereotypes of labeled people and sexuality in order to holistically support the labeled person to govern themselves? Continuing the status quo avoids this support in favor of more oppressive government. 
A Foucaultian Discourse Analysis 160

\section{Co-Creator/Subject}

Labeled people are functioning from a deficit that has nothing to do with functional assessments or impairments. Labeled people are functioning from a deficit in their own subjectivity - years of stigma and oppression that have been historically normalized as discussed in the genealogical framework. Subject refers to subject of discourse and subject to discourse; meaning, people unconsciously experience interpellation simply by existing and interacting in the world. Labeled people, then, create subjects that take into account the hegemonic understandings of ID, including the problematic ideas associated with sexuality and ID. Labeled people also live in a world governed by social services, social workers, parents, and society in general. To successfully navigate the world under these governments, labeled people must follow rules, leaving little room for identities and characteristics that are viewed as outliers. The paradox here: how does sexuality education, social work, or social services work to acknowledge and mitigate oppressive forces and facilitate labeled people as authentic co-creators of their lives when labeled people are governed by their own subjectivities they've created from a limited/limiting discourse? Again, the field should be aware of these forces and be critical during the PCP process as well as when interacting with labeled people. This is an example of the importance of knowing the history of labeled people as well as being mindful of socialization (interpellation) processes.

Sexuality Education. Sexuality education has worked to be inclusive over the past few years (Gowen \& Winges-Yanez, 2014). Programs attempt to represent varying races, ethnicities, orientations, and gender identities because sexuality is a part of the human 
experience. This can guide us as we approach sexuality education for labeled people. In one study asking queer youth about their experiences with school-based sexuality education, many commented that the curricula did not seem relevant to them, so they didn't pay much attention (Gowen \& Winges-Yanez). This response can be viewed as dangerous given studies citing sexuality education can help reduce negative outcomes for youth (Sinclair et al., 2015). In a study asking youth to identify ways sexuality education could be more inclusive for queer youth, one respondent said to:

...bring up the subjects instead of waiting for the questions to be asked...even if it makes people uncomfortable, you know, 'cause everything about it makes people uncomfortable, so...just try (Gowen et al., 2014, p. 794).

Another student said:

I think it would bring down bullying a lot more if they talked about it...if they taught about it more and talked about more, if it was okay to be gay...kids would be comfortable [with LGBTQ kids] (Gowen et al., 2014, p. 795).

I refer to these statements about LGBTQ issues because they hold an important lesson: the suggestions were to just talk about the issues so that all kids feel comfortable. This leads to LGBTQ youth creating their own subjects that have agency because they seem themselves included in the narrative of healthy sexual beings. Inclusive narratives are critical for labeled people, too.

Labeled youth do not see themselves in sexuality education. Many do not receive any sexuality education and those that do often receive very censored versions that avoid discussions of intimacy, orientation, or gender identity (Winges-Yanez, 2015). Instead, 
labeled youth are subject to narratives that posit labeled people as asexual, victims/perpetrators, child-like, and/or only heterosexual. This leaves a very limited range from which to create a subject and less room to co-create a narrative that includes healthy sexuality, queer identities, or agency.

Sexuality education needs to continue to work on inclusion, specifically for labeled students. Labeled students need to see themselves represented as complex sexual beings with information and resources available to them. This is one way to broaden the narrative from which labeled people will create their subjects and begin to change the narrative for those governing them because they will have the vocabulary and practice.

Social work. Social workers tout the importance of labeled people being selfadvocates and practicing self-determination. However, do they acknowledge that through the interactions labeled people have with social work, a "totalization [sic] and simultaneous individualization" (Foucault, 1997b, p. 336) occurs in which a narrative of "disabled versus abled" is constructed for them? Social work's primary focus is:

...to enhance human well-being and help meet the basic human needs of all people, with particular attention to the needs and empowerment of people who are vulnerable, oppressed, and living in poverty (NASW Code of Ethics, 2008, preamble, emphasis mine).

Social workers emphasize work with those who are "vulnerable, oppressed, and living in poverty," which individualizes them as members of these marginalized groups while also totalizing them as other. This narrative provides little opportunity for labeled people to see themselves as co-creators when they are identified in terms of marginalization. Assistance 
is required, through school, social services, or waiver programs. To revisit an example from Yates (2005), he talks about how two labeled individuals describe themselves:

The first thing to notice in Anne's and Paul's accounts is the way that they talk about themselves in relation to things that they can and cannot do and the way that they are expected to behave (p. 72).

Similarly, when the authors Dumas, De La Garza, Seay, and Becker (2002) discuss efficacy perceptions while using PCP, they state:

...many participants believed that person-centered planning gave them [labeled people] more control, albeit limited, because they also still believed that they had to accept whatever services and supports were offered to them (p. 237).

These examples illustrate labeled people having a subject status that is subject to a discourse of limitation, which is not conducive to being a co-creator in their own lives. In the last example, the fact that labeled people need a plan to be successful and exert coauthorship speaks to the "totalization and individualization" Foucault (1997b) claims occurs through the modern state and its institutions (p. 336).

Social services. Similar to social work, but broader in outreach, social services and DSWs govern labeled people, constantly exposing them to limiting narratives that juxtapose private with public. Social services and DSWs provide support for traditionally private activities, such as bathing and dressing, while also supporting labeled people with social skills in public situations. When the topic of sexuality is brought up, though, staff often refer to the argument that "intimacy is private and not the business of organizations" (Kendrick, 2001, para. 34). This argument adds to the narrative that if labeled people want 
to be intimate, they can figure it out on their own because they are co-creators of their plan/life, which is a convenient justification. This ignores the subjectivity of labeled people that has been exposed to narratives of asexuality and dangerous sexuality as well as ignoring the deficit labeled people function from (historical stigma and oppression). Additionally, as several studies have shown, staff are often unwilling to broach the topic of sexuality with labeled people for fear of "opening a can of worms," (Samowitz, 2010, p. 18) and also because there is little guidance from organizational policies. Therefore, labeled people who do interact with social services have little ability to authentically cocreate when their choices are oppressively governed.

In this discussion, social services provide the object discussed in the discourse analysis: the nondisabled helper. This nondisabled helper provides a specific narrative through consistent interaction. The question becomes: what is the narrative the nondisabled helper provides? As Samowitz (2010) hypothesizes, this person could "theoretically impose his or her values" (p. 18) onto labeled people as well as provide a lot

of input into PCP plans that govern labeled people's lives. Labeled people are also subject to the narrative that they require a nondisabled helper in order to succeed in life, so expecting labeled people to self-advocate and co-create plans that explore sexuality is unlikely.

\section{Biopower/Normalization}

Throughout the discourse analysis of PCP, various techniques, specifically normalization, act to oppress labeled people. However, the concept of biopower offers a pathway to productive forces, working within the oppressive forces. Biopower, as I have 
interpreted, refers to a mode of power acting on the level of population using normalization as a guide to foster life while also incorporating techniques that "classify, codify, manage, and control social anomalies through which some people have divided from others and objectivized..." (Tremain, 2005, p. 6).

Biopower is a productive form of power that has fostered life for labeled people through classification systems that require support services and social workers to support labeled people and their families. Families are also supported through support services and gain understanding of ID through these same support services. In this way, labeled people are experiencing life outside of institutions (for the most part) and are encouraged to be cocreators in their plans and life paths (theoretically). However, normalization has limited the narratives from which labeled people can construct their subjectivity and truly cocreate. Normalization provides for more oppressive government via support through these same limited narratives. Families and support people are not necessarily willing to advocate for or educate labeled people about sexuality, therefore ignoring an entire facet of someone's being. Or if they do advocate, a limited view of sexuality, one that is often rife with platonic relationships and heteronormative ideals, dominates. I discuss these implications for sexuality education, social work, and social services. Because biopower is a much more overarching concept, social work and social services share many implications. I try to parse out these differences, but the line is difficult to delineate.

Sexuality education. Sexuality education can be viewed as a form of biopower. Sexuality education provides guidance in how to have healthy sexual expression and relationships as well as how to practice good hygiene and safe sex (using contraceptives 
and barriers). In this way, the population is thriving through education in how to reproduce "appropriately" and "safely" while reducing transmission of sexually transmitted infections (STIs) and boosting the overall health of the population.

Society provides sexuality education to who it deems the productive people in the population, as evidenced by society not providing it, for the most part, to students with disabilities. Normalization refers to techniques that reify what is "normal" in a society. Intellectual disability is not normal, then. Society does associate some norms with ID: asexuality, victim/perpetrator, heterosexual, and perpetual child. Given these norms, sexuality education is not provided because it is unnecessary (asexuality), "opens a can of worms" (victim/perpetrator), or is not developmentally appropriate (perpetual child). If sexuality education is provided, a limited narrative of relationships is often presented (heterosexual or asexuality).

Sexuality education is supported through federal funding and by federal institutions. The Centers for Disease Control (2014) have an outline of 16 topics that should be covered in sexuality education. These topics relate to healthy behaviors related to sexuality, including "how to create and sustain healthy and respectful relationships" (CDC, 2014). This information would be beneficial to all people, including those labeled with ID. Biopower speaks to the population level of analysis and supports assessing norms that fall outside of the curve in order to bring it closer to the norm. This viewpoint directly affects labeled people and advocates for sexuality education for labeled people. 
For example, labeled people are sexually assaulted at a rate seven times that of nonlabeled people (Shapiro, 2018). According to a report for the Saskatchewan Prevention Institute in 2015 , sexuality education can:

...help to empower individuals with intellectual disabilities to explore their sexuality in positive ways, learn how to have healthy relationships, learn how to make their own decisions related to their sexual health, and reduce their vulnerability to sexual abuse (Saskatchewan Prevention Institute, 2015, p. 4, emphasis mine).

From this standpoint, then, normalization works within biopower to advocate for sexuality education to be provided to labeled people. In this example, biopower speaks to the codifying and classifying for the health of the population, which then can use normalization to advocate for providing sexuality education to labeled people. Additionally, the authors Sinclair, Unruh, Lindstrom, \& Scanlon (2015) note the addition of PCP into discussions of sexuality can align practices with the "sense of citizenry" advocated for by disability scholars (p. 14). Citizenry speaks to the population of a society, the health of which is of utmost importance in techniques related to biopower.

Unfortunately, normalization limits discussion of labeled people as healthy sexual beings. Biopower classifies, codifies and manages anomalies; in this case, the anomaly could be the high rates of sexual abuse occurring in the population of labeled people. This anomaly possibly raises rates of STI transmissions, unwanted pregnancies, and trauma, which again, affect the entire population, not just labeled people. 
Social work. Social workers are integral to biopower through the requirement of social work in the lives of labeled people. The label of ID, once assigned, opens the door to services for labeled people and families. This same label provides certain employment for social workers through specialization. Social work is also integral to normalization for labeled people because the helping professions are implicated in the managing of their behaviors for them to succeed in society. One way in that this occurs is through PCP.

Social workers work to provide information for the PCP plan and to facilitate the goals of this plan. But then, as mentioned, social workers often have little experience with advocating for healthy sexuality expression, especially if this expression is not viewed as necessary to succeed in society. Often, behaviors associated with problematic sexuality are addressed as opposed to healthy sexuality. In the example of Harry, sexuality was not addressed as an issue to be discussed with him until his past behaviors of stalking were brought up. These then become part of the plan (to keep Harry and others safe) and a part of his file.

The implications for social work to work within the paradox of biopower/normalization are thus complicated. Could social work use the necessity of the plan and the functional assessment to classify levels of knowledge associated with sexuality? Using these assessments, this classification could help advocate for sexuality education from a health standpoint. However, this would require the inclusion of sexuality into institutional classificatory practices that often reduce individuals to a support level/functioning level. The use of PCP could also aid in advocating for the inclusion of 
sexuality if social workers are willing to cite this as an integral facet of a typical life, as defined by the typical population.

Social services. The main mission of many social service agencies serving labeled people is to promote and maintain the health and safety of the labeled individual. This mission is foundational to additional priorities. Person-centered plans are also required for all persons receiving services for long term care services or home and community-based services by Section 2402(a) of the Affordable Care Act for all states receiving federal funds (www.medicaid.gov). Utilizing the normalization techniques of PCP, such as fostering goals to lead a typical life within the community, encourages a quality of life that has historically been impossible for labeled people. Biopower has helped produce our current understanding of ID through the classification and codification systems as well as providing the infrastructure for maintaining the support systems (social services) for labeled people, as required per classification. However, the mandate to provide a personcentered plan can be viewed as a pathway to reframing our understanding of ID.

PCP encourages support staff, social workers, families, and labeled people to envision a world that fosters inclusion and community. PCP also provides the guidelines for labeled people, and their supports, to live a typical life, their best life. This is one of the main tenets of PCP. Given this, it is impossible to separate sexuality from the personcentered process. Sexuality is innate to all humans, albeit is expressed differently by all humans. Labeled people who are expected to participate in this process of PCP and envision a typical life and advocate should also be expected and supported to explore their sexuality by the very processes of person-centered planning. 
As the main institutions of support for labeled people, social services should be the place that could provide this support and education. Given that many labeled people have limited social circles, despite goals of community inclusion and integration, social services should incorporate sexuality education and support into services. As Frawley and Wilson (2016) note in their work with labeled people regarding sexuality education:

In their life experiences they did not have places or relationships they could ask questions or rehearse their ideas about sex and relationships within. The young men reported having no or limited social networks and lacked regular contact with other young men in places where they could talk about these things (p. 475).

Using PCP tenets of relationships, community inclusion, dignity and self-determination and living as typical a life as possible, providing sexuality discussions and education are integral to social services providing supports to labeled people.

\section{Limitations}

Before closing, I must note the limitations of this work. First, a Foucaultian methodology is inherently not generalizable-- these discoveries can vary greatly depending on the researcher and the context. My interpretation is one viewpoint. Another limitation of this work lies in its scope. Given that this research was conducted for my doctoral work, I did not have the time to create a full genealogy of intellectual disability or analyze additional texts.

Finally, I want to acknowledge the lack of input from labeled people themselves. Because I analyzed an intervention (PCP) as it relates to labeled people and their lives, it would have seemed logical to solicit their input regarding my findings. However, there are 
some issues with this approach. The labeled people I currently work with have either become peer mentors in the PCP training or have gained much more independence due to the person-centered planning process. In Texas, state supported living centers are large institutions (similar to state hospitals like the now-closed Fairview in Oregon) that currently house many labeled people. Many people we work with have had some experience with the SSLCs, and person-centered planning has helped them to have more control over their lives. I did not feel comfortable having a discussion critiquing PCP given the benefits they have elicited from it. I did not think it would have been beneficial or fair to have these conversations given the reality of social services in Texas, where I currently reside. However, I do think this reality speaks to the heart of the paradoxes that exist in PCP and that the paradoxes are not unresolvable or absolute. The social services that use PCP garner very different results given the context they work within and the social service providers facilitating the process.

\section{Conclusion}

In this work, I have found implications for sexuality education, social work and social services. The paradoxes, I believe, offer fruitful ground for conversations on how to move forward in social work and provide opportunity and integration of labeled people into these discussions. Currently, we, as social workers and service providers, facilitate plans for how to support labeled people to live their best lives. Based on my analysis of the texts, these best lives do not include a necessary component: sexuality. The paradoxes discussed open the door to having these conversations. 
In thinking about how to move forward with this knowledge, I feel confident that I am already doing so. I cannot un-know the genealogical framework I drafted. This historical outline is part of every presentation I have with social service providers, every graduate student I work with, and every presentation I give at a conference. I advocate for the inclusion of labeled people into sexuality education and the inclusion of sexuality education into social services because the genealogical framework acknowledges the points when stereotypes and bad science were mistaken for facts and sexuality was twisted into something better left unsaid.

Instead, the paradoxes offer hope. I see social workers as social justice advocates who now know and must acknowledge the deficit from which labeled people are working from and the interpellation they experience every day; therefore, these social workers must, according to the Code of Ethics, advocate and support labeled people in all areas of life, including sexuality. Social service providers, as sites of biopower techniques, must adhere to PCP tenets and acknowledge the whole person, including their sexuality. Sexuality education must do better and provide accurate, comprehensive, and inclusive curricula for labeled people so they can be informed citizens of our community, the one they are expected to navigate successfully with support. As components of biopower, we must support labeled people through this governance (PCP plan) and acknowledge their sexuality, as with any person, in order to change the discourse of sexuality and ID to one that acknowledges the stereotypes for what they are and offers education and support.

Throughout my time reading Foucault's work, I became hopeful. Where I had previously believed that following Foucault's work was similar to taking the red pill from 
the film The Matrix, where a limitless rabbit hole opened up - a rabbit hole that was hopeless - I now see unlimited futures. Foucault (2000b) stated:

Maybe the target nowadays is not to discover what we are but to refuse what we are. We have to imagine and to build up what we could be to get rid of this kind of political "double bind" which is the simultaneous individualization and totalization [sic] of modern power structures (p. 336, emphasis mine).

I imagine what we, as social workers, sex educators, and social service providers, can do to refuse the subjectivity foisted upon us and upon labeled people. I imagine how we can enter these paradoxes, acknowledging their illogicality, in order to reframe the power structures in a way that causes them to be productive and life-giving. 


\section{References}

Alcorn, D.A. (1974). Parental views on sexual development and education of the trainable mentally retarded. The Journal of Special Education, 8(2), 119-130.

Arnold, S. \& Vincent-Pennisi, A. (2010). Sex, disability and the DSP: Ethically supporting sexual choices. Impact: Feature Issue on Sexuality and People with Intellectual, Developmental and Other Disabilities, 23(2), 20-21.

Ballan, M. (2008). Disability and sexuality within social work education in the USA and Canada: The social model of disability as a lens for practice. Social Work Education, 27(2), 194-202

Barnard-Brak, L., Schmidt, M., Chestnut, S., Wei, T., \& Richman, D. (2014). Predictors of access to sex education for children with intellectual disabilities in public schools. Journal of Intellectual and Developmental Disabilities, 52(2), 85-97.

Barry, D. (2016). The boys in the bunkhouse: Servitude and salvation in the heartland. New York, NY: HarperCollins Publishing.

Baynton, D.C. (2016). Defectives in the land: Disability and immigration in the age of eugenics. Chicago, IL: The University of Chicago Press.

Bedard, C., Zhang, H.L., \& Zucker, K.J. (2010). Gender identity and sexual orientation in people with developmental disabilities. Sexuality and Disability 28(3), 165-175.

Bernert, D. (2011). Sexuality and disability in the lives of women with intellectual disabilities. Sexuality and Disability, 29(2), 129-141.

Bigby, C. \& Frawley, P. (2010). Social work practice and intellectual disability. New York, NY: Palgrave Macmillan. 
Block, P. (2000). Sexuality, fertility, and danger: Twentieth-century images of women with cognitive disabilities. Sexuality and Disability, 18(4), 239-254.

Bruess, C.E. \& Schroeder, E. (2014). Sexuality education: Theory and practice (6 $6^{\text {th }}$ ed.). Burlington, MA: Jones \& Bartlett Learning, LLC.

Carlson, L. (2005). Docile bodies, docile minds: Foucauldian reflections on mental retardation. In S. Tremain (Ed.), Foucault and the government of disability (pp. 133-152). Ann Arbor, MI: The University of Michigan Press.

Carlson, L. (2009). The faces of intellectual disability: Philosophical reflections. Bloomington, IN: Indiana University Press.

Chambon, A.S. (1999). Foucault's approach: Making the familiar visible. In A.S. Chambon, A. Irving, \& L. Epstein (Eds.), Reading Foucault for social work (pp. 51-81). New York, NY: Columbia University Press.

Chambon, A.S. \& Wang, F.T.Y. (1999). Glossary. In A.S. Chambon, A. Irving, \& L. Epstein (Eds.), Reading Foucault for social work (pp. 269-280). New York, NY: Columbia University Press.

Cohen, A. (2016). Imbeciles: The Supreme Court, American eugenics, and the sterilization of Carrie Buck. New York, NY: Penguin Press.

David, H.P., Smith, J.D., \& Friedman, E. (1976). Family planning services for persons handicapped by mental retardation. American Journal of Public Health, 66(11), 1053-1057.

Davis, P. \& Faw, G. (2002). Residential preferences in person-centered planning: Empowerment through the self-identification of preferences and their availability. 
In S. Holburn \& P.M. Vietze (Eds.), Person-centered planning: Research, practice, and future directions (pp. 203-221). Baltimore, MD: Paul H. Brookes Publishing Co.

Dean, M. (1994). Critical and effective histories: Foucault's methods and historical sociology. London, UK: Routledge Books.

Dowling, M. (2012). Reflexivity. In L.M. Given (Ed.), The SAGE encyclopedia of qualitative research methods (p. 748). Thousand Oaks, CA: SAGE Publications, Inc.

Duke, T.S. (2011). Lesbian, gay, bisexual, and transgender youth with disabilities: A metasynthesis. Journal of LGBT Youth, 8(1), 1-52.

Dumas, S., De La Garza, D., Seay, P., \& Becker, H. (2002). "I don't know how they made it happen, but they did": Efficacy perceptions in using a person-centered planning process. In S. Holburn \& P.M. Vietze (Eds.), Person-centered planning: Research, practice, and future directions (pp. 223-246). Baltimore, MD: Paul H. Brookes Publishing Co.

Eastgate, G. (2008). Sexual health for people with intellectual disability. Salud publica de Mexico 50(2), s255-s259.

Eig, J. (2014). The birth of the pill: How four crusaders reinvented sex and launched a revolution. New York, NY: W.W. Norton \& Company.

Epstein, L. (1999). The culture of social work. In A.S. Chambon, A. Irving, \& L. Epstein (Eds.), Reading Foucault for social work (pp. 3-26). New York, NY: Columbia University Press. 
Faubion, J.D. (2014). Constantine Cavafy: A parrhesiast for the cynic of the future. In J.D. Faubion (Ed.) Foucault now: Current perspectives in Foucault studies (pp. 225242). Cambridge, UK: Polity Books.

Foley, S. (2012). Reluctant "jailors" speak out: Parents of adults with Down syndrome living in the parental home on how to negotiate the tension between empowering and protecting their intellectual disabled sons and daughters. British Journal of Learning Disabilities 41(4), 304-311.

Foucault, M. (1977). Discipline \& punish: The birth of the prison. (2nd ed.). New York, NY: Random House Books.

Foucault, M. (1980). Two lectures. (A. Fontana \& P. Pasquino, Trans.). In C. Gordon (Ed.), Power/knowledge. New York, NY: Vintage Books.

Foucault, M. (1990). The history of sexuality volume I: An introduction. (R. Hurley, Trans.). New York, NY: Random House Books. (Original work published 1976)

Foucault, M. (1997a). On the genealogy of ethics: An overview of work in progress. In P. Rabinow (Ed.), Ethics: Subjectivity and truth (pp. 253-280). New York, NY: The New Press.

Foucault, M. (1997b). The masked philosopher. (R. Hurley, Trans.). In P. Rabinow (Ed.), Ethics: Subjectivity and truth (pp. 321-328). New York, NY: The New Press.

Foucault, M. (1998a). On the archaeology of the sciences: Response to the epistemology circle. In J.D. Faubion \& P. Rabinow (Eds.), Aesthetics, method, and epistemology (pp. 297-333). New York, NY: The New Press. 
Foucault, M. (1998b). Nietzsche, genealogy, history. In J.D. Faubion \& P. Rabinow (Eds.), Aesthetics, method, and epistemology (pp. 369-391). New York, NY: The New Press.

Foucault, M. (2000a). About the concept of the "dangerous individual" in nineteenthcentury legal psychiatry. In J.D. Faubion \& P. Rabinow (Eds.), Power (pp. 176200). New York, NY: The New Press.

Foucault, M. (2000b). The subject and power. In J.D. Faubion \& P. Rabinow (Eds.), Power (pp. 326-348). New York, NY: The New Press.

Foucault, M. (2003). Abnormal: Lectures at the College de France 1974-1975. (G. Burchell, Trans.). (New York, NY: Picador Press. (Original work published in 1999)

Foucault, M. (2006). Psychiatric power: Lectures at the College de France 1973-1974. (G. Burchell, Trans.). New York, NY: Picador Press. (Original work published in 2003)

Foucault, M. (2010). Archaeology of knowledge. (A.M. Sheridan Smith, Trans.). New York, NY: Vintage Books. (Original work published 1969)

Frawley, P. \& Wilson, N. (2016). Young people with intellectual disability talking about sexuality education and information. Sexuality and Disability, 34(4), 469-484.

Garland, D. (2014). What is a "history of the present"? On Foucault's genealogies and their critical preconditions. Punishment \& Society, 16(4), 365-384.

Garrity, Z. (2010). Discourse analysis, Foucault and social work research: Identifying some methodological complexities. Journal of Social Work, 10(2), 193-210. 
Gill, M.C. (2009). Intellectual disability and sexuality: Challenging paternalism, harm reduction, and incompetence. ProQuest Dissertations and Theses, 232. Retrieved from http://search.proquest.com/docreview/276216526?accountid=13265.

Goodey, C.F. (2011). A History of intelligence and "intellectual disability": The shaping of psychology in early modern Europe. London, UK: Routledge Books.

Gougeon, N.A. (2009). Sexuality education for students with intellectual disabilities, a critical pedagogical approach: Outing the ignored curriculum. Sex Education, 9(3), 277-291.

Gowen, K. \& Winges-Yanez, N. (2014). Lesbian, gay, bisexual, transgender, queer, and questioning youths' perspectives of inclusive school-based sexuality education. Journal of Sex Research, 51(7), 788-800.

Graham, L.J. (2011). The product of text and "other" statements: Discourse analysis and the critical use of Foucault. Educational Philosophy and Theory, 43, 663-674.

Hammar, S. I.., Wright, L. S., and Jenson, D. L. (1967). Sex education for the retarded adolescent: A survey of parental attitudes and methods of management in fifty adolescent retardates. Clinical Pediatrics, 6, 621-627.

herising, F. (2005). Interrupting positions: Critical thresholds and queer pro/positions. In L. Brown \& S. Strega (Eds.), Research as resistance: Critical, indigenous, \& antioppressive approaches (pp. 127-151). Toronto, ON: Canadian Scholars' Press.

Holburn, S. \& Vietze, P.M. (2002). Person-centered practice: Research, practice, and future directions. Baltimore, MD: Paul H. Brookes Publishing Co. 
Hook, D. (2005). Genealogy, discourse, "effective history": Foucault and the work of critique. Qualitative Research in Psychology, 2(1), 3-31.

Institute for Person-Centered Practices. (2012). Person-centered thinking training. Austin, TX. The Learning Community.

Jenkins, S.C. (2012) Disabling ethics: A genealogy of ability (Unpublished doctoral dissertation). Pennsylvania State University, State College, PA.

Kelly, G., Crowley, H., \& Hamilton, C. (2009). Rights, sexuality and relationships in Ireland: "It'd be nice to be kind of trusted." British Journal of Learning Disabilities, $37(4), 308-315$.

Kendall, G. \& Wickham, G. (1999). Using Foucault's methods. London, UK: SAGE Publications Ltd.

Kendrick, M.J. (2001). Opening keynote presentation for the Congress "Crossing Boundaries". Wageningen, Netherlands.

Kincaid, D. \& Fox, L. (2002). Person-centered planning and positive behavior support. In S. Holburn \& P.M. Vietze (Eds.), Person-centered planning: Research, practice, and future directions (pp. 29-49). Baltimore, MD: Paul H. Brookes Publishing Co.

Klatt, K.P., Juracek, D.B., Norman, K.R., McAdam, D.B., Sherman, J.A., \& Sheldon, J.B. (2002). Evaluating preferred activities and challenging behavior through personcentered planning. In S. Holburn \& P.M. Vietze (Eds.), Person-centered planning: Research, practice, and future directions (pp. 315-332). Baltimore, MD: Paul H. Brookes Publishing Co. 
Koopman, C. (2013). Genealogy as critique: Foucault and the problems of modernity. Bloomington, IN: Indiana University Press.

Kulick, D. \& Rydström, J. (2015). Loneliness and its opposite. Durham, NC: Duke University Press.

Levin, G. R. and Simmons, J. J. (1962). Response to food and praise by emotionally disturbed boys. Psychological Reports, 11, 539-546.

The Lewin Group. (2008). A synthesis of direct service workforce demographics and challenges across intellectual/developmental disabilities, aging, physical disabilities and behavioral health. Washington, DC: Author.

Lofgren-Martenson, L. (2004). "May I?" About sexuality and love in the new generation with intellectual disabilities. Sexuality and Disability 22(3), 197-207.

Lovaas; 0. I., Freitag, B., Kinder, M. I., Rubenstein, B. D., Schaeffer, B., and Simmons, J. Q. (1966). Establishment of social reinforcers in two schizophrenic children on the basis of food. Journal of Experimental Child Psychology, 4, 109-125.

Magito-McLaughlin, D., Spinosa, T.R., Marsalis, M.D. (2002). Overcoming the barriers: Moving towards a service model that is conducive to person-centered planning. In S. Holburn \& P.M. Vietze (Eds.), Person-centered planning: Research, practice, and future directions (pp. 127-150). Baltimore, MD: Paul H. Brookes Publishing Co.

Malette, P.H. (2002). Lifestle quality and person-centered support: Jeff, Janet, Stephanie, and the microboard project. In S. Holburn \& P.M. Vietze (Eds.), Person-centered 
planning: Research, practice, and future directions (pp. 151-179). Baltimore, MD: Paul H. Brookes Publishing Co.

Mansell J. \& Beadle-Brown, J. (2003). Person-centered planning or person-centered action? Policy and practice in intellectual disability services. Journal of Applied Research in Intellectual Disabilities, 17(1), 1-9.

Marinucci, M. (2010). Feminism is queer: The intimate connection between queer and feminist theory. London, UK: Zed Books Ltd.

McDaniels, B. \& Fleming, A. (2016). Sexuality education and intellectual disability: Time to address the challenge. Sex and Disability 34, 215-225.

McDonagh, P. (2008). Idiocy: A cultural history. Liverpool, UK: Liverpool University Press.

McKee, K. (2009). Post-Foucauldian governmentality: What does it offer critical social policy analysis? Critical Social Policy 29(3), 465-486.

McRuer, R. (2006). Crip theory: Cultural signs of queerness and disability. New York, NY: New York University Press.

McWhorter, L. (2009). Racism and sexual oppression in Anglo-America: A genealogy. Bloomington, IN. Indiana University Press.

McWhorter, L. (2009). Racism and sexual oppression in Anglo-America: A genealogy. Bloomington, IN: Indiana University Press.

Milligan, M.S. \& Neufeldt, A.H. (2001). The myth of asexuality: A survey of social and empirical evidence. Sexuality \& Disability, 19(2), 91-109. 
Mitchell, L.K. (1977). A program for modifying sexual behavior in the retarded. (Unpublished doctoral dissertation). California State University, Northridge, CA.

Mollow, A. \& McRuer, R. (2012). Introduction. In R. McRuer \& A. Mollow (Eds.) Sex and disability (pp. 1-34). Durham, NC: Duke University Press.

Neely-Barnes, S., Marcenko, M.,, \& Weber, L. (2008). Does choice influence quality of life for people with mild intellectual disabilities? Intellectual and Developmental Disabilities, 46(1), 12-26.

O'Brien, C. (1999). Contested territories: Sexualities and social work. In A.S. Chambon, A. Irving, \& L. Epstein (Eds.), Reading Foucault for social work (pp. 131-155). New York, NY: Columbia University Press.

Oliver, M. (1996). Understanding disability: From theory to practice. London, U.K.: Macmillan.

Parton, N. (1999). Reconfiguring child welfare practices: Risk, advanced liberalism, and the government of freedom. In A.S. Chambon, A. Irving, \& L. Epstein (Eds.), Reading Foucault for social work (pp. 101-130). New York, NY: Columbia University Press.

Philp, M. (1979). Notes on the form of knowledge in social work. The Sociological Review, 27(1), 83-111.

Pitceathly, A. \& Chapman, J. (1985). Sexuality, marriage and parenthood of mentally retarded people. International Journal for the Advancement of Counselling, 8(3), $173-181$. 
Redl, F. \& Wineman, D. (1951). Children who hate: The disorganization and breakdown of behavior controls. New York, NY: Free Press.

Richards, D., Miodrag, N., \& Watson, S. L. (2006). Sexuality and developmental disability: Obstacles to healthy sexuality throughout the lifespan. Developmental Disabilities Bulletin, 34, 137-155.

Richards, D. A., Watson, S., Monger, S., \& Rogers, C. (Ed.). (2011). The right to sexuality and relationships. St. Catharine's, ON: The 3Rs Community University Research Alliance.

Rogers, C. (2009). (S)excerpts from a life told: Sex, gender, and learning disability. Sexualities 12(3), 270-288.

Samowitz, P. (2010). A sexuality policy that truly supports people with disabilities. Impact: Feature Issue on Sexuality and People with Intellectual, Developmental and Other Disabilities 23(2), 18-19.

Samuels, E. (2014). Fantasies of identification: Disability, gender, race. New York, NY: New York University Press.

Sanderson, H. (2002). A plan is not enough: Exploring the development of person-centered teams. In S. Holburn \& P.M. Vietze (Eds.), Person-centered planning: Research, practice, and future directions (pp. 97-126). Baltimore, MD: Paul H. Brookes Publishing Co.

Saskatchewan Prevention Institute. (2015). Sexual health education for adolescents with intellectual disabilities: A literature review. Saskatchewan, Canada: Kaylee Ramage. 
Schalock, R.L., Luckasson, R.A., \& Shogren, K.A. (2007). The renaming of "mental retardation": Understanding the change to the term "intellectual disability." Intellectual and Developmental Disabilities, 45(2), 116-124.

Siebers, T. (2008). Disability theory. Ann Arbor, MI: University of Michigan Press.

Sinclair, J., Unruh, D., Lindstrom, L., \& Scanlon, D. (2015). Barriers to sexuality for individuals with intellectual and developmental disabilities: A literature review. Education and Training in Autism and Developmental Disabilities, 50(1), 3-16.

Skehill, C. (2008). Researching the history of social work: Exposition of a history of the present approach. European Journal of Social Work 10(4), 449-463.

Smith, J.D. \& Wehmeyer, M.L. (2012). Who was Deborah Kallikak? Intellectual and Developmental Disabilities, 50(2), 169-178.

State Laws Regulating Marriage of the Unfit. (1913). Journal of the American Institute of Criminal Law and Criminology, 4(3), 423-425. Retrieved from http://www.jstor.org/stable/1133362

Strega, S. (2005). The view from the poststructural margins: Epistemology and methodology reconsidered. In L. Brown \& S. Strega (Eds.), Research as resistance: Critical, indigenous, \& anti-oppressive approaches (pp. 199-235). Toronto, ON: Canadian Scholars' Press.

Swango-Wilson, A. (2008). Caregiver perceptions and implications for sex education for individuals with intellectual and developmental disabilities. Sexuality and Disability 26(3), 167-174. 
Swango-Wilson, A. (2010). Systems Theory and the Development of Sexual Identity for Individuals with Intellectual/Developmental Disability. Sexuality and Disability, 28(3), 157-164.

Taylor-Gomez, M. (2012). The S words: Sexuality, sensuality, sexual expression and people with intellectual disability. Sexuality and Disability 30(2), 237-245.

Thi Nguyen, T. S. (2012). Peer debriefing. In L.M. Given (Ed.), The SAGE encyclopedia of qualitative research methods (pp. 604-605). Thousand Oaks, CA: SAGE Publications, Inc.

Thompson, S.A. (2007). De/centering straight talk: Queerly informed inclusive pedagogy of gay and bisexual students with intellectual disabilities. Journal of LBGT Youth, $5,37-56$.

Tremain, S. (2005). Foucault, governmentality, and critical disability theory: An introduction. In S. Tremain (Ed.), Foucault and the government of disability (pp. 1-24). Ann Arbor, MI: The University of Michigan Press.

Tremain, S. (2013). Educating Jouy. Hypatia 28(4), 801-817

Trent, Jr., J.W. (1994). Inventing the feeble mind: A history of mental retardation in the United States. Berkeley, CA: University of California Press.

Villadsen, K. (2008). Freedom as self-transgression: Transformations in the "governmentality" of social work. European Journal of Social Work, 11(2), 93104. 
Walker-Hirsch, L. (2010). Sexuality meets intellectual disability: What every parent should know. Impact: Feature Issue on Sexuality and People with Intellectual, Developmental and Other Disabilities 23(2), 4-5.

Wang, F.T.Y. (1999). Resistance and old age: The subject behind the American Seniors' Movement. In A.S. Chambon, A. Irving, \& L. Epstein (Eds.), Reading Foucault for social work (pp. 189-217). New York, NY: Columbia University Press.

Weeks, J. (1998). The sexual citizen. Theory, Culture \& Society, 15(3-4), 35-52.

Wehmeyer, M.L. (2002). The confluence of person-centered planning and selfdetermination. In S. Holburn \& P.M. Vietze (Eds.), Person-centered planning: Research, practice, and future directions (pp. 51-69). Baltimore, MD: Paul H. Brookes Publishing Co.

Wehmeyer, M.L. (2013). The story of intellectual disability: An evolution of meaning, understanding, and public perception. Baltimore, MD: Paul H. Brookes Publishing Co.

Werner, S. \& Grayzman, A. (2011). Factors influencing the intention of students to work with individuals with intellectual disabilities. Research in Developmental Disabilities, 32(6), 2502-2510.

Winges-Yanez, N. (2014). Why all the talk about sex? An autoethnography identifying the troubling discourse of sexuality and intellectual disability. Sexuality and Disability 32(1), 107-116.

Winges-Yanez, N. (2015). Discourse analysis of curriculum on sexuality education: FLASH for special education. Sexuality and Disability 32(4), 485-498. 
Yang Tan Institute. (2017). Person centered planning education site. Course 1: Introduction to person-centered planning. Cornell University ILR School Employment and Disability Institute.

Yates, S. (2005). Truth, power, and ethics in care services for people with learning difficulties. In S. Tremain (Ed.), Foucault and the government of disability (pp. 6577). Ann Arbor, MI: University of Michigan Press. 


\section{Notes From Voice Recorder}

\section{Appendix A}

\section{October 4, 2017 11:03 am}

I'm looking at how to fully identify enunciative modalities. I have historically understood this to be the authority one has to make statements, as in when a doctor can identify symptoms and prescribe or identify sicknesses, um, because that person is a doctor. I don't think that is fully what enunciative modalities encompasses, so I will be looking at the Archaeology of Knowledge as well as, uh, some secondary sources to try to sift through and try to find a more robust way of understanding what enunciative modalities are and I am working on identifying the three texts that I'm analyzing, which is the PCP training, the textbook on PCP foundations, and an online training module for PCP to assert that they are in fact related and share the same four components of a discourse: object, enunciative modality , concepts, and strategies - however, the concepts I've already put forth from the literature associated with the discourse of ID, which is subject, government, biopower, and normalization. So, um, we are looking at those right now. I would say that just through my initial readings and after my training that I do think these discourses are related. Through my analysis, the object does appear to be ID as the object and subject of the text. I'm really looking at concepts also to see if I can find examples of them throughout the texts to identify if there are additional concepts or if those concepts don't work...so I'm working on that. The strategies also seem to be similar...and I am on working on what strategies are emerging, however, the enunciative modalities is where I'm a little bit iffy and I just want to make sure I'm looking at the right thing. As it stands, from my understanding of enunciative modality, the authority to do PCP comes from expert standpoint, expert in human sciences, usually, a trainer who has been trained in this or a social worker who has been trained in this. Other people take this training or read up on these trainings, however they generally dont provide the full on PCP process which includes an ELP or a PATH or Circles of Support or something, but they are the ones carrying it out - which is interesting if they are not fully trained or they do not fully understand the concepts, are they truly adhering to the model? My understanding of enunciative modality is are these human service professionals and experts also.... when we're looking at this, it's usually a team meeting and everyone is included in this meeting who could have insight. So, if we're going to an institution, the facilitator suggested having everyone be in on the meetings including janitors and cafeteria workers, etc, so that we can get a full understanding of this person. However, that's not always possible and I wonder, given that the person running the meeting is the one who is relaying back this information while checking in with everyone who is contributing to the meeting, making sure they are writing down the info accurately - they are still the ones putting out this plan and figuring out ways to move forward. I still think the enunciative modality would fall onto that human services professional - but we're going to look more into that and then move into strategies to see what themes emerge. That is going to be an area that will dovetail, I think, into a further analysis of what is this discourse revealing using a genealogical framework, which is not 
being used at this moment, to identify if they are related. The next step will be to look at what discourse is revealed using a genealogical framework, so I think what strategies are used will come up again. My next step is to look at Archaeology of Knowledge and secondary sources to become familiar with a fuller understanding of enunciative modalities and strategies.

\section{0/4/17 11:38 am}

I'm going over the AofK and there's a description of statements, I need to look at this more for later analysis. Graham also does a lot of work on statements, but the second to last paragraph on page 117 in AofK....discursive practices:....[reading].

Reading that, it would seem the discursive practice here is PCP and what comes from that are the discursive formations, which I'm going to look at a little bit more and then statements are going to be the function of these discursive formations, I think, which I'm going to go into a bit more. I know statements act as a function in society, according to Graham, so I'm going to look at that a little more, which is what I'm hoping to kind of identify through the analyses of the texts, so I might need to redo a little bit of methodology and I'm going to go back and look at discursive formations...he does say [pg 116] [reading]...that is what he is calling a discursive formation. INstead of enunciative modality, he is saying subjective positions. [reading...statements...] "a statement belongs to a discursive formation as a sentence belongs to a text"

\section{0/4/17 3:38pm}

I think I need to change the phrase "enunciative modalities" to [subjective positions]. I don't think enunciative modalities is the right phrase given that it keeps being used in relation to the sentence, articulation ...I need to change that to subjective positions - note to myself.

\section{$\underline{10 / 4 / 173: 57 p m}$}

I keep going back and forth on this AofK trying to really hammer home the four formations are of a discourse: object, I understand; enunciative modalities, which is going to be rephrased - but it does seem to relate to the rules of who can speak who can make the statements...who leads or constructs this discourse. Not so much people as institutions and people within the institutions, so I think that has remained. Concepts: as i'm looking through seem to be discussing the formations of the discourse -rules of the discourse- how did these rules come about...so looking at page 62: it is not an inexhaustible ...[reading] I think that this is a good description of looking at concepts as a rule of formation in how things are either part of a discourse or not part of a discourse, the concepts range...it can be something that specifically not exist in a particular discourse and still be a part of the wider discourse. So if I'm thinking of the four I've already put into the graph: normalization, subject, biopower, government we can see the emergence of these concepts through the genealogical framework, but without that we can see that these concepts emerged in the earlier 20th century and have remained part of the discourse that is associated with ID up 
until present day. We saw the emergence of biopower specifically when we were looking at who was segregated and who was not and when we're looking at government we are looking at how people were governed and how people governed themselves within these serrated institutions, societies, obviously within biopower we see a whole other more current iteration of biopower in eugenics which is continued today in coexistence with the previous iteration of biopower which was segregation by gender. Also, subject throughout and normalization really begin to take hold in the earlier 20th century, however it has changed how it is viewed. Normalization was - they are not normal and must be kept separate - now it is they are special or have exceptional needs. Again it is a different iteration of the same concept. These concepts have not been ahistorical, but did arise in the early 20th century and have continued to shape the discourse of ID. In fact, I should see how ID the term has been changed using these concepts. ... anyway, looking at PCP, I can see all of these concepts emerging are related. The object is the same, I'm going to look at strategies and government, however these texts do seem to discuss government in a specific sense in that PCP is a PLAN. IT's a plan of how staff are going to interact with the person who is labeled but it also an implicit plan for the person - in that they have this plan now and how they are going to live and move forward. Again, it's important to understand that power is not one sided but it is productive. These plans have allowed people to live in the community - and I say ALLOWED because that is exactly how it has been put forth. I can find examples of all of this in each text $i$ have looked at. IF there are any examples of concepts that go against the concepts that have been predetermined, that too could be an indicator that it is still a part of the discourse in that it is different or possibly opposite, but I will see if that has happened.

Foucault talks a lot about how discourses are different based on these four formations over time how a discourse of economics is different from the 14th century to the 17th century (this is not verbatim, but a summary of what i read) however if $i$ am looking at the discourse from the early 20th century, I am not necessarily seeing a difference and i think that is part of the issue when looking at the discourse that it has not changed. So, it appears it is a historical, even though there are new iterations, they have not completely done away with the previous understandings, they've only built on them so that those become implicit versus explicit. I am not saying that implicit is what is not said or the hidden meaning (which is in opposition to Foucault's work) but $\mathrm{i}$ am saying that they do still exist. They have been built upon, they act as the foundation of current iterations and I think we can still see examples of all of those in play. Perhaps I can look at different local examples and that would change, but only slightly...this may not be a part of the analysis at this point, perhaps later on, but as I'm looking at the different texts, i think naïveté comes to mind. Looking at the fact that this practice [pcp] has been in play for about 30 years and not much has changed, and $i$ think that people within the movement would be very much divided on that point.

I'm going to look at strategies now and that will be the next recording: to pick apart what strategies especially mean and to make sure $i$ am clear on them as $i$ am now on enunciative modalities and concepts and strategies...I'm looking at right now and I'm going to move 
into statement. I think statement is going to be the next level of analysis when I'm looking at what discourses emerge or what that discursive formation is that emerges out of PCP after I've made sure that these are related to $\mathrm{s}$ the same discourse (which $\mathrm{i}$ feel fairly confident in). I wasn't so sure the online one was, but that is the only holdout. Right now I'm focusing on picking apart the training while its still clears in my mind. I do have the training binder so I can go back and once Ive done that, I will go back to the online one because that is the one I have questions about...if it is tangential in relation...i don't know, i'll see.

\section{0/6/17. 2:56pm}

I'm starting looking into the online training in order to see its relation to the overall texts of PCP including the training and the book. So in the beginning on the first page it says: Simply thinking we are being person centered does not make us person centered, it's what we actually do that ultimately reveals our true priorities... which means engaging in conscious awareness and self-reflection about the relationships between how one thinks, feels and acts...it's beliefs....All of this seems to be echoing the other trainings. It's hard to not go into analysis right away using my framework, and doing just the preliminary work to make sure they are actually all a part of the same discourse, so I keep going back and making sure I'm not doing that. It's hard, though. There's an interesting line in here that says: It's always a sign of hope when people sincerely come together to take stock and correct past errors and to dedicate themselves to future progress ...I think that saying correct past errors is kind of a weird phrase to use. There's no way to correct how people were treated historically or not even that far long ago - or currently. There's no way to correct. There's ways to change now... anyway, I just find that strange. I think a theme that I am seeing is ..maybe not so much in the training but in the book and the online work that I'm reading right now is to emphasize that we are all sharing the (the written sentence is not written right) so sharing in the same intrinsic humanity....common human family. It reeks of color blindness that seems to have finally begun to lose trend in current society - but it is still pretty prevalent in the world of disabilities such as when people are saying differing abilities and differently abled- it's a way to normalize the person in a way that almost erases what is unique about them. It's also a different side of the same coin to at the same time...it provides opportunity for people to say special needs or exceptional needs... which is also not helpful.

So the beginning of this training really encourages people to be reflective of their beliefs and preconceived notions in order to move forward. I just go through reading the first part by Kendrick... and there's a lot of his work in here. A lot of his concepts he was bringing up are ones that $\mathrm{i}$ would generally put under the concept of normalization or biopower, government...there are some other ones that kind of float in and out, but I want to see how prevalent they are throughout. Obviously if they keep coming up that will add to the concepts. Right now the person with ID or disabilities is still the object so far...strategy and subjective position.... still echoing the other two texts so I'm going to keep going and see what else comes up here. 
Kendrick is very concerned with self-reflection and moving forward in this type of approach. Again, he says: what is truly in our hearts will eventually show itself for what it really is...it will be our deeds that matter in particular...it will be very important to not lose sight of the intentions and motives that lie behind our words. I just have a lot of trouble with that. That is exactly what has been the undoing of good work in the past. Hiding behind good intentions.

Looking at concepts...maybe strategies...something that does come up a lot in PCP flexibility and creativity are actually really important to this approach. I need to see where that would fit in. I think that it is really important. Individualization is really important to this approach, each person has their own meeting and has their own form of plan and creativity and flexibility lend to this person centeredness and individualization that happens...we need to see how that works. I think the strategy is actually creativity/flexibility, $i$ think those two are interwoven for many reasons. I think those would be the strategies and then the concept would be individualization in that this plan cannot be - plans cannot be one size fits all. However the approach is also something...pcp is an approach...and there are standard ways to do it, however, i think one of the key ideas is that it is still individualized.

I think that $\mathrm{i}$ would change that creativity is a strategy of the discourse because it is not a strategy of the DISCOURSE, it's of the plan - which is different. Again, it's hard to go through and look at the relation of the texts as one discourse as opposed to each text to see what is being put forth, so that's my difficulty right now. I would still say that individualization through creativity is possibly a concept that is touted throughout the discourse...I'm looking at some of my notes on the discourse of the book that i was looking at and there are approximately 6 ideals that are held up - i say ideals so as not confuse the term concept - that PCP puts forth in its work of what it means to use PCP, so those are going to be different from the actual discourse. That's what I am trying to pick apart right now (which is another one of my favorite phrases).

Okay, so creativity is NOT a strategy but individualization through creativity is possibly a concept if - it's hard to - I think right now I'm trying to kind of understand what concepts are this discourse (the RULES of this discourse) and the strategies of this discourse as opposed to the what the approach says. That's where it becomes really hazy looking at something. So, if you're talking about a medical discourse, a concept of a discourse on cancer is not necessarily going to be talking about the specifics of cancer, it's going to be talking about causes or treatments - not the specific causes or treatments, though. The strategies are going to be medical terminology - no. Strategy. Is the theme...so strategy would be awareness or prevention. I think that that is what I need to be holding in my head and it feels like holding 5 (arbitrary number) different levels of analysis at the same time and that's where it becomes confusing. I don't want to fuck up the analysis and look at one 
thing when I'm actually analyzing another thing altogether...or place one level in another level. That's my challenge right now.

\section{$\underline{10 / 6 / 175: 51 \mathrm{pm}}$}

I have just redone my graph. I took out the predetermined concepts so I can look at this right now clearly. I have the texts: training, online, and book and the vertical lines are object, subjective positions, strategy, and concepts. Overall, this is the umbrella of PCP, theoretically. I'm going to use this graph right now to kind of see what concepts are emerging. I have the background of Foucault in there...I think for the overall discourse relationships, I need to start from here and then moving forward, when I'm looking at statements for different parts of the overall discourse. I think i might reintroduce the predetermined concepts - they might come up now? I'm not sure, it feels too clunky and too inorganic to be looking at this using the predetermined concepts. I'm going to move forward therefore without the predetermined concepts and see what emerges. As I'm looking through these works, the person labeled with ID has been object but i feel like there has always been this underlying object maybe that's there and $i$ can't pinpoint it- if it's the service provider or ...I'm not sure what the object is? Is the object the method (plan)? I don't know, there seems to be an underlying thing that's nudging me whenever i look at object, like: it IS the person that's labeled, that's always the person being talked about, so that is always an object. But there might be other objects, there doesn't just have to be one, and $i$ think there's another at least, that's there and it's not emerging because I'm not "allowing" it to...? I'm going to sit with some of this as i read through and see what is coming up right now. Talking this out is really helpful and then typing out what I've recorded helps me see what I'm thinking- this is much better than writing because i stop writing when I'm thinking. This is acting as my reflexive journal, also, because I'm interacting with the material and thinking through it and interacting with some of the other works...

I think one thing that is interesting is that as I've been analyzing these works and looking at different things emerging and relationships - i really find it helpful to keep Foucault's concept of power and how it is productive as well as possibly oppressive - that it's an ongoing relationship- has helped me see a balance when I'm looking at this approach because as I've stated, I have a bias going forward because I've worked in organizations that have used PCP and I've seen how it has not been held to fidelity and how people have manipulated it saying it is the person's choice - which relieves staff (or whoever) from any responsibility and then i can see people manipulate it in ways where the person says they are trying to "help" the person, which is really just creating a plan for another person without real input from the person. I've seen all this happen to this training and i had some questions about the training and some of the approaches - but this approach HAS opened doors for many many people and it has kind of changed the paradigm of how certain service providers approach works for people who are labeled. I think looking at it as a flawed approach, which is definitely what it is - I don't know how it could not be or how any 
approach could not be, really - so i think moving forward, it is kind of ...it is a different way to see things and reminding myself of this [the power relationship] has really opened up the analysis and allowed the works to speak more a little bit more. I think all of this sounds hokey, but that is how it has been proceeding, which has been really interesting.

Looking at different parts of the training, the in-person training, some subjective positions we can see are definitely parents, all the facilitators were parents. We can also see service providers, because they were also providers and most people in the training were providers of some sort. I don't think that parents are just the training - i see a lot of PCP came from parents because a lot of the advocacy movement is from parents, so i see that just kind of dovetail into today's work.

Looking at object, we are definitely going to see the labeled person in all of these. Again, though, there are other ones emerging that $i$ haven't been able to pinpoint...it's been a little...when looking at an approach for service [like PCP] for providers, it's hard to identify specific object or objects because this is for how to provide service for a whole population - it becomes that "level" problem I talked about earlier.

Strategies: when looking at strategies, themes that came up in the training and then concepts. I think another confusing thing is Foucault's version of normalization and Wolfensberger's version has been confusing because there is a thin line between those two where Wolfensberger's version is that people should be living their best life despite any sort of impairments and we should be interdependent with each other in providing that good life to whomever, whereas Foucault's is there is a version of what normal is and that is what is considered the ideal and everything else gets taken out to the margins. So, if you don't fit that version of normal, you become marginalized. But looking at the concepts, though, what comes up is not Foucault's version of normalization but Wolfensberger's because what is often brought up and is a concept throughout all of these texts is the good life that we should be providing plans and ways of interacting with communities in a way that anyone necessarily would want to interact with their communities or live their lives. So $i$ think it's necessary to put Wolfensberger's normalization as a concept...this is where it is hard because $\mathrm{i}$ want to do a deeper analysis where $\mathrm{i}$ see Foucault's normalization emerge, but that is not in the relationship between the texts (remind myself to stay on track with this level!).

Wolfensberger's normalization is a concept in all three of these texts. Self-determination is another important concept that is interchangeable with choice, at least in these works, which in the further analysis, it starts to take on a different level when using my framework of genealogy...the limitation of choices actually made available. Anyway, looking at these texts, concept that repeatedly comes up is self-determination the person being able to have say in their plan and in their life.[writing on board] Another thing coming would be community - whatever community looks like. So, specifically, community inclusion and integration, but also including the community on plans and including community in the 
person's life. So community could be including family, staff, coworkers, medical, therapists, friends, the community is a broad term that has come up over and over again to mean a wide variety of things - not necessarily opposing, but i don't want to single out each individual community so $\mathrm{i}$ am going to utilize the term community to encompass a wide range of people. That is really important in all the texts. I haven't SET on this yet - and I've gone back and forth so many times - but I think one of the objects for PCP is the plan. PCP, or person-centered thinking, which is what the training is called because it's about a shift that happens to move forward, not just using the approach itself (even though it is difficult to change another person's paradigm) but, i think the plan is an object. That is one of the important things and $i$ think we need to say plan...but that is tentative... [writing on board] or if it will fall anywhere on the graph. Coming from a higher level and looking at the relationship of the texts as opposed to analyzing them, which is different, THIS is making a lot more sense and more organic. It seems to "fit". The emerging things seem to be emerging without so much turmoil as before so I think that is actually...this graph is working well and that my original graph with the predetermined concepts - that is for a different analysis. That is where the trip up was occurring. This is the first level, and then proceed from here....I'm tired.

\section{$\underline{10 / 6 / 176: 27 p m}$}

So, just an image to keep in mind moving forward in trying to keep the different levels of analysis straight, right now I'm looking at the overall construction of PCP as a discourse to make sure the three texts are actually related and are part of PCP. I'm identifying that...so, I'm imaging PCP as a cake and if you sliced it open, as in archaeology mode where one looks at a slice of time, you can see the different layers of the cake. You can identify them and see that this is all the same cake, basically. The next level of analysis is going to be looking at the ingredients of these layers and I think that is where I will see the differentiation between Wolfensberger's normalization and Foucault's concept. I think that's where we're also going to see subject take hold from the object of PCP and see biopower and government because even now I can see the plan is the object of PCP, but I can see how that plan has led to a government happening. I'm starting to see how this actually falls together, the interesting thing is that we are starting with a whole cake first and then looking backwards at which ingredients were included and which ingredients, after going through them and identifying them, which ones maybe to keep or change or get rid of altogether in the end of all this. I really like that image.

\section{$\underline{10 / 9 / 172: 33 p m}$}

Ok, I'm looking at my graph and I've been going over the texts and looking at concepts as rules of formation, which is how Foucault describes them, this is how the discourse is formed using these rules. Looking through ALL of the texts, they all have community, self-determination, normalization, individualization, and also organizational change, 
which whenever discussing PCP, it seems necessary to discuss org change and i think that's because proponents of PCP realize and acknowledge the necessity for organizational change and therefore for PCP to be authentic and effective. ..so that is a concept that has shown up in all three of them and it is definitely integral to the discourse. I find it, out of all of the concepts, I find it really interesting because it is obviously the most nebulous one - the most nebulous to (sigh)...it's part of the discourse, but I don't know that it has really become part of many organizations, so i think it's an easy target for people to point to and say "this isn't working" because organizational change hasn't really taken hold whereas the other concepts are at least put into place through "lip service" and touted as being used. I think it's hard to look at those and say they're not happening, which isn't necessarily true and I'll go into that in the next level of analysis. I need to take a picture of this graph. I'm feeling really happy, satisfied, content with this graph because looking over all the texts, $i$ am seeing that if you're talking about PCP, these are the concepts that are going to be coming up. This may not be an all-encompassing list, and I think this group of concepts could be broken down into more specific items, but I wanted - like when i was talking about community, community is a very diverse term, but I wanted to keep it at community and not go into super specifics.

Going into strategies, I again found it a little bit difficult to put this in there, but going through the texts, i really think it is a theme and I think it's a theme that helps with the formation of the concepts, which is humility. But I have my own thoughts on that actually being authentic...but looking again at all the texts, it appears that this subjective position, though problematic, and some of the concepts (also slightly problematic) (no normative judgements yet!) but it is difficult to say that humility is a strategy but it is. The constant emphasis on working with the labeled person and working with their chosen community to create a plan really points to the traditional service provider expert being the end all of this process and instead it really is about humility and looking to others to create this as much as possible. Support is another strategy. I went back and forth on whether this a concept or a strategy, but $i$ think the entire process is about support and the concepts would not exist without the theme of support. So, support is kind of both, but it really is the framework for the concepts. And finally, creativity: I think this is a huge strategy moving forward with the plans, talking about self-determination and community and really the approach to PCP - it's important that whoever is facilitating, or working with, or learning this approach - be open minded and resourceful and most of the time, that means being creative and looking at current resources and supports and using them in a creative way. That is often looked at- so, if you're looking at the same situation with the same people, if we look at it in a different way or view it as a means to an end versus an end, that's where we see creativity come into play a lot. Also, looking at how relationships are important, that's creativity. When we see community, it's important we see creativity is taken into account.

For the online one, I said creativity in context because I think it is very cut and dry [the online text] and it isn't necessarily discussing creativity in depth, it's looking more at actual 
templates and plans and talking about those plans a little bit. But the plans themselves are different from what a lot of service providers are used to and it talks about moving forward is contingent upon looking at things in a different way. So i have that up there. The structure of the online discourse is a little bit different, but i don't think it isn't related to the other two (this is the only one i really had some questions about). I think that because it provides more templates and is probably one of the most accessible because it is free, or at least the readings etcetera that I am looking at, from online, that is what makes it the most different; it's providing the basics of this discourse, but still has the concepts and strategies. The subjective positions as experts because it seems to come from a very third person viewpoint. It doesn't really talk from a provider's - it has some assessment in there and the plans and the plans are from service providers and possibly from family members (as authors) but that is not explicit...i just know from my own research. Looking at the book from a viewpoint of someone without my background, i can see how this looks like experts versus service providers, which is another subjective position I've put up there [on white board] (parents, service providers, experts). There might be some interchange of experts and service providers depending on who views it, so I'm keeping both terms up here.

It does appear that all texts are related, they just play different parts. It's really interesting because the book provides an overall - context of where PCP came from and then some case studies and then some assessments and then future possibilities, so it's just a a full circle of PCP. The training didn't really didn't talk about historical context, but talked more about skills and ethics, and the online one talks a lot about ethics and some very basic templates. So, Foucault talks about how you can't identify if a discourse is related based on the point of it, which is absolutely true. I don't think the point of these are similar, but they all complement each other. I think doing this analysis really helped me identify they are related. At first $i$ assumed they were related, but then $i$ had some misgivings about the online one more than anything and even now i can see the online one is still just kind of on the fringes of the discourse but absolutely related and it's interesting to see where some of those differences lie and what some of the commonalities are. I don't think i would have necessarily seen PLAN as, as obvious as it is, as an object without doing this analysis. And $i$ don't think i would have seen humility as a strategy even though it most certainly is, and almost even explicitly when reading about moving forward in this approach. The concepts are interesting because i don't know that $\mathrm{i}$ would have made the differentiation between Wolfensberger's normalization and Foucault's normalization even though i knew that was an issue going in because PCP came out of the normalization movement; i didn't necessarily realize the thin line that $\mathrm{i}$ think is going to be the building block of PCP and then moving into a more in-depth analysis using my framework and seeing how it [normalization] shifts. Which is what $i$ think will happen just based on from starting from the graph with the predetermined concepts and then stepping back into this bigger picture relationship analysis. I think this has been really helpful. I think it's going to make the deeper analysis a lot smoother, so $i$ think it has shed some light on some really interesting building blocks of this discourse, again with the humility. Just seeing it [humility] pop up 
and seeing it through the texts; i have a knee jerk reaction that it's a faux humility but it's not and it's definitely a strategy. I find that interesting and $i$ think this is part of my reflexive work and looking at this as always keeping in mind that power can be productive and always keeping in mind that the subjective positions are historically specific and local like in when we're talking about parents and where they lie in the structure: either as subjective positions but also as community, so $i$ think this has been really enlightening.

\section{$\underline{10 / 9 / 174: 22 \mathrm{pm}}$}

So just kind of summarizing since $\mathrm{i}$ have been doing a lot of talking through the analysis and reading and noting [sometimes] where I'm reading from but not necessarily doing a lot of writing, but $i$ have been going back and forth with Foucault and piecing together what all of these things in the discourses analysis means, so i just wanted to go back and reiterate that this graph shows the relationships and the texts are related. So $i$ am looking at ONE discourse. Moving ahead to my next analysis using my genealogical framework looking at this ONE discourse using these separate resources or artifacts but not looking at each resource separately, which is important to note.

When I'm looking at identifying the object, which i have said is labeled person or people and plan, the labeled person is a little bit abstract and probably the most abstract I've put up there [ on whiteboard] because implicit in this discourse is always a labeled person in that is who providers would work in creating the plan and talking with the labeled person as expert, which is how this is posited in literature, so the labeled person emerges out of this as object versus being an explicit object. The plan is explicit object, it was so obvious it hit me in the face. Talking about objects, so treating discourse as group of signs no longer, but as practices that systematically form the objects of which they speak page 49 of AofK.

Looking at concepts, Foucault had described this as a rule of formation...subjective positions are not just a form of knowledge, nor the concepts either to the form of the structure of ideality, or to successive ideas, one must relate the formation of theoretical choices which would be the strategies to the fundamental project or secondary play of opinions....it is a theoretical framework. Last are my words...page 70. From here we have identified the discourse and it's rules and some of it's structure. There is no finite structure, though, because it is just me looking at this. But we have identified these texts are related with the same concepts and strategies...I think we have identified a pretty strong structure, or case for the structure.

I'm going to find some examples of each to highlight, but this is the pivot of me going into the deeper analysis now. I'm going into using the genealogical framework to identify what comes out now and I'm going to use the predetermined concepts in the graph.... These concepts came from the literature as being associated with the discourse of ID as noted in my previous work in the proposal, so that's where these concepts came from. Moving forward with the relationship and structure, I'm going to see what kind of emerges out of 
the PCP discourse if we use a genealogical framework, which could also be called a historical framework as noted by Aimee Hamraie, a disability scholar. Which is cool. So, using this framework to see what emerges out of it and that is the next step.

I'm really tired.

\section{October 16, 2017}

So, Ive taken a few days off from recording, but I have not stopped looking at the analysis. So I've taken a picture of the whiteboard...after doing the first analysis of PCP and moving into the second analysis with my genealogical framework, the analysis has been a lot easier...so a lot of stuff kind of bubbled up and jumped to the surface and I've been going through the texts and I'm using the predetermined concepts for this one. So, I think that using the four categories that Foucault used (used in the previous analysis), so: object, subjective positions, strategy, and concepts - and that's where everything has just bubbled up organically. So, I'm letting that kind of simmer and I'm moving some things around and drawing some arrows for connection and going back to the texts and looking at Foucault, I think after this analysis is finished, I want to look at "statements." Which is what Graham looked at in her discourse analysis. So, what did this statement do? The function of this works, the statement of this work? I think this is ultimately going to provide an answer to "what does a genealogical framework reveal about ID in PCP?" I think that with the assistance of the boundaries and building blocks coming up here and now are going to provide a robust discussion for what do these findings hold for sex ed and social workers who work in ID services.

I've been going back and forth and moving some things around and rereading the genealogical framework that I've done and I think I have some really good understandings of the boundaries and building blocks, rules of formation of the discourse, using this genealogical framework. So now I need to interrogate it a little bit more and reach out to some of Tremain's readings and McWhorter's readings and Simon Foley has some work on patriarchy and sexuality and ID and Amie Hamraie has some work on historical epistemes as a way of looking at disability as opposed to the social or medical models, so I'm using those works to move forward and interrogate what I've got so far that's bubbled up. I say bubbled up because it just seemed to explode once I did this first analysis, the second analysis using the genealogical framework just exploded using these predetermined concepts, which I find surprising. I think it is also not yet finished, I think there is other stuff not so obvious, but it's just interesting to see how everything kind of exploded and is connecting in such an interesting way.

I keep messing with the whiteboard to see what happens. I keep staring at it..it seems to be very fluid and dynamic versus static, which is how the first analysis seemed. It seemed to grow and then kind of solidify. This analysis seems to be a lot more dynamic and I don't know if it's because of the genealogical framework necessarily, but $i$ have a feeling that 
it's contributing to that. But things seem to just be connecting and moving and making way for others and turning into more specific terms, so it's really interesting and fun.

I started to draft out the findings from the first analysis of PCP, which was just looking at the relations of the texts, but it isn't working out very well because I don't think I'm in a writing place right now. I'm still in an analysis place, so I'm just kind of recording and transcribing and going back to works and looking at sources before I start to draft anything. Although, I still have a timeline that I want to stick to, but it's hard because I feel like I have to harness a lot of information and I don't want to prematurely stop the analysis, so I'm trying to be really open and mindful of what is coming up in the analysis so I'm not missing anything. I did reach out to my colleagues at UT in the person-centered institute and asked them what their thoughts were on my initial analysis of PCP and two people responded and agreed with what came up just as something they see. They were also the facilitators of my training, so that was cool. SO, I have some checking going on and I have a person I am going to to go back and forth on terminology just to make sure I stay focused because it is easy to kind of float when one uses Foucault into other areas. So, I. Keep going back to my sources like Graham, Tremain, McWhorter, Carlson, Butler so I don't float away too much.

When I'm looking at the subjective positions in this discourse using the genealogical framework, I have white, hetero able male AKA hegemony, but that is also over in strategy and $i$ think those are connecting to normalization in concepts, so it's really interesting to have that kind of bubble up and looking through McWhorter kind of mentions this in her analysis in mention disability and sex, and looking at Tremain. Anyway, this is just really interesting and fun. Like, placating came up in strategy and I definitely have seen this coming, but not necessarily hegemony, but support also came up! So, support seems to be at odds with placating but as I'm going through Foucault's work and he's stating that it is important to identify parts that seem to not fit in at all because that is a way of actually fitting in and working at the same type of discourse - the boundaries of the discourse. I think this comes back to looking at power being productive and oppressive. Similar to how "co-support/power" comes up in strategy and this ties in directly with the concept of government because labeled people are part of governing and this is a circular relationship of governing themselves with this limited choice, but the choice creates a facade of ownership and self-determination. This is similar to the idea of the HRC (gay rights) being an advocate group that pushes normalization and is headed (historically) by gay, white, male people, leading to a homonormative way of being that is not representative of the queer community. I think this mirrors the idea of government in PCP. Normalization and government are a lot easier because the labeled person is taking part in it. I think i noticed this before, but in an abstract way - which is now much clearer.

I'm excited to move into statements and see what happens with this discourse using Graham's work as a jumping off point. As I let all of this shift into where terms want to be with some of them hanging out in the fringes because I'm not sure where they ought to 
be , like plan and organizational culture......this pops up a lot throughout all of the texts and $i$ think using this genealogical framework hones in on this because authors cite "perversion of this work" whenever discussing the use of PCP, which is interesting. There's a lot of talk about making sure to include people from all levels of the organization in order to have a cultural change or paradigm shift, so I'm just not sure where that goes yet. Also, I have body sovereignty up on the board and I'm not quite sure where that goes..there's a lot of discussion of this person as someone who is a part of their own plan and future, but the silence that is around sexuality is very loud and $i$ think the fact that we are talking about teams being involved as being productive so we have many viewpoints is interesting because we may not end up hearing the person and what they want to do and how they want to be in the world - instead we have a lot of bouncing off points. So, I'm waiting to see where that fits...this person has existed and learned in a world their body and their being is open to teams and their viewpoints, which is another side of the interdependent coin. It's always this team, it's not just YOU even though it is...

\section{October 27, 2017}

So, I've been going through some of the pCP texts by Holburn \& Vietze and also reading through McWhorter's book just to kind of get an idea of some overlaps and looking at my whiteboard and going through, i really feel like PCP is much more of - it IS an approach and has always been an approach- but I feel like there is so much talk about the labeled person....at least through the texts that I have and the training I went through, the labeled person as object seems to be almost tangential to organizational culture/ change. Because so much of it is about creating an organizational culture that embeds PCP in every aspect, every decision, every meeting, which I knew was always the case, but I don't think I knew or saw it as an approach working with a labeled person, but now I see it as an approach. It happens in organizations, at least in this context specifically for labeled people, so it's a slight nuance. It seems to be kind of taking on the idea of people need to get on board with this in order to help provide the best life for the labeled person, but I still - there's not much in the way of how that happens. In the training there are skills in how to move forward and pick that out, but then there are some chapters in the book and how important it is for staff to be on board and staff to have communication. Again it becomes this eerie productive, and I can't stop saying power as this productive force because if I'm using a genealogical lense, I am looking at how previous approaches explicitly segregated and institutionalized in some form - whereas now integration and inclusion are the main ways of moving forward in PCP. But I still think the concept of government comes into play and normalization, so when we're talking about choices, we're not really saying this person is interested in punk or rap - which is why I keep saying this is white hetero male because we really rely on the staff that are involved in these organizations and this is looking at people who live in residential homes or moving from institutions moving into residential homes, or some how taking part in social services. So we are seeing the "counterpart" in staff. So, the labeled person CAN go explore the world as long as there is this counterpart staff interested in $\mathrm{X}, \mathrm{Y}, \mathrm{Z}$; but if that counterpart person is not interested in $\mathrm{X}, \mathrm{Y}, \mathrm{Z}$, then that 
labeled person takes a second or third choice because that counterpart staff person Will do A,B, C. So it's really interesting because a lot of this [what is on whiteboard] comes into play, I just - oddly, I think I am having the most trouble with Object in this whole analysis because the labeled person is the understood object of PCP in this regard, but I don't think that is the object...or there are more. I think organizational culture is - all staff and administrators are buying into PCP, which includes integration and inclusion and buying into this plan. So I'm seeing how this view changes...I think what white hetero male is actually captured in the training and the writings, but it is in the subjective positions...so whomever is in charge. I think service providers, mostly staff, but I think this concept needs to be in subjective positions because this person is not going to explore the world unless there is a staff person [counterpart] service provider who is willing to enthusiastically engage in these activities without having an interest, which seems like that would be possible but I don't that it is, going through these writing and reading about creativity and flexibility and finding staff that share these interests...when we are looking at counterparts, I think that is what we are looking for. We are looking for able counterparts. Looking through some of these chapters and the training, we're looking at these counterparts who are safe in some way and who hold this view of the person being asexual or at least incapable of being sexual...I think this sexuality dispositif that I'm using actually runs through everything, but is a little more insidious and implicit, so we are talking about counterparts that are generally going to be the same sex as the person and if that's not explicit, than it is implicitly. And when we are talking about how labeled people interact with other labeled people, it is generally very vague about the relationship or is assumed they are a couple even though stereotypical couple behavior is not necessarily noted or identified, it's just that two people are together and they are of opposite sex. This scenario has come up a couple of times in the book and then there was the Harry story in the training which was just problematic overall...and it wasn't really mentioned online.

I think there is a lot of discussion of relationships in this very holistic way of relationships in that they are important and need to be maintained, but it is a very desexualized relationship. I think this is implicit. It's hard to identify specific instances of sexuality in these texts because it is so implicit and I think it's important that what is not being said are the choices that are what is being said is what is "needed" to be said. Foucault says don't look for hidden meaning in between the lines because what is being said is what is said and what is not being said is what is not included, which is a very distinct nuanced way of looking at things. I need to figure out how to specify counterpart or same sex counterpart or desexualized counterpart in organizational cultures as object and subjective positions in a way that flows with this a little bit more because there has been a lot of: where do I put organizational culture? Where do I put integration and inclusion? Is plan in there? Is labeled person- where do they fit? Is hegemony in there? I think hegemony IS in there but maybe as a strategy versus subjective positions, I think maybe it's a strategy to use hegemony to the concept of normalization. 
I think subjective positions will be: service providers, family, staff, but also really important object is that idea of counterparts. I keep going back and forth on this subjective position versus object in relation to counterpart. What needs to come out of this is a counterpart for the labeled person to experience the world or advocate or ally. I think this comes back to the whole idea of power is productive and that is where a lot of this is complex and very gray and $i$ think some people would see this as very critical of PCP and I am not meaning to be critical, but as a way to shift how we see PCP in this framework. If we see that we have counterparts for people to go out and examine the world - if we use a genealogical framework, it's important to be like, we're not changing too much, we're not putting people into the institutions ideally through PCP - we are encouraging people to get out and live their best lives BUT we are doing this through services and these services are functioning under a hegemony and these services are functioning under stereotypical beliefs and how far have we come when...it's still very confusing and complicated.

So, a question that keeps recurring is if we are doing all of this work only with organizations that tailor to labeled people, how are we changing access? Experiences are still segregated then. Unless the person has excessive amounts of resources and money. If we are talking about access, then this directly relates to my second question looking at how these implications affect sex ed and social workers...sex ed is a separate institution and is used in public schooling. Are the authors for this using PCP? Or social workers? As social justice advocates, are we using PCP with all people in all institutions? In both, we still use these very explicit lines of who can be sexual and who can access sex ed and as social workers, are we advocating for this or not? Are we advocating for every person to experience their best life, which likely includes sexuality, at least education and access. And how are teachers being taught to teach sex ed...?

I've been reading through McWhorter and reading about how people are viewed as temporal... and then looking at how we don't see people at temporal unless it is more convenient, like work or education. For instance, the rise of post secondary options for labeled people really shows how people can interact and grow, but we don't have that same discussion regarding sexuality. Looking at PCP we still the discussion of "has the person identified interests that will work towards their job or free time" but it is still limited and negates a lot of what many people would view as Normal, like dating etc. I am going off a little, so I will stop pontificating.

\section{November 2, 2017}

Since it's been a few days since I've recorded anything. I've been letting everything kind of marinate and rereading through my resources and I am really excited to move on to the next level of analysis which is statements. I am still feeling really good about this analysis because $\mathrm{i}$ think a lot of this is still pretty right on. Looking at object as plan and the counterpart and organizational culture/change..thinking about moving into statements, I think that is where I will see - not judgement - but real...Graham looked at statements and

noticed there was a real othering happening and looking at the building blocks of this 
discourse using a genealogical framework and identifying that the silences are actually a tangible part of this discourse and that limitations are a tangible part of this discourse as well as hegemony and inclusion and support and co-working, but they all turn into these weird concepts: biopower, normalization, subject, government and that these all work in productive and oppressive ways means that the statements that come out of this will be really interesting. I can't even start to predict what that may be because I've been surprised by this whole analysis and the balance that emerges from this. Ive talked about how I went into this with some bias, but using this method and then using the genealogical framework has led to some interesting building blocks and the predetermined concepts are definitely there and explicit but I don't think that some of this other stuff was explicit. Like, looking at the building blocks of PCP, the object was labeled person, but using the genealogical framework, the counterpart really seems to emerge in a way that there needs to be a support person in order to make this plan work and that seems to be a different player if we look genealogically at it. It's not about having a counterpart, but if we look at Seguin, he was very big on him being involved in the work and him being seen as the authority and he could teach "them" in growing past their disability and using a pedagogical approach. So his approach was having face to face and putting a face to the authority. I think that turned out that staff were these counterparts; a way to live and exist in this world depended so much on staff and now we are changing that to a counterpart person. Seeing how that object has changed over time is interesting and seeing how important organizational change and culture is important - that has existed in some way in services for so long. In PCP it is emphasized often because it speaks to the idea that change is not going to happen unless PCP is embedded at every level because perversity of an approach is inevitable.

The strategies that come to play in that are really - and I might be repeating myself, but using the genealogical framework highlights the object as change and counterpart..So, I'm excited to move forward in this. Not to write, but move forward with the analysis. It is so

hard to capture this articulately in writing - $\mathrm{i}$ wish I could play my tapes, but that would put them to sleep.

\section{November 6, 2017}

I was thinking about this discourse, graph, building blocks and was looking at counterpart...looking at that using the genealogical framework, i changed it to non-disabled helper with helper in quotes because I'm not sure that's the right term. I think if we are using a genealogical framework, we see this nondisabled helper person in various forms throughout social services for ID and in PCP we see it as the staff that is assigned to the person to support them, so I wanted to change that because counterpart is not necessarily staff and how we think of staff. It's really about nondisabled helper. As i was looking at subjective positions, labeled person is definitely there, but $\mathrm{i}$ want to hold it and trouble it a little given the genealogical framework and where strategies include placating and silence and concepts include things like government, normalization, and biopower; given all this, i want to take in the complicated relationship labeled people have in self-determination and advocating for themselves and what they have been told they are capable of and what they 
can do. So, looking at being a part of this process, PCP process, it's often brought up that self-determination is very important in this and needs to be taught, but i don't think it is explicit enough that labeled people are told from the day they are born that there are things they will never be able to do, either implicitly or explicitly, or things they should do or shouldn't do - from family, service providers, teachers, media, general society. When we are talking about what does this person want, and what is important to this person, there is a lot that comes into play that we're not necessarily knowing where that comes from. So, we have the important to/for discussion again and I don't think its really looked at from the labeled person or how they got there or why they might not be advocating for sexual info or education and this may be because it has been told to them that it's not for them. Or they may not have the language because it has been censored from them.

I want to put in this just side note that I watched a webinar recently from Katherine Mclaughlin recently (she did the sex ed curriculum from PP in New England). It was being presented in California for parents and how to talk with their kids (grown or young) about sex. One parent asked how to tell her daughter, who has Down syndrome, that she will never grow up. This is after listening to the webinar for about 45 minutes and hearing very positive and progressive discussions on sexuality. A second question was: when is an appropriate time to have my son sterilized? He is very good looking and I'm afraid that some woman is going to want to have sex with him and become pregnant. So, these questions blew my mind, but they happen ALL the time and I don't think people necessarily know they happen all the time or how prolific these thoughts or viewpoints are despite being a part of this discussion of how to talk with kids about sex and looking at this curriculum and asking how to move forward. :(

So, when looking at subjective positions, we're still not paying attention to the fact that labeled people have been told from day one that sexuality is not for them and genealogy framework really shows this and that labeled people have constantly been told they cannot be a part of sexuality or they can't because they are never going to grow up. So, looking at objects and subjective positions and concepts, it's not going to be cut and dry graph, but will require some explanation and that the discussion is a lot more fluid and dynamic. Using the genealogical framework has opened up the discussion and requires critical thought and reading when looking at PCP. And looking at how important it is to balance this out and see it is not one sided and not all negative or positive.

Still moving some things around and reading through McWhorter. This framework is such a complex way to look at something and that's important because we are talking about a "Plan" that helps someone move forward in their life and have the life they want and have the best life possible. So we are talking about people and dreams and desires and challenges, and it needs to be complicated and it's not just black and white or just using these skills to get to an end point. If we acknowledge that, it will make the process and facilitators much more skilled in this and provide opportunities to improve PCP. In moving into statements eventually, I think it will have a lot to say about the process and using this 
framework about what is missing from that process. It is like the longer I sit here, the more complex it becomes. Not that things change, but become more specific and complex, so, yeah, we'll see where this goes.

\section{November 11, 2017}

So, I was transcribing some of the recordings I did and I was wondering why organizational culture/change wasn't an object on PCP (w/o using the genealogical framework) even though it was just as important and embedded throughout the discourse. I think it's because looking at it statically, then looking at the goal is labeled person and plan and moving forward versus some of these other objects that are now coming up using the genealogical framework, such as labeled person's plan, nondisabled "helper", and organizational culture/change. I really want to dig in and see why that's happening with the genealogical framework and not just PCP discourse analysis, also because I think my committee will have those questions as well as my audience. I was looking at organizational culture and PCP really talks about how it needs to be embedded in every level, but using a genealogical framework, it's not about necessarily "change". So using PCP, it's being embedded, but it's still this, PCP itself doesn't necessarily change how people view sexuality. So, if using this framework with sexuality as a dispositif, we're using the same framework of sexuality, which is one of the issues. Looking through how ID has been constructed using different instances of sexuality throughout history and how it has played a major role in constructing ID, and I think that's because the idea of sexuality hasn't changed and so if we are embedding PCP throughout the organization and really infiltrating the entire organization culture, that is a change of using PCP, but it's embedding this culture of sexuality as it has been, such as using the strategies of patriarchy, limitations, and silence and hegemony and everything else. It is THROUGH silence or THROUGH ....also kind of thinking of this idea of having this nondisabled "helper" and having that person be so imperative to PCP in making that so successful (PCP) and we're still using this framework of sexuality that has been present and been maintained throughout history so that it becomes part of the organizational culture. So, PCP hasn't necessarily done anything to change the way we see sexuality, but it has put forth this way of providing a plan and approach to create this plan and we're using staff and service providers and family, who have empirically and historically, had challenges seeing a labeled person as sexual and also the labeled person has since day 1 been told that they are not a sexual person or that sexuality is not for them and we still have these pillars in place so that even though we have an approach that puts the person first and espouses having the best life possible, we're not changing the culture. We're not changing these implicit pillars of ID, so instead of changing that, we're immersing it into culture, it seems, more and more because we have these concepts of normalization: let's have this person live their best life. What that means is that we are using these nondisabled helpers who might not be as diverse (in thinking) given who is going to into services and we're looking at what people are willing to be a part of. Saying this person should live the life every other person should live, but that really gets filtered down to what is available, so we look at limitations and we look at subject and we see how 
labeled people are part of subjective positions; however they have this idea of what they are supposed to be through various subjective positions and strategies. So labeled people really see this plan as their way forward. So, they do work towards being co-creators and being in on this process, however, that becomes this idea of government where the person is the governor of what they SHOULD be doing and what they SHOULD NOT be doing in order to be seen in this normalized way. Through all of this there is this very insidious and implicit concept of biopower that exists and it is through this PCP framework, which is supposed to be, very centered on the person, but it's building on the previous approaches without changing or questioning them without picking them apart first and saying what NEEDS to be worked on first is not the person but some of these services or outside organizations that this person will come into contact with. This shows how the social model of disability comes into play here, but still genealogically, we are looking at how we're building on top of or pretending there is a linear construction of progress happening instead admitting we need to start over or start from a different place instead. I am saying this all now because I'm thinking of this and seeing this hiccup in objects [see beginning of recording session] and I'm wanting to move forward into the next level of analysis, but I wanted to feel confident that this framework is adequately capturing what it can right now. From a Foucaultian standpoint, this is one version of reality that exists and this is my analysis and I think it's really saying the issue is that using this genealogical framework we are moving forward with this idea of ID constructed through sexuality and we're not questioning. We are then continuing moving forward without progressing. I think this idea will be important when moving forward into the next level of analysis (statements) because we do have a really great approach - I think PCP is a really great approach however, it is not a silver bullet, there is no panacea to progressing services for labeled people if we are not willing to go back and dismantle some of these ideas or cultures (sexual culture). This is what was tripping me up. The genealogical framework really works through the entire analysis and shows how insidious and implicit this dispositif of sexuality truly is. IF we don't see that, then we are going to continue on in this belief that a linear path forward is possible and effective.

So, given what this shows, if i look to tentatively answer the research question of: what does a genealogical framework reveal about ID in PCP? I would answer that it reveals we are maintaining the concept of ID without progressing much. Instead, we are still pushing forward that a labeled person is asexual and needs a nondisabled support person to guide them because access is limited to other organizations or institutions or life experiences, however, the question of growing tends to fit with education and employment, but not so much in sexuality. If we are embedding the culture with the importance of interdependence, should we not also be discussing the importance of seeing labeled people as sexual beings who need access to information, social outlets, and education? Given labeled people have been and continue to be told sexuality is not for them, how do we embed that discussion into PCP to change this belief? 
So, the subjective positions of family and staff provide a lot of silence regarding sexuality, as seen empirically. It's how PCP is used, strategy wise, as seen in the film (kink and Autism) and seeing the service provider speak of how the main character would never be independent based on her experience versus on the ability to learn and adapt and grow of the person. Disability as master status.

I want to hold onto this vision $\mathrm{i}$ have of how PCP is seen using the genealogical framework and how ID is seen using this. It is fascinating and not obvious or not easy to see.

\section{November 15, 2017}

Today was the first day of my sexuality educator training with Katherine McLaughlin (PP curriculum for adults with DD). The other participants were mostly providers (case managers, program managers, etc) from the east (Vermont, NY, MA, etc.) and a couple from schools or PP (Syracuse). Overall, I found the interactions to be similar to others I have had with providers from anywhere in the US. Some people identified religious backgrounds as challenging to be "open" while others talked about the perceived opposition of parents vs. staff. Some people identified as parents - no siblings. Most were not sex educators, so discussions revolving around sexuality, such as polyamory, furries, and plushies - were very foreign to many and many talked about their lack of knowledge. We role played some very minor interactions (one person asked the other what a boner was; another time, a person asked what a clitoris was) many found these uncomfortable, but talked about how it would be easier to have this interaction with one of their clients versus the other participant in the room. The facilitator used the words: pussy, dick, and cunt when briefly describing language and some people in the room gasped.

I'm writing all of this down because the interactions are all relevant to my dissertation as far as sexuality and ID. Most in the room, however, stated their belief that people labeled with ID were sexual and should be able to express this - but trip ups included parenting and safe masturbation and having many partners. I know my own journey with this topic has been much more involved and I should not judge, but it is hard to see people who have been "in the field" for many years still stumble with this integral part of human experience and appear to just now be wrestling with how to move forward.

\section{November 15, 2017 7:24pm}

I've been reading up on statements and I'm trying to really get my head around this, so the analyses I've been doing thus far would appear to be identified as discursive formations. Looking at AofK and identifying some of that, I would say I have really been laying out the discursive formations, or building blocks, of a discourse and to move forward in a true analysis of the discourse, past the building blocks - which I feel confident have been named and identified - without being too wishy washy about the finality of it, but I think that to do a true analysis of the discourse I do need to go into the statements. I've been reading 
side by side AofK and comparing that with Graham's description of statement and how she has done her discourse analysis. The statement Foucault defines as "the atom of discourse" on p. 80, but, of course he goes on to NOT define what that means and instead goes on to define what the statement is not. Eventually, Graham says the statement as a function can be theorized as the discursive junction-box in which words and things intersect and become invested with particular relations of power resulting in an interpellative event...and I've looked up interpellative event a couple of times and I still cannot wrap my head around what it means. I am going to go to the people she cites, Althusser 1971 and Butler 1990, and I've gone to Butler but she is not necessarily helpful...Okay, but in which one can recognize and isolate an act of formulation (citing Graham)...the act of formulation she goes on to describe is flyers for the event and looking at the problematic use of "local" and "multicultural". She says placing the word local alongside multicultural results in what Foucault calls an act of formulation; qualifying the third circle above as a statement appropriate for analysis. So, in this example, ...I'm going to pause here and read.

She goes on to say how these are problematic and basically uses citations to describe how she is analyzing this as problematic. She cites the claims and goes over how that it is and I'm saying this and thinking about how doing the analysis doesn't mean citing Foucault at this point because I will be talking about Foucault when looking at the discursive formations and how I came to those concepts that were predetermined and really talking about this journey I have had and looking at these building blocks and coming to the realization that this is not a critique necessarily, that it is just using the building blocks and that using the genealogical framework starts the wheels turning and then if I do a full analysis of looking at statements and maybe using examples from different texts that I think have really stood out or I have continuously come back to over and throughout the analysis - I think those provide the fodder for this analysis so this is where I would look at statements and maybe "harry's story" and say we have these building blocks and looking at this statement, we can see how this played out using the genealogical framework. Maybe framework provides the undercurrent to these building blocks, which is the 4 categories I have used, so that current throughout. Using these different examples throughout that I am choosing. The rigor comes from pointing them to how they are...illustrative of the statement and showing what that statement does, so what that statement does is the function and kind of looking at what is being DONE and what is being DONE is going to be what is really interesting. So maybe it's not doing anything or it's not negative as I foresee, seeing how a lot of this has not been as negative as I thought, so I'm curious to see how that goes and I am kind of feeling like I am walking along this cliff with Foucault and I am holding onto this thread and pushing myself to go into this deeper analysis of these illustrative statements, maybe? I want to look deeper or past this discursive formation and see what comes of it...this is why I'm recording this now so I can listen to this again...I think this is where I am going.

I'm looking at Graham's work here and seeing what the statement consists of, which is description, recognition, and classification, and she is using that as the Foucaultian building 
blocks. I'm also using my own discursive formation as the backbone, but when I am actually looking at the statements, I think it's going to be imperative to bring in other writers specifically from disability, like Tremain, McWhorter, Carlson, and so forth and relying on them to provide the robustness of the statement that I'm looking at. I think this is where I'm heading, I think. I feel very tentative and like I am walking on these ice floes and at any moment they will slip out from me. Or that I am just doing this wrong! Some would argue there is no wrong way to do this, except for Tremain, possibly - which is why I'm recording this the whole time! So people can follow, maybe?, what I've done.

\section{November 21}

As I've been reading through Foucault and looking over Graham's work more and more looking at statements, it SEEMS statements offer another way of doing discourse analysis and what I've been doing is discursive formation. Then Graham says she uses statements to do DA. I think that, after reading more, that what I've done using the genealogical framework, I think the analysis is already a lot deeper than what it originally been intended as discursive formations since archaeology is more or less looking at a static time, static frame of time, and looking at some different points of it. I think using the genealogical framework has allowed a deeper delve into that, which might be correlative to statements in that statements are looking at particular works and picking out statements from those works...using those three identifiers that Graham said, but I think I might actually forgo statements because it attempts to go into a much more specific analysis that I think I have reached using the genealogical framework and I say this because I have rereading Foucault and Graham and looking at what is coming out of those and then comparing that to what I've done on the whiteboard previously and the statements, at least the way Graham is using them, has identified specific wording to highlight kind of the functions that are being used from the statements I think that because I am looking at entire curricula, it would be hard to pinpoint particular wordings that weren't viewed as cherry-picking. I think that using the genealogical framework and coming up with these less specific but more analytical (?) analyses, so looking at how those predetermined concepts just emerged and flew up and how the objects and strategies just flew out of those. I think because I was using the genealogical framework - which, the difference is seen from the first analysis I did linking the curricula together to first identify that this was a unified discourse - and then using those curricula as one giant object of analysis, using the genealogical framework delved deeper into what I was doing because I am using a specific framework that highlights sexuality, so it delves deeper and has a much more intense analysis than just using the previous level and previous method (used for first level). The dispositif and the historical framework I created blended together to create a really intense analysis. I think instead of moving forward - and I know this is a constant back and forth with "I think I am going to do statements now" and "well, maybe not.." -

I'm looking at this and realizing that statements are not going to reveal anything different than what I have already uncovered, it might provide some examples, but if I stick with what I have already done, then delve a little deeper into what I've done and go to Tremain, 
McWhorter, Carlson and highlight how those have been shown through the disability world and how they've interacted and how PCP is utilizing - for lack of a better word - these, I think that would be much stronger and more rigorous.

I might go back to statements, who knows? This process is ever changing.

For right now, though, I think that I've been trying to figure out how to move forward and it just clicked tonight that I've already moved forward with this analysis, I just need to unpack what I've done. I want to look at how these building blocks have historically influenced and maintained these discourses for people labeled with ID and also look at how PCP is utilizing these ideas or strategies or concepts in a way that is active.

We'll see what emerges and happens in the next few days. 


\section{Photo Audit Trail}

\section{Appendix B}

I've included the photos of my process, mostly using a white board, for several reasons. First, providing a record of the analysis process aids in transparency as well as accountability and trustworthiness. These photos do not necessarily follow the notes from Appendix A, but they do complement one another.

Throughout this process, I constantly searched for examples of other studies that utilized a Foucaultian discourse analysis for guidance. I found very few and none that were very helpful. I reached out to some of the researchers to ask how they determined whether they did the FDA "correctly" and how would I know if I was doing it "correctly"? Dr. Graham, cited throughout my methodology section, provided me with the most effective advice:

There are no hard rules (which I know can make things more scary in the beginning) but my advice is to read Foucault deeply and develop a set of rules for yourself from his work.

That's what I did. And, yes, it was intimidating but you just have to remember that everyone else is doing the same as you: interpreting.

As long as you can defend your approach with reference to Foucault's own words and ideas, you'll be fine.

This is the way we make an original contribution to knowledge. Couldn't do that if we follow instructions, hey (Graham, 2017, personal communication)? 
I followed her advice. I continually went back to Foucault's primary works and reread them. I would then compare these readings and my interpretations with other scholars, such as Tremain. The entire process felt as if I was walking through fog in a forest and each step was potentially wrong. This is why I recorded my notes and took photos of my analysis. I wanted to show my process and possibly provide a bit more of a guide for future researchers. This is not to claim my way is the right way, but it is one way. I developed my own rules and relied on my interpretations. 


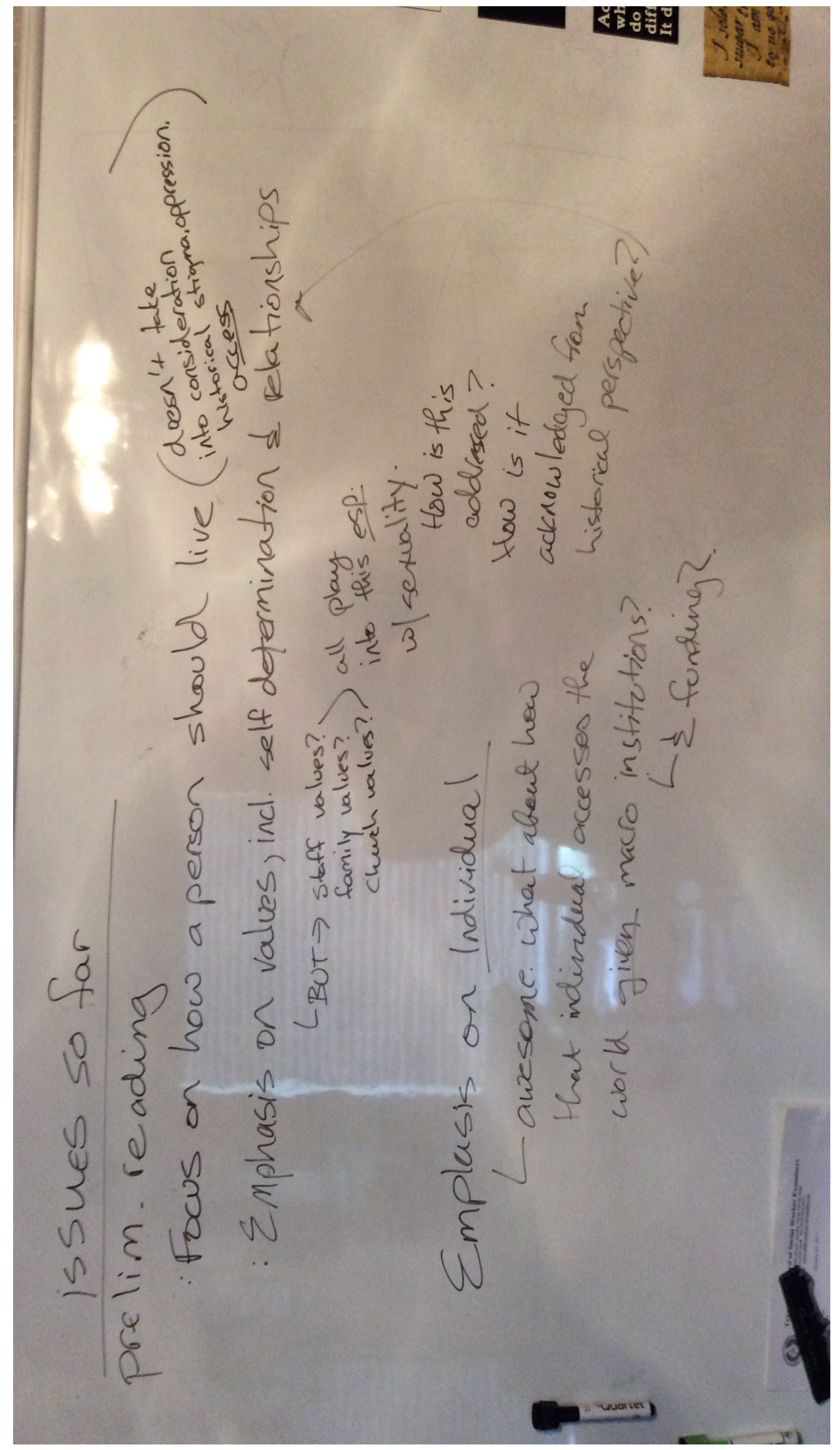


A Foucaultian Discourse Analysis 216

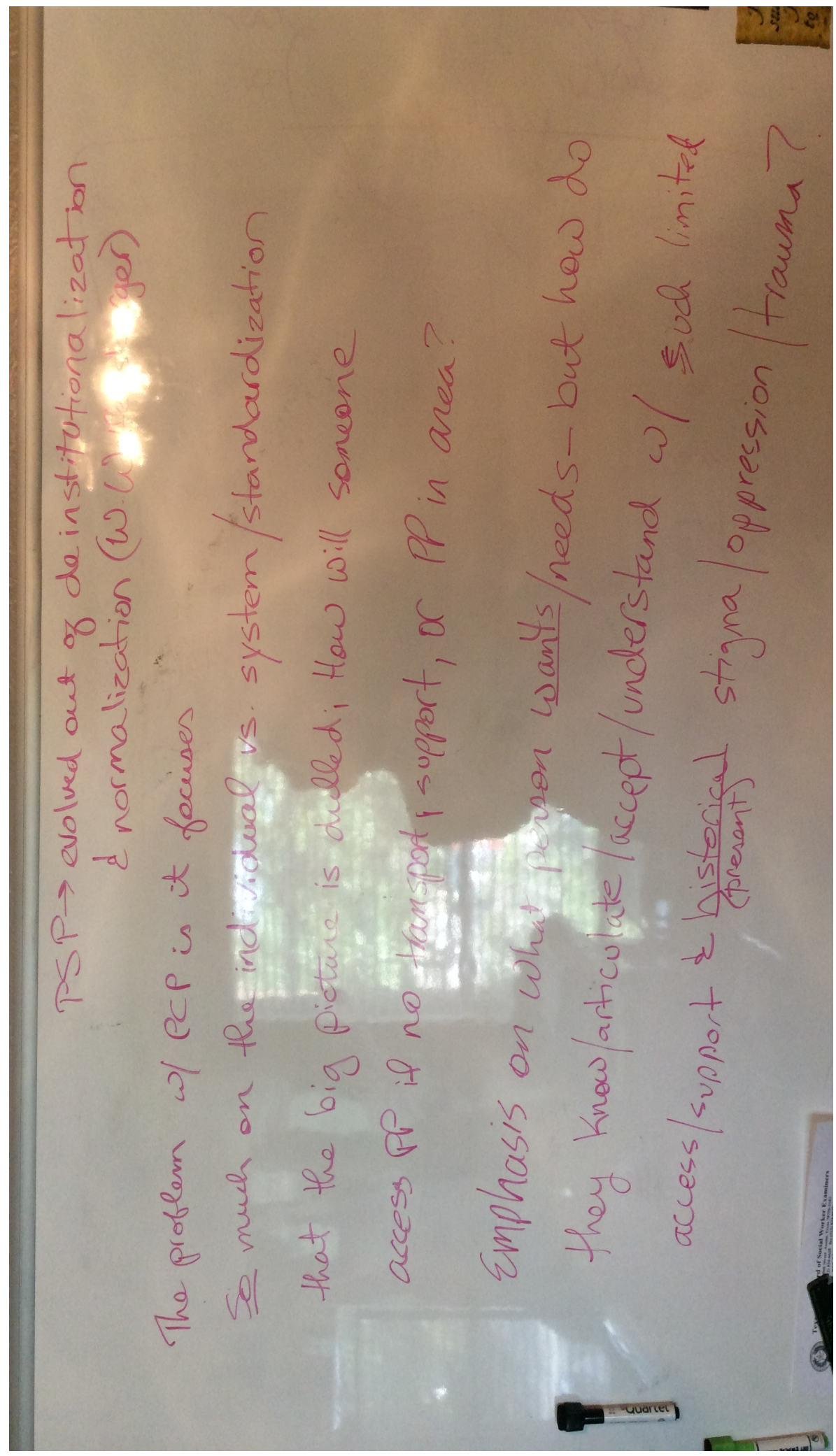


A Foucaultian Discourse Analysis 217

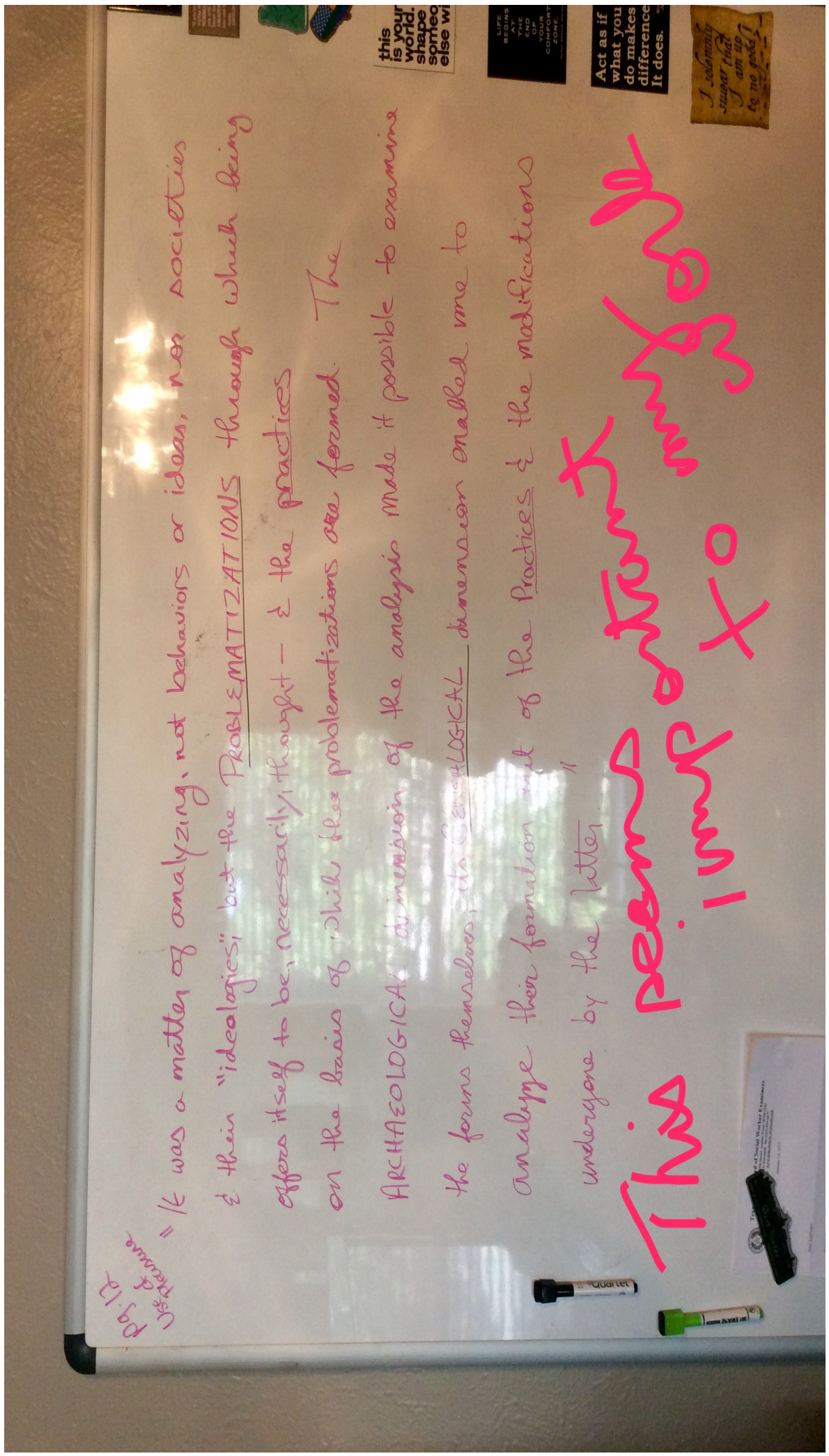


A Foucaultian Discourse Analysis 218

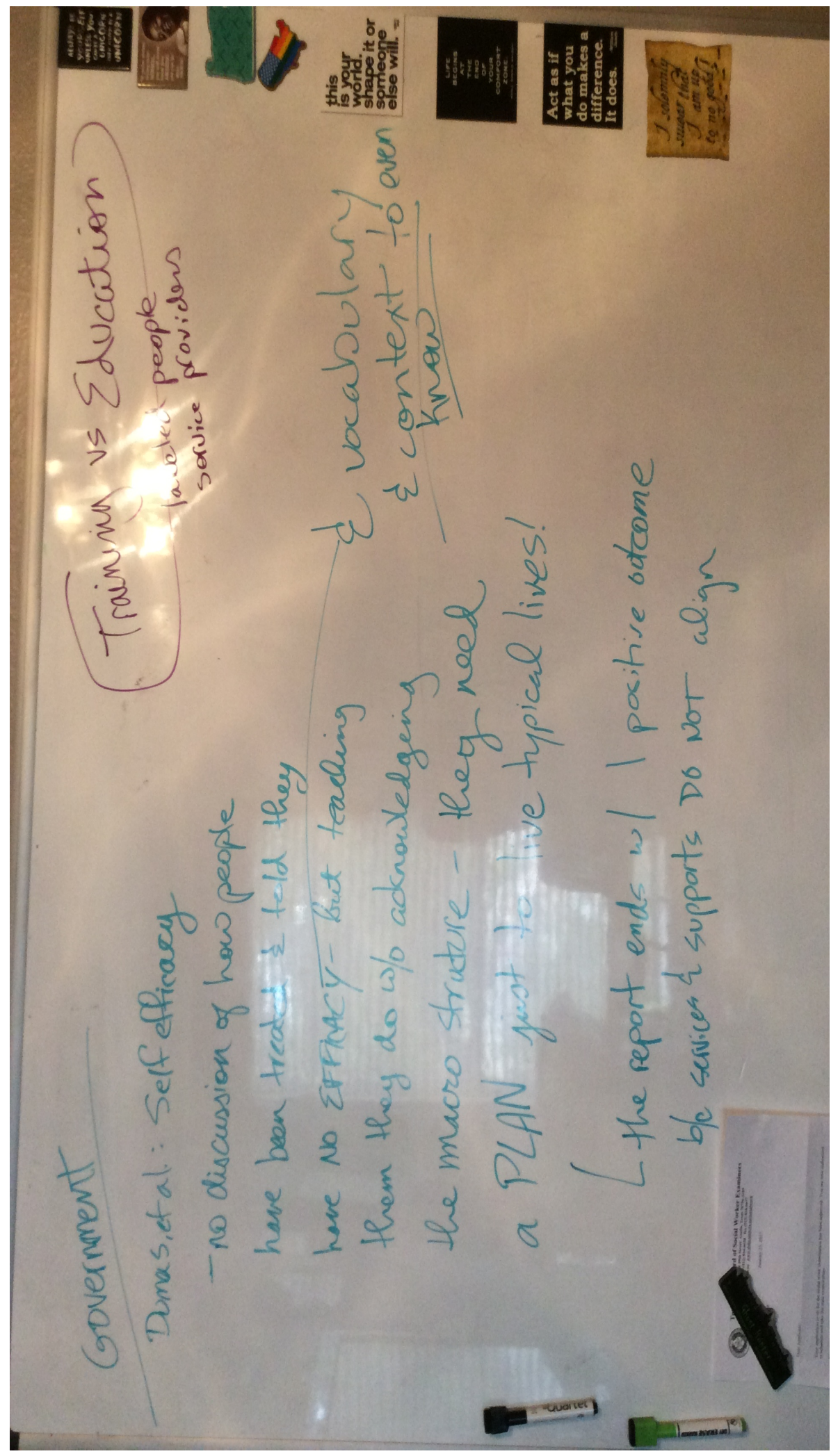


A Foucaultian Discourse Analysis 219

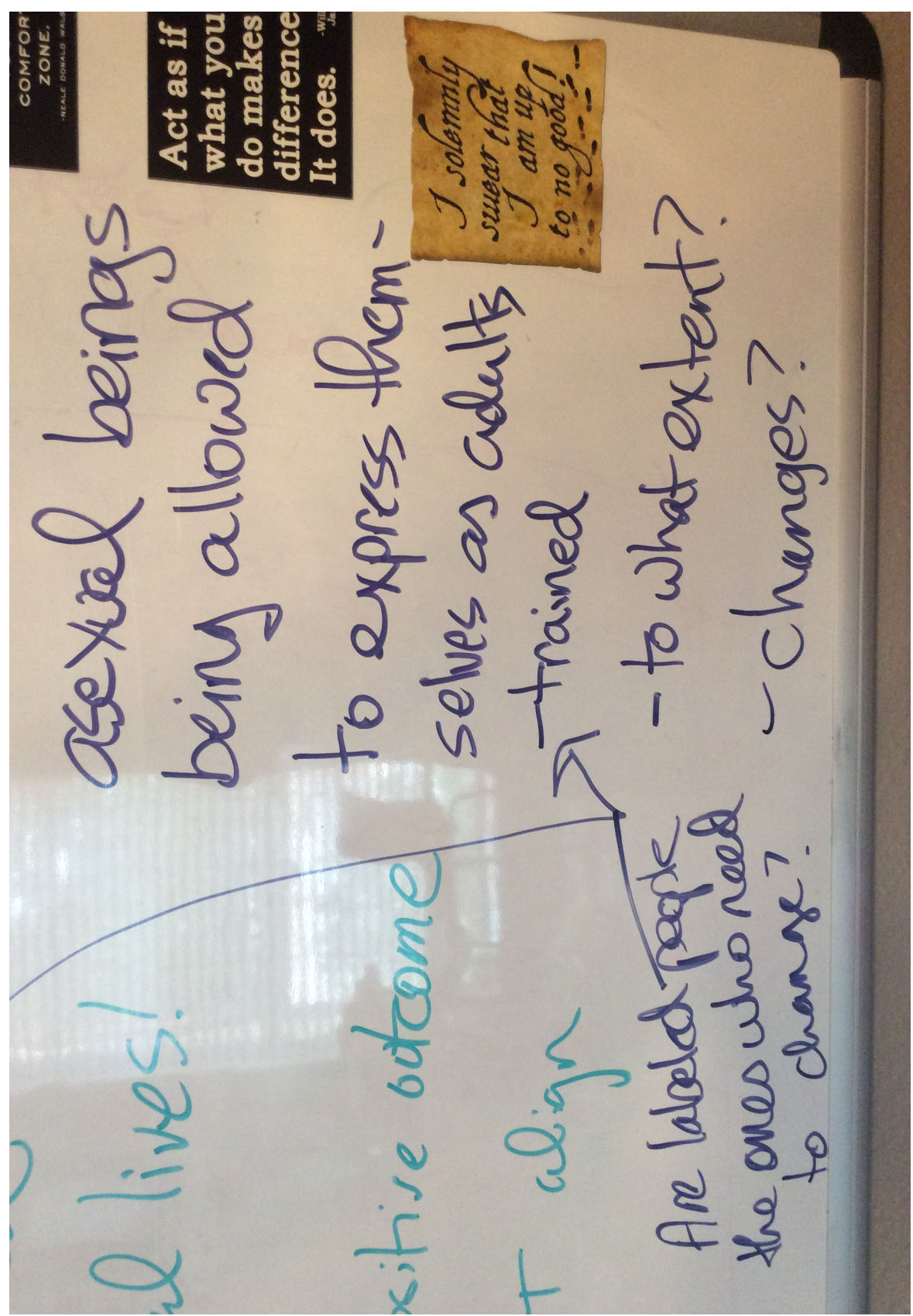




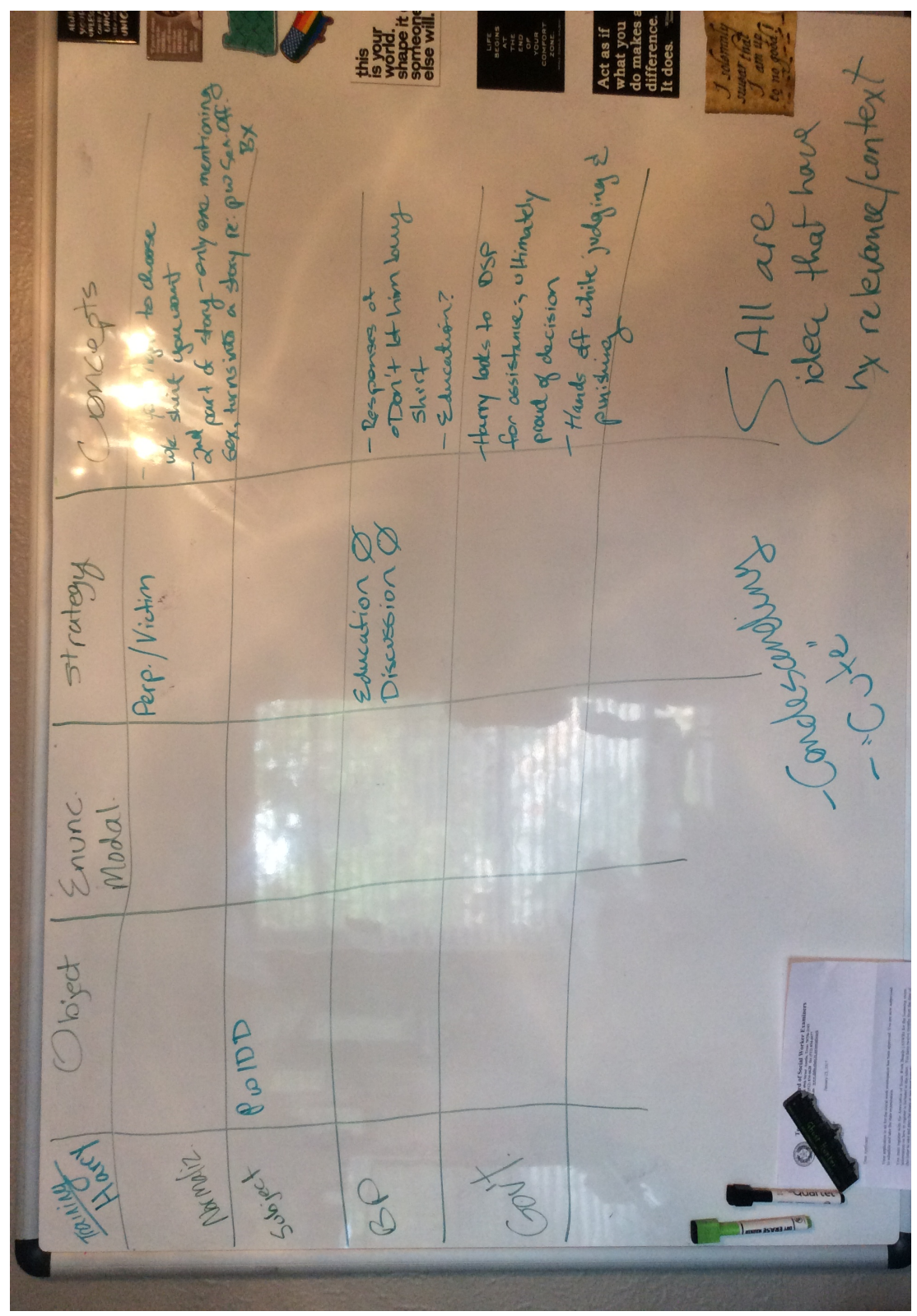

This part of the analysis is really focusing on the Harry story from person-centered thinking training and the first concept reads: You get to choose the shirt you want (referring to Harry); the $2^{\text {nd }}$ part of story - only one that mentions sex turns into a story of PWD sex. Offending bx. 
A Foucaultian Discourse Analysis 221

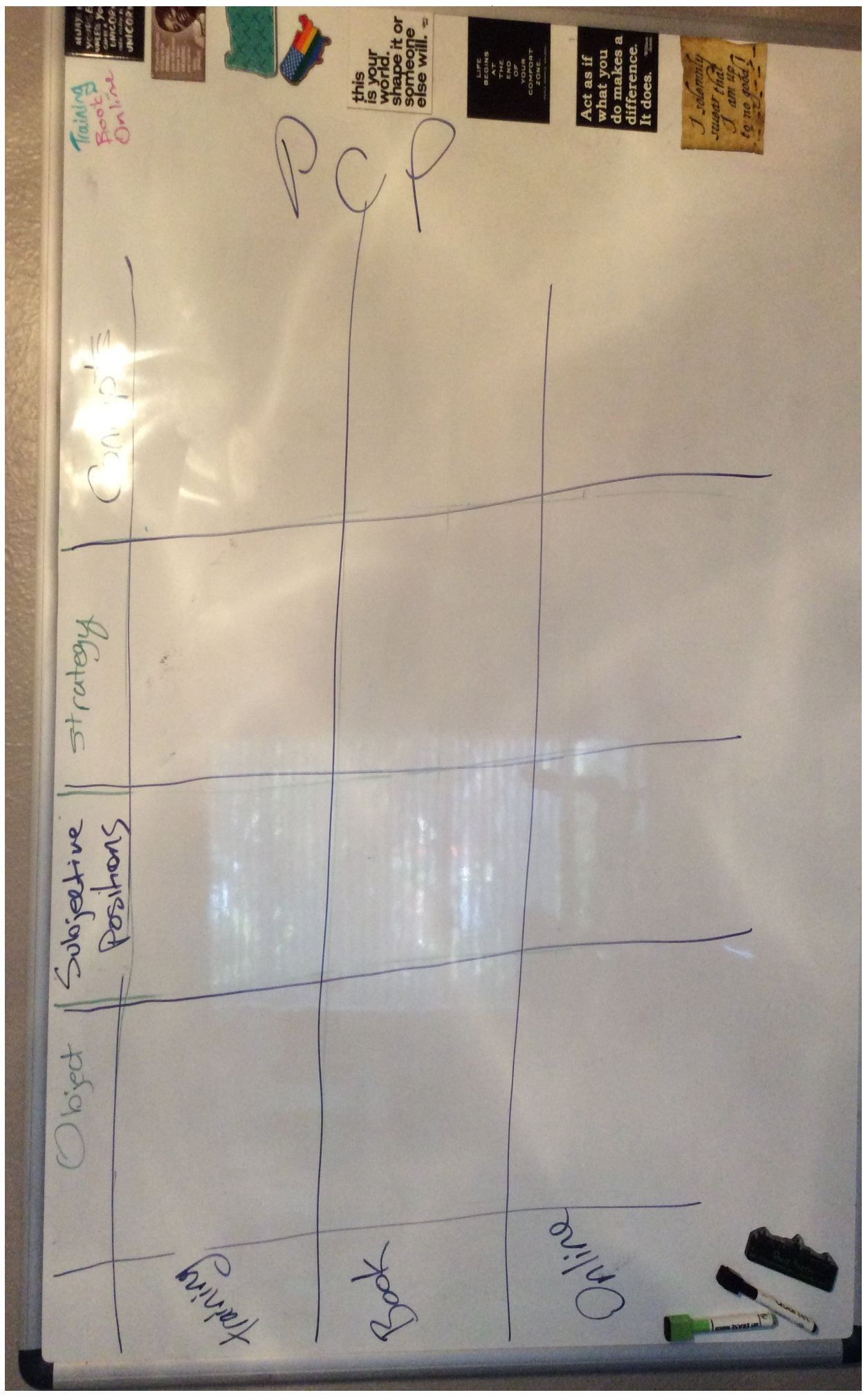




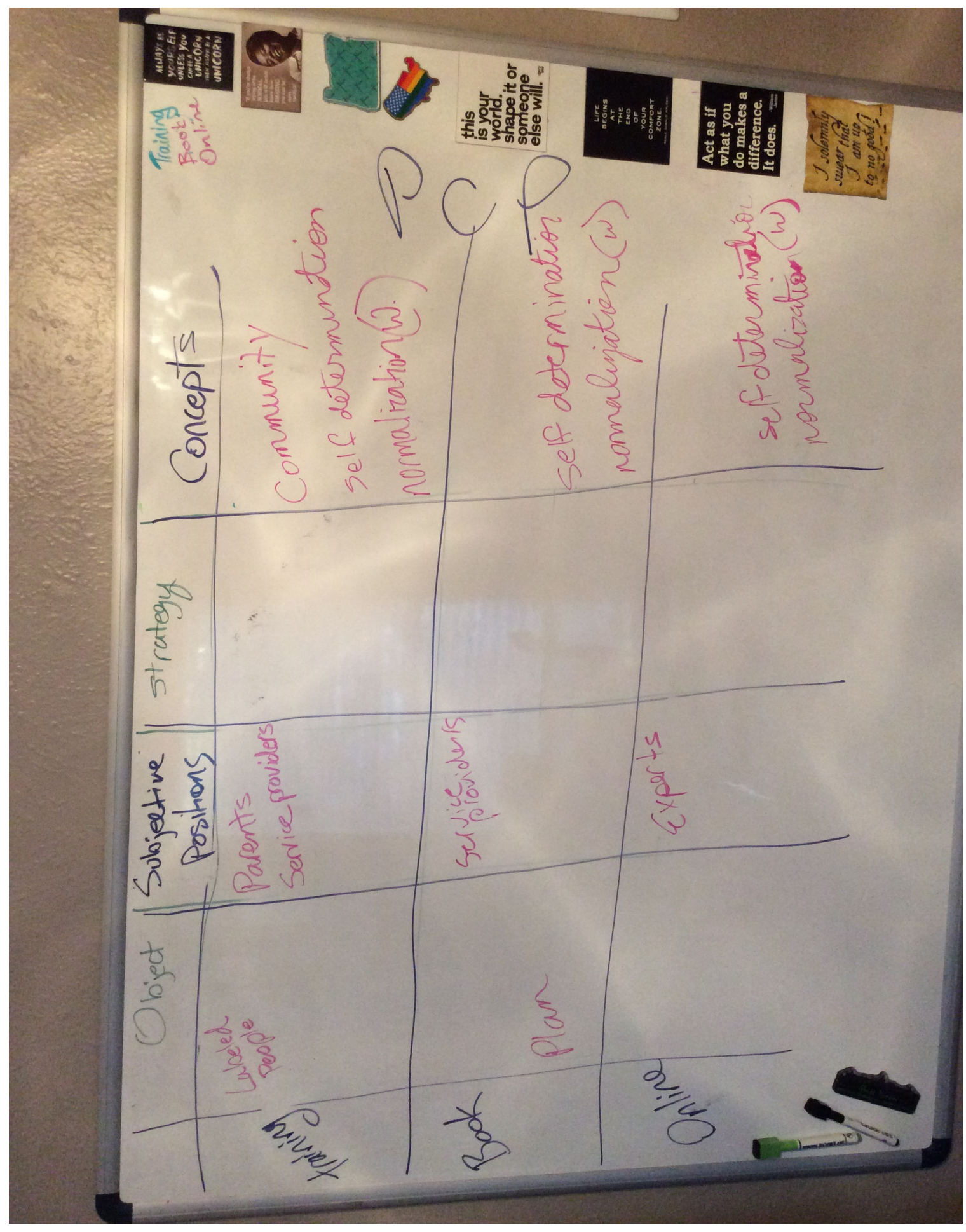




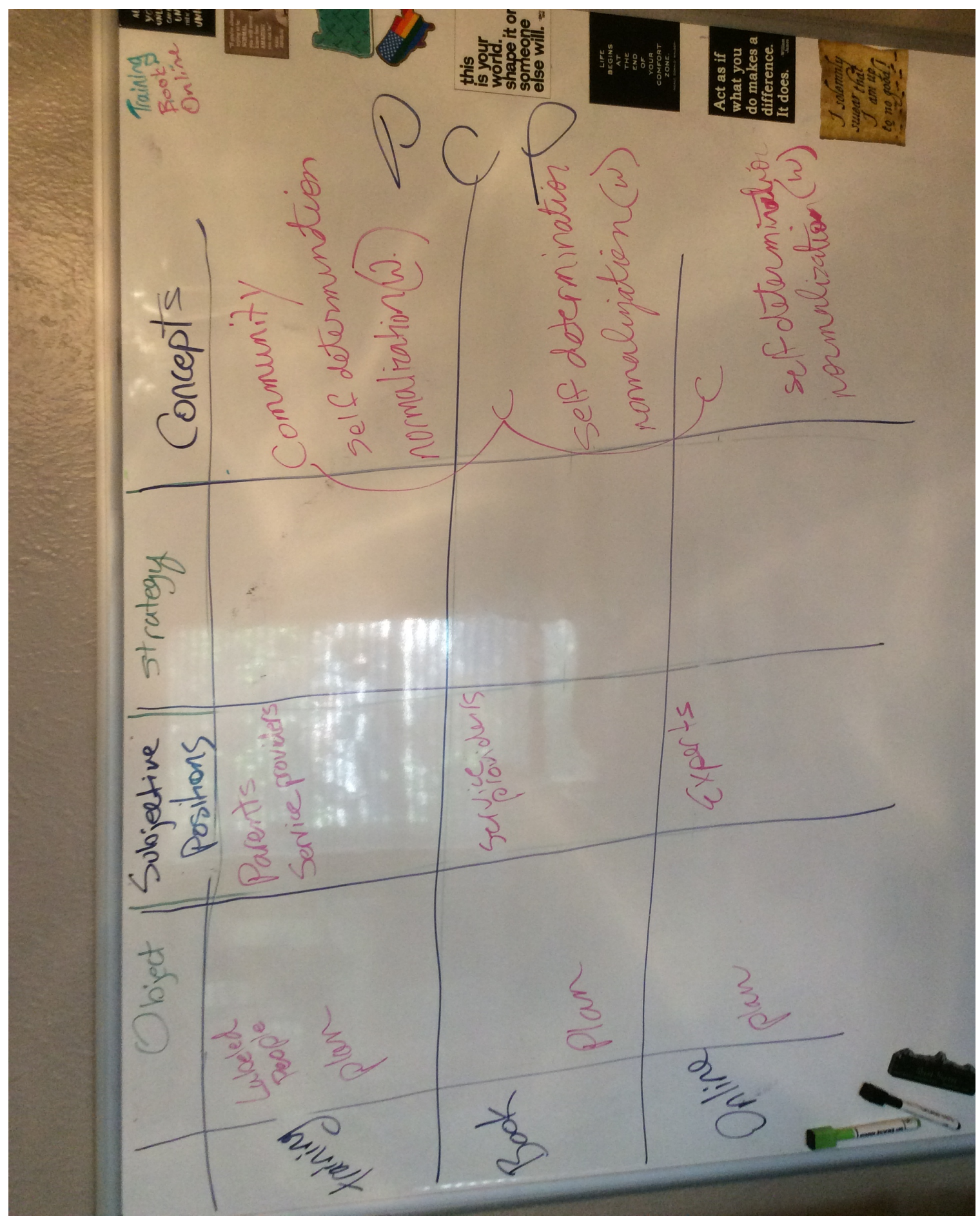




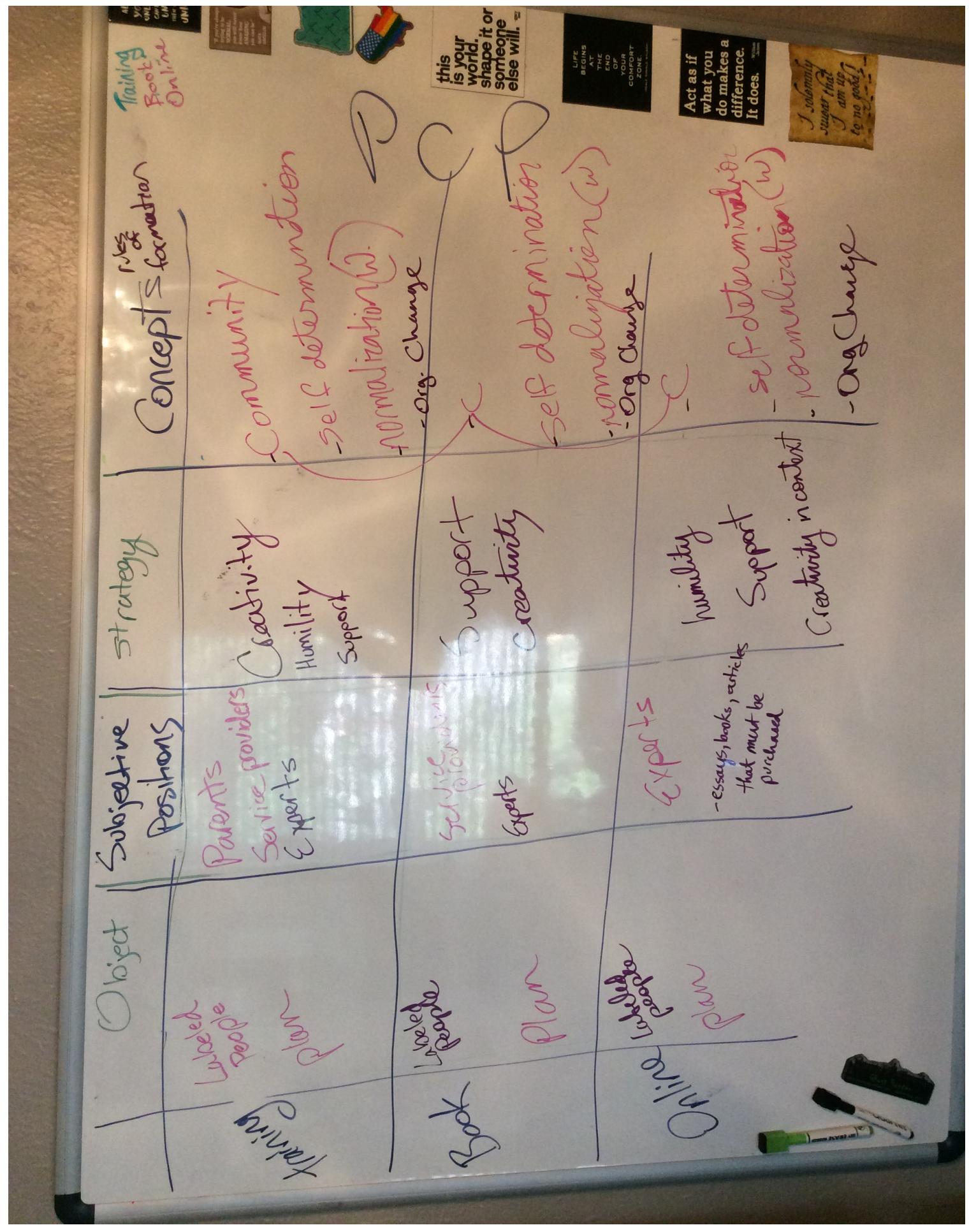




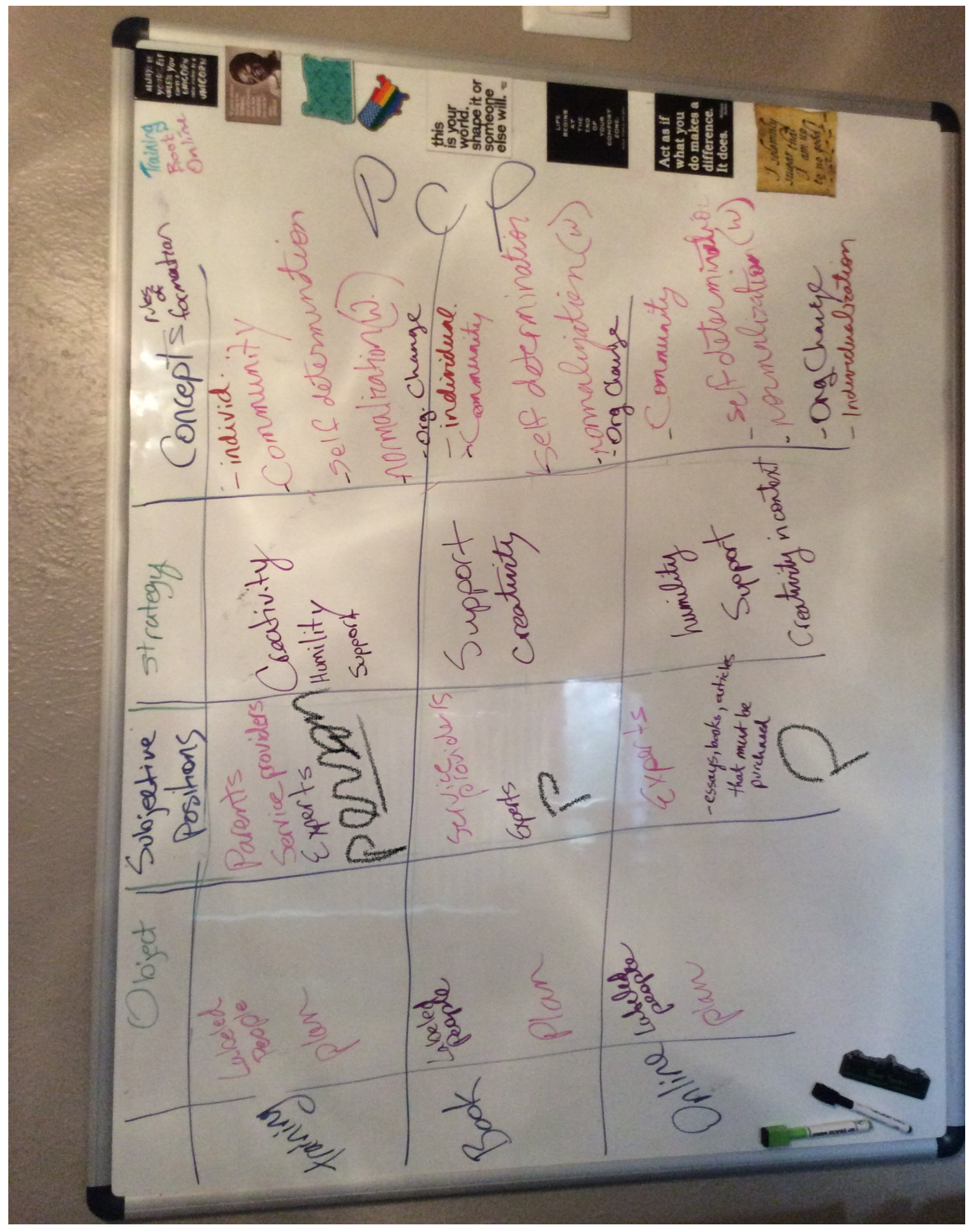




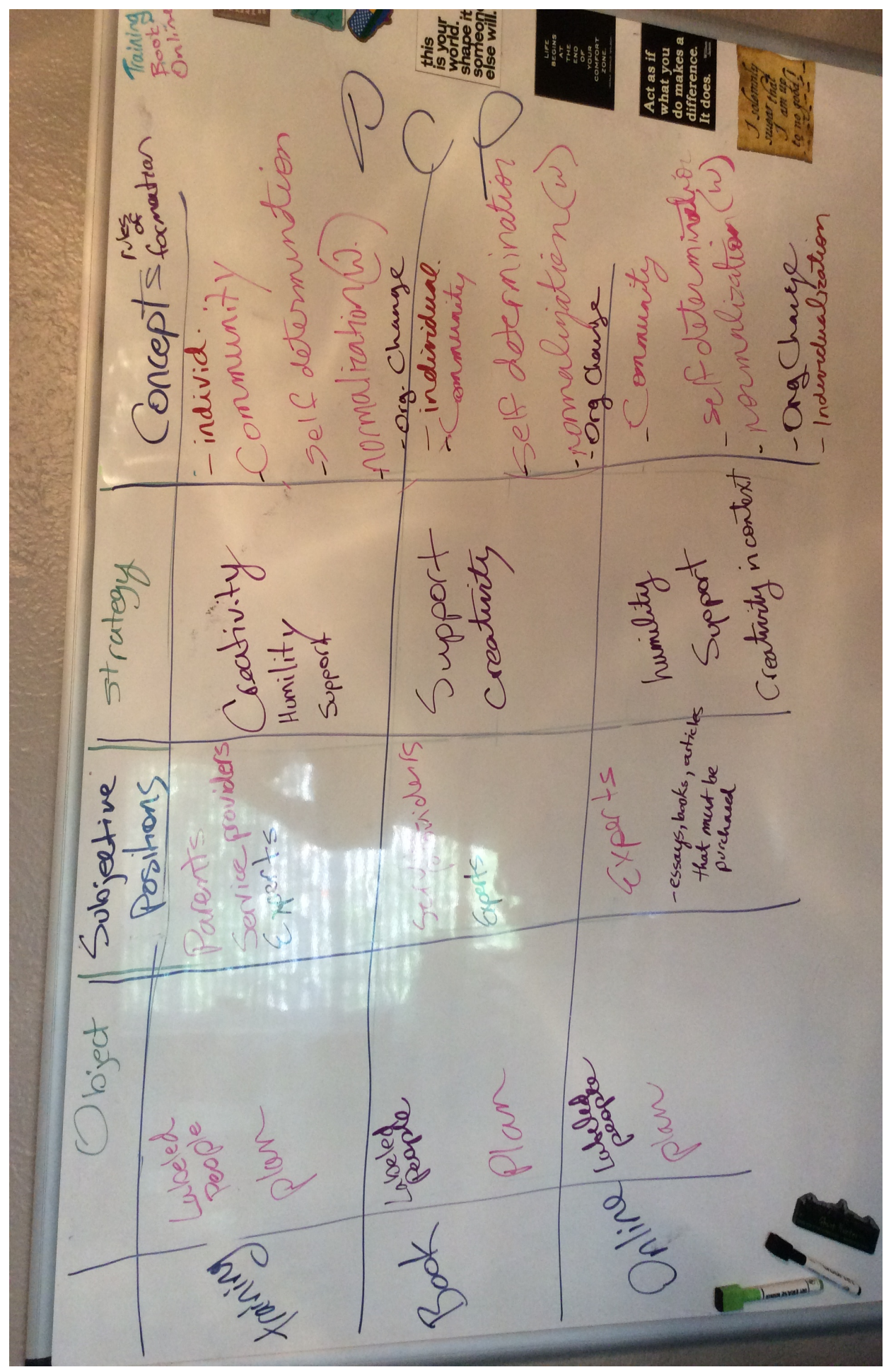

This graph shows the connection between all the texts and that they do share a common discourse. 


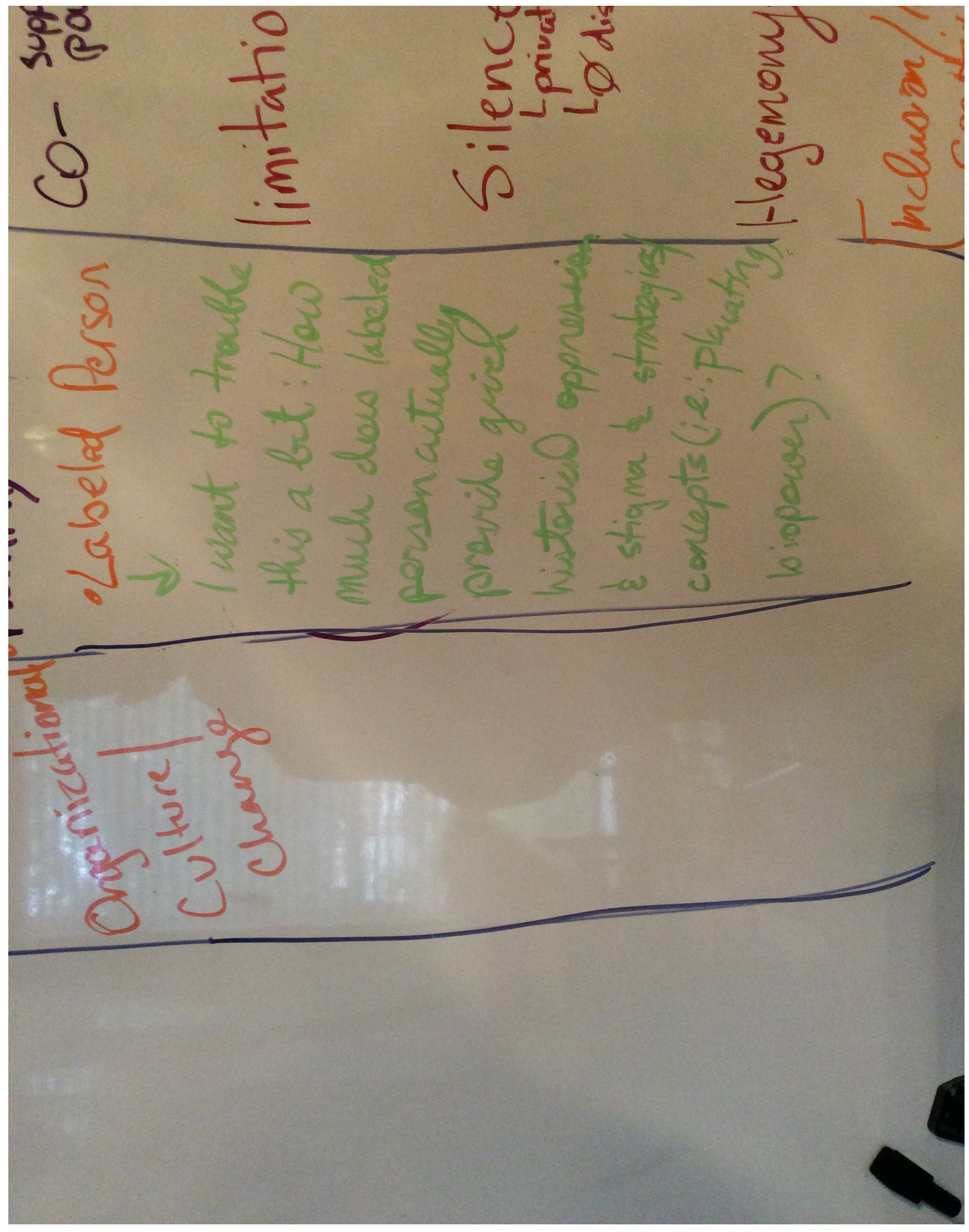




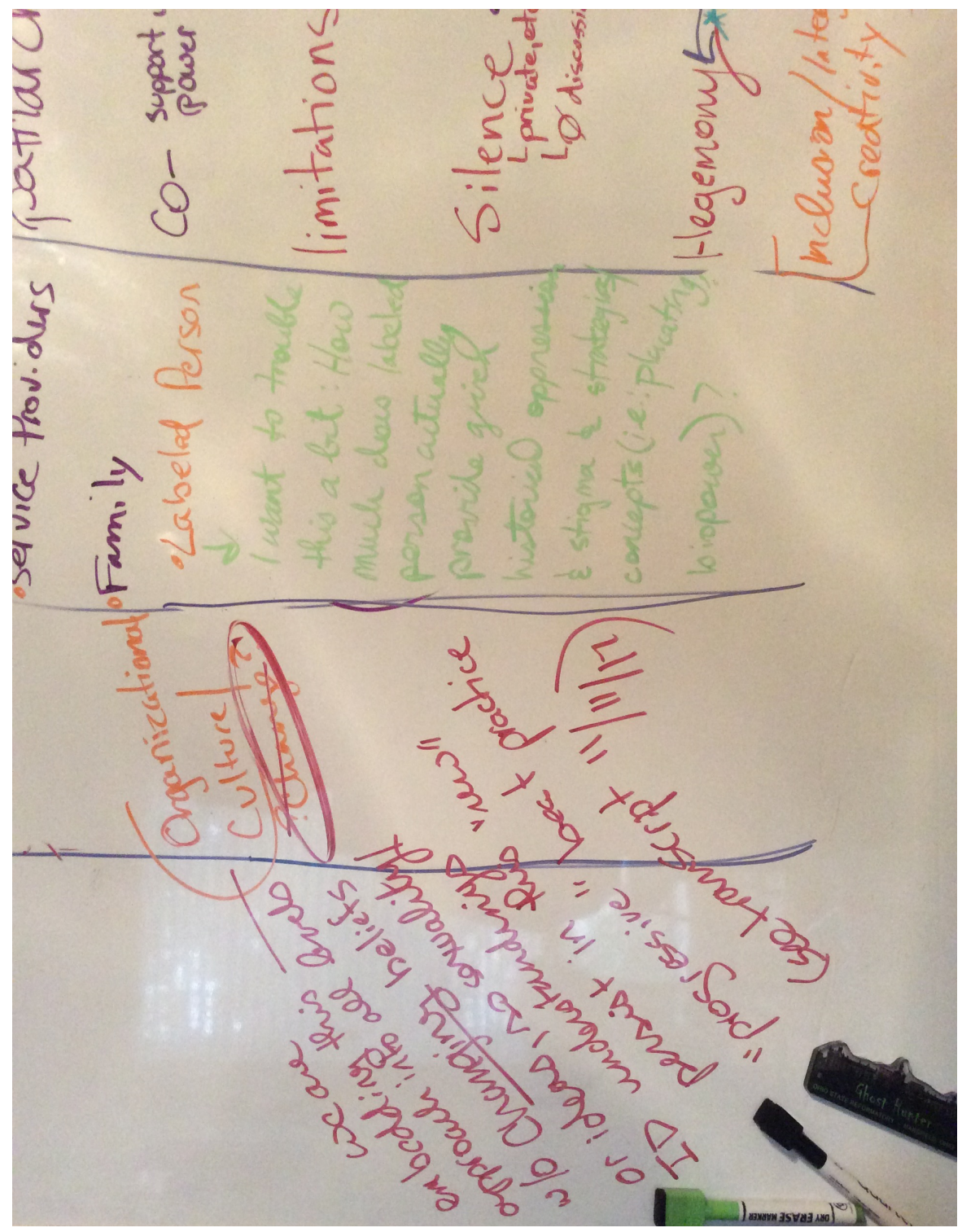

The analysis of PCP throughout all the texts was a bit of a whirlwind. I commented here that I wanted to trouble the inclusion of "labeled person" as a subjective position in this work because of historical oppression, stigma, strategies and concepts. 


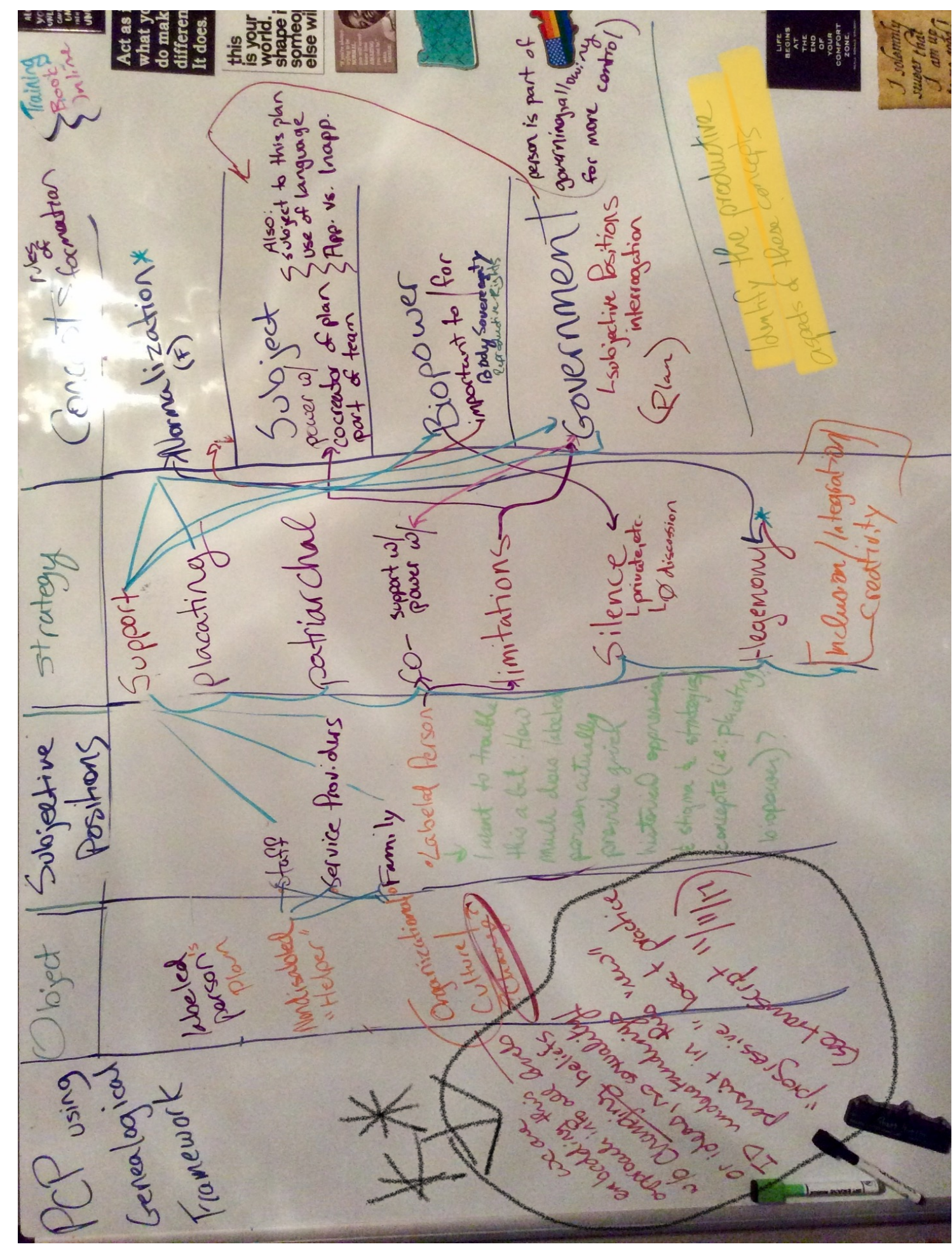




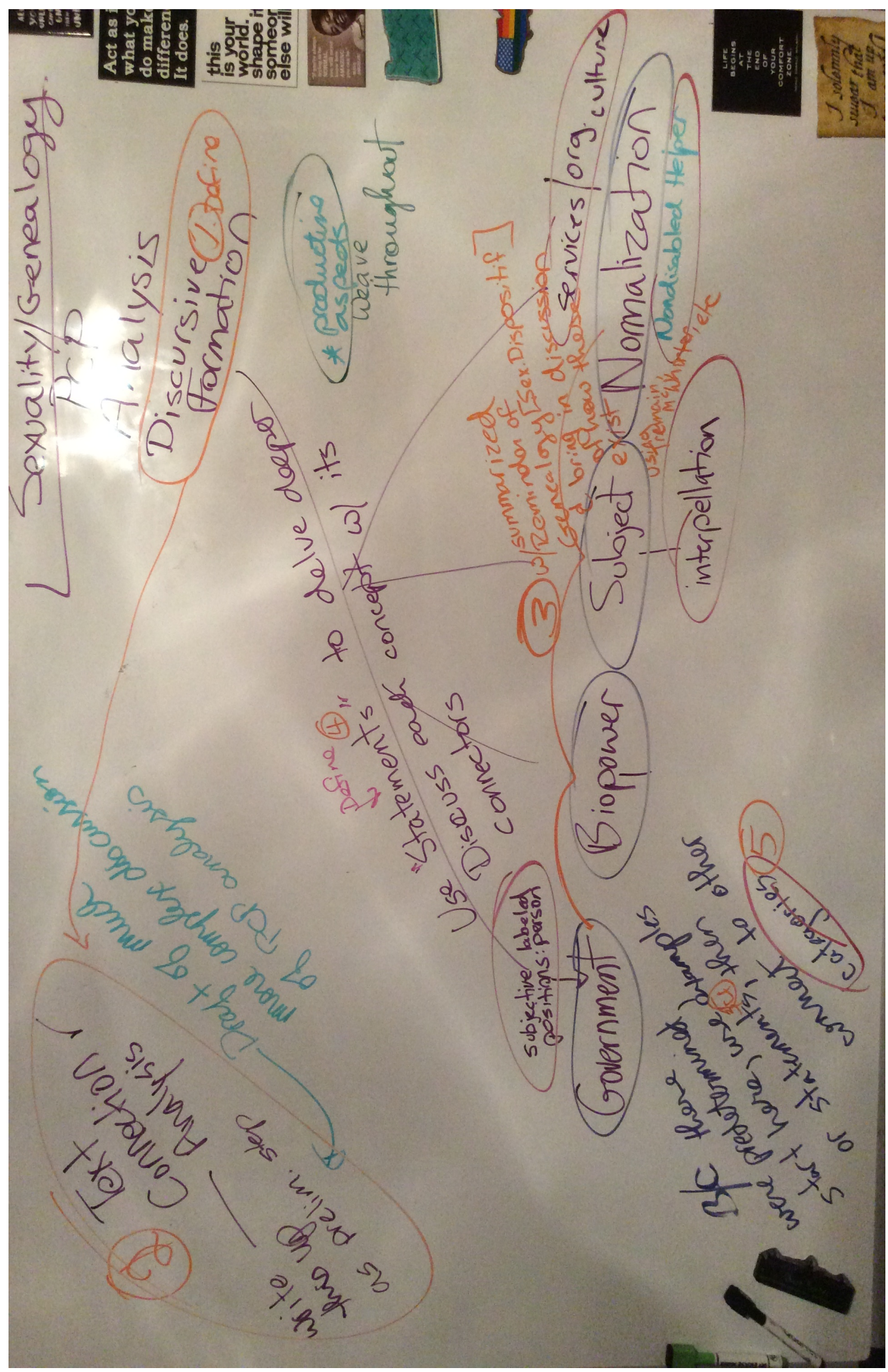




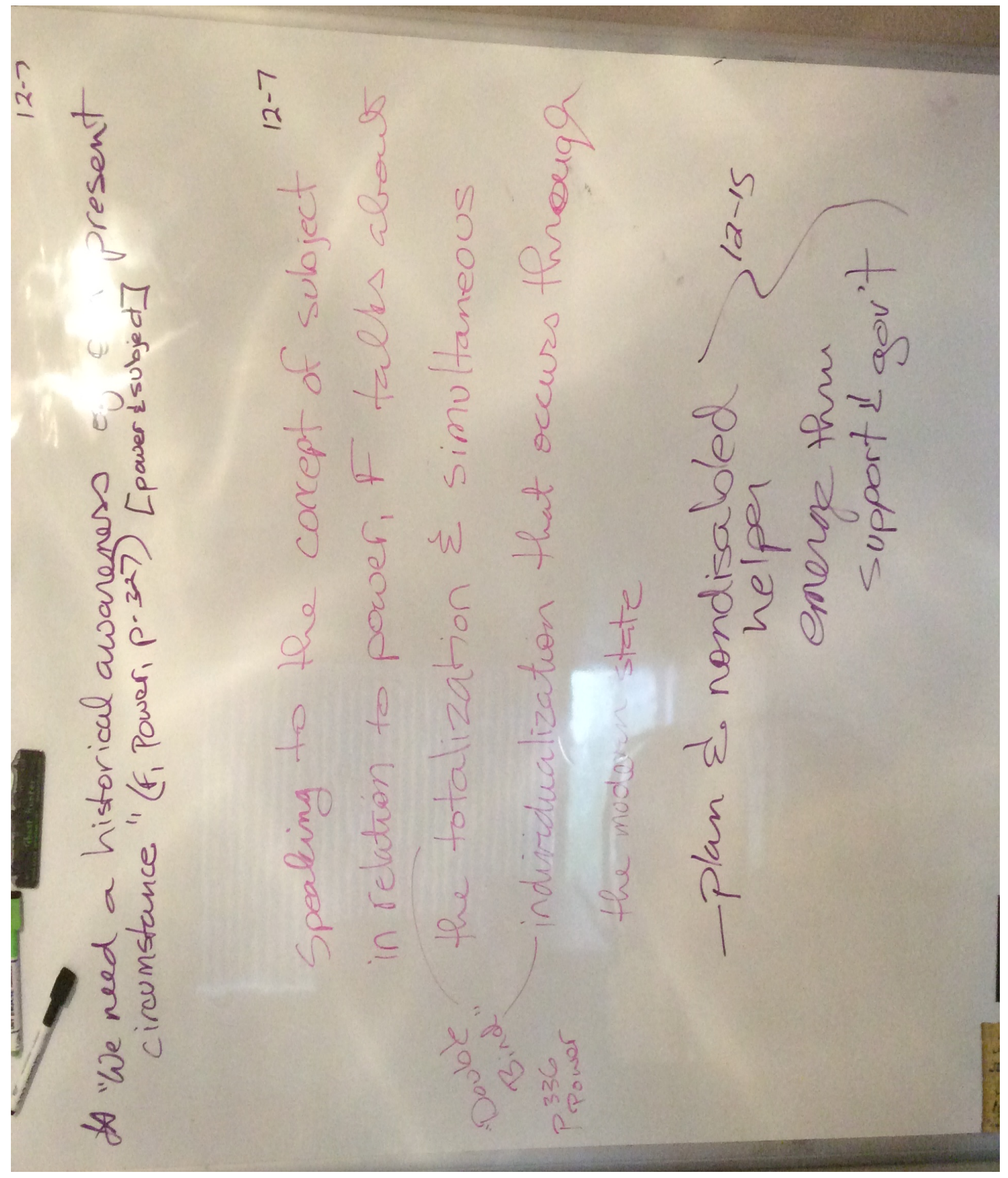

This part of the analysis is me going over how to disseminate the discoveries (rereading Foucault). 